\title{
Critical review of latent heat storage systems for free cooling in buildings
}

\author{
Rami Zeinelabdein ${ }^{1 a b}$, Siddig Omer , and Guohui Gan a \\ ${ }^{a}$ Department of Architecture and Built Environment, Faculty of Engineering, The University of \\ Nottingham, University Park, Nottingham NG7 2RD, UK \\ ${ }^{b}$ Department of Housing Studies, Faculty of Architecture, University of Khartoum, Sudan
}

\section{Abstract}

Buildings have a major contribution to the global energy consumption. Heating, ventilating and air conditioning systems (HVAC) are responsible for most of the energy use in buildings. Thus, clean and sustainable alternatives such as free cooling of buildings have recently gained much attention as means to reduce the operation hours and capacity of the conventional cooling and heating systems. The free cooling could be provided by collecting the natural cold energy during night time in appropriate thermal storage form and this could be retrieved when needed. Phase change materials are exploited by a number of investigators as a storage medium in free cooling applications, as these substances possess high energy densities, and absorb and release heat at a narrow temperature range, hence, the comfort temperature can be maintained day and night. The objectives of this article are to provide a comprehensive review on recent development on free cooling technologies incorporating latent heat storage and to shit lights on the most significant parameters affecting the performance of these materials in free cooling strategy. The outcomes of this review would be helpful in providing clear insight information on potential improvements that can be applied to the storage materials. All the reviewed studies demonstrated that the night cooling strategy using PCMs has the capacity to maintain the indoor temperature well within the comfort zone whilst providing a considerable reduction in cooling loads in all considered climates.

Keywords: Free cooling; Thermal energy storage (TES); Latent heat storage (LHS); Building cooling; Phase change material (PCM).

\footnotetext{
${ }^{1}$ Corresponding author: Tel.: +44 7478800413; +249918011132

E-mail address: rami.zeinelabdein@gmail.com; rami.zeinelabdein@uofk.edu (R. Zeinelabdein)
} 


\section{Contents}

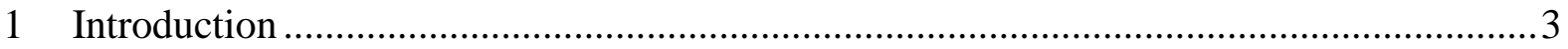

2 Overview of latent heat storage (LHS) for building application ....................................

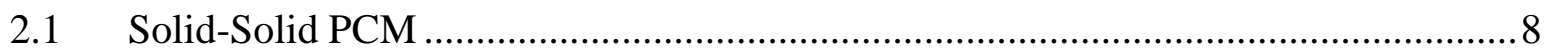

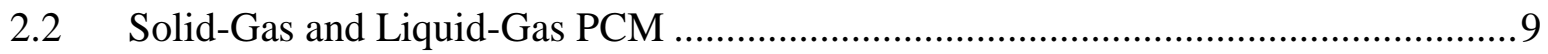

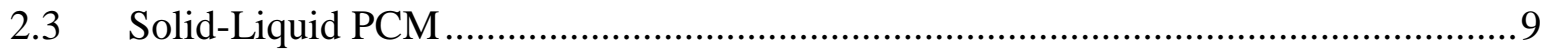

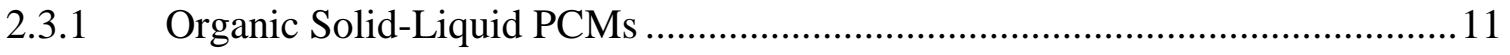

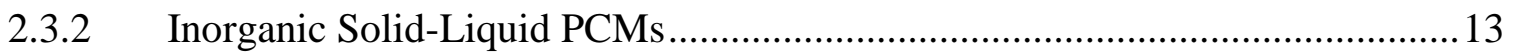

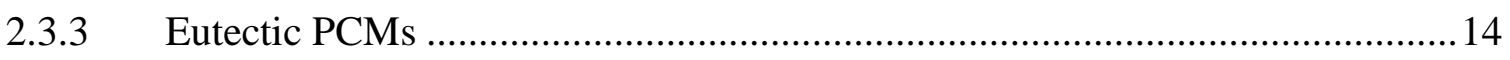

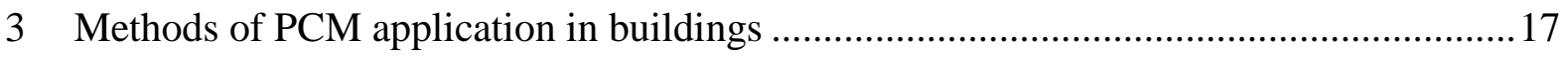

3.1 Impregnation of PCM into the construction materials ........................................ 17

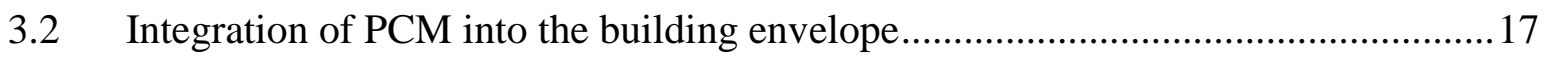

3.3 Other concepts of PCM applications for building cooling and heating ................... 19

4 Research development on PCM based free cooling of buildings....................................21

5 Discussion of the factors affecting performance and application of PCM in free cooling systems.....

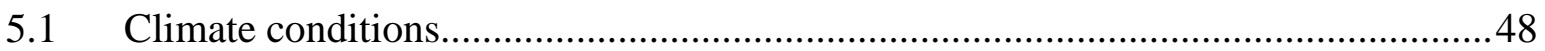

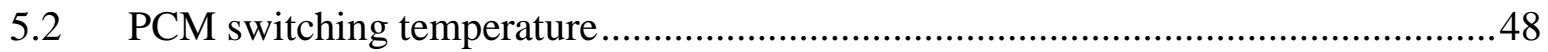

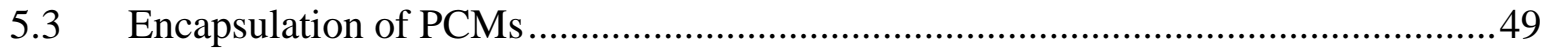

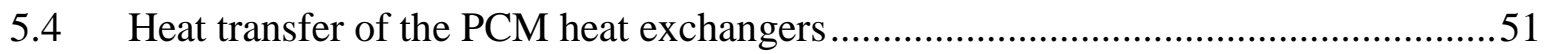

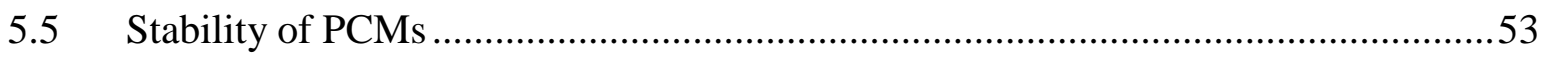

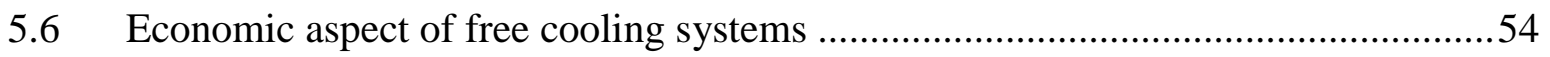

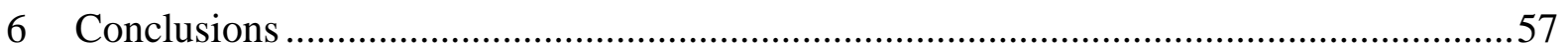

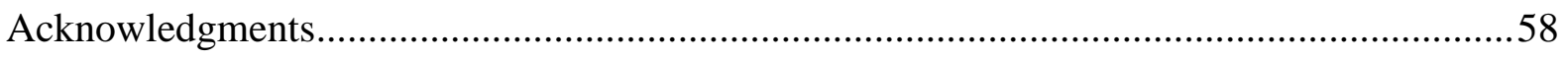

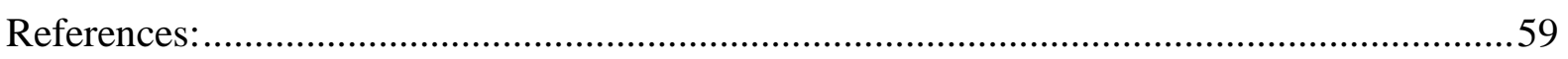




\section{Introduction}

The recent concentrations of the greenhouse gases in the atmosphere are vastly higher than at any time before [1]. According to some studies [1-3], the current rates of greenhouse gas concentrations are expected to continue to a very high level in the coming few decades. Accordingly, a substantial consciousness towards energy saving techniques in all kinds of sectors from transportation to buildings has increased [4].

Buildings have the dominant contribution to the global energy use accounting for about $40 \%$ of the total energy consumption and are responsible for over $30 \%$ of the $\mathrm{CO}_{2}$ emissions, and a large amount of this energy is exhausted to provide thermal comfort in buildings [5]. According to Pérez-Lombard et al. [6], this situation is expected to augment significantly in future due to the predicted growth in population, growing need for buildings and provision of comfort conditions, and the rise of indoor occupation time due to changing lifestyle.

Heating, ventilating, and air conditioning (HVAC) systems are widely exploited as indoor climate regulators to maintain thermal comfort and improve indoor air quality. These systems utilise a large amount of energy, and hence have many deleterious effects on human health and the natural environment and cause significant problems at peak energy load time [7:p.6]. Thus, alternative sustainable strategies such as thermal energy storage (TES) can be exploited to replace or at least, to mitigate the increasing demand for these systems in buildings by preserving the available energy at a time of surplus to be extracted and used during the unavailability period [8-10]. TES systems are capable of delivering thermal comfort, offering potential energy saving and peak load offset [11-13].

The natural cold energy due to temperature drop at night can be admitted into the building interior to provide instantaneous cooling or it can be stored for later utilisation. The lower the nocturnal air temperature, the more effective the night cooling process will be [14]. The usage of buildings' mass to store the cold energy from the ambient night air is referred to in the literature as night cooling. However, the phenomenon of accumulating the night cold energy in a specialised thermal storage unit to be retrieved when it is needed during the day is referred to as free cooling [15]. Some researches show that free cooling concept is much applicable for locations with a large diurnal temperature variation between 12 and $15 \mathrm{~K}$ [16, 17]. 
Thermal Energy Storage (TES) systems can be utilised for both short and long-term storages for high or low-temperature energy [18-20]. In principle, TES mechanisms are classified into sensible heat, latent heat and thermo-chemical energy storages or a combination of these [21:p.2, 22:p.1]. The recent development in properties and features of the TES have been reported in many published reviews $[23,24]$. It is also crucial to have an understanding of the different TES technologies and their pros and cons in order to select the most appropriate storage system for a particular application [25].

Thermochemical energy systems (TCES) make use of generation and release of heat during dissociation and synthesizing of chemical compounds in a reversible endothermic chemical reaction [26:p.246]. TCES systems have the advantage of high energy density at a constant temperature, long-term and stable storage, wide temperature ranges, and easy transportation [27, 28]. However, some of the disadvantages are poor heat and mass transfer property under high-density conditions. They are also expensive, and there is limited experience on their long-term operation [29:p.63]. The research in reversible thermochemical reactions is still under development and there are some technical and economic barriers that need to be tackled before a wider implementation of the technology [30].

Sensible heat storages (SHS) make use of increasing temperature of a storage substance without any phase change process [31]. The ratio of the heat stored to the temperature rise is the heat capacity of the storage medium [32:p.257]. SHS substances can be classified into liquid SHS such as water and oil or solid SHS such as rocks, metals, and masonry materials. Since gases have a very low heat capacity, they are not usually suitable for cold or heat storage [33:p.257]. Water can be considered the best of all ordinarily used substances, as it has the highest volumetric heat capacity $\left(4187 \mathrm{~kJ} / \mathrm{m}^{3} \mathrm{~K}\right)$, which is almost double of that of the concrete and much larger than that of other masonry materials. SHS systems are very well developed and are readily available in the literature. More details about thermal properties of a range of SHS substances commonly used in buildings are available in references [34-37]. The shortcomings are the limited storage capacity, bulkiness, and the non-suitability for most practical applications with a narrow temperature range due to the large temperature variation between the charging and discharging periods $[38,39]$.

Latent heat storages (LHS) on the other hand store energy by making use of the phase changing process of a substance by melting or vaporization without a significant temperature 
change. Such materials are referred to as phase change materials (PCM) [40:p.141]. The use of LHS as thermal energy storage has attracted vast attention over the past decades owing to the effectiveness and the superiority of these substances compared to other TES materials [41, 42]. In general, LHS substances have energy densities greater than SHS and lower by around 5 times than those of the TCES. However, the lower complexity and effective cost make the LHS more practical compared to TCES [43-45]. The latent heat transfer is approximately an isothermal process as PCMs absorb and discharge heat at almost a constant temperature or within a narrow temperature range which is more applicable for maintaining thermal comfort compared to SHS $[46,47]$. Another important advantage of LHS is their easy integration where other SHS substances are difficult to be installed particularly in existing buildings and lightweight structures [48]. This is because PCMs are capable of enhancing the mass effect with much lighter weight and volume estimated at 5-14 times compared to conventional SHS systems which require a large space for accumulator accommodation [49, 50]. Table 1 compares the required weight and volume of some LHS and SHS substances to store $10^{6} \mathrm{~kJ}$ of energy at a temperature rise of $15 \mathrm{~K}$ during heat storage [50,51]. Moreover, LHS can be used as appropriate storage or can be added to enhance the performance of SHS systems [52]. On the other hand, the performance of LHS systems is largely limited by the low thermal conductivity and the lack of thermal stability of PCMs [53]. The cost of PCMs are relatively high at present, nevertheless, they are widely available in various forms and temperature range. The current prices are predicted to drop in the near future due to the extensive research carried out on PCMs nowadays in addition to the increasing number of PCM manufacturers around the world [15].

Table 1: Comparison of required mass and weight of LHS and SHS substances to store $\mathbf{1 0}^{\mathbf{6}} \mathrm{kJ}$ with $\Delta \boldsymbol{T}=15 \mathrm{~K}[50,51]$.

\begin{tabular}{lllll}
\hline & \multicolumn{2}{l}{ Sensible heat storage } & \multicolumn{2}{l}{ Latent heat storage } \\
\cline { 2 - 5 } & Rock & Water & Organic PCM & Inorganic PCM \\
\hline Required weight of storage $(\mathrm{kg})$ & 67,000 & 16,000 & 5,300 & 4,350 \\
Required volume of storage $\left(\mathrm{m}^{3}\right)$ & 30 & 16 & 6.6 & 2.7 \\
\hline
\end{tabular}

Some of the first studies of exploiting PCM for space cooling and heating were conducted four decades ago by Telkes [54] and Barkmann and Wessling [55]. Nowadays, PCM products are widely available in several forms such as powder, granule or rubber, and in a wide range of container types such as tubes, spheres, and panels. This diversity allows a variety of 
integration means into buildings such as in construction materials [56-59] and into external and internal building envelope $[60,61]$. PCMs are also incorporated into other systems such as trombe wall, solar chimneys, PV panels, and solar heating or night cooling of water/air [62:p.133]. Sometimes, PCMs are included in the indoor furniture.

There have been a considerable number of published reviews in the area of LHS [63]. The majority of these articles have focused on reviewing the development of the PCM substances, the heat transfer enhancement, the mathematical modelling developed for the latent heat problem, and the application of PCM in buildings by addressing the integration methods [63-92]. However, there have been few reviews that focused on PCM incorporation in free cooling of building technology, although this area has been investigated for over 25 years and numerous systems have been developed and assessed. Only few review publications have targeted PCM application in free cooling include Raj and Velraj [93], Waqas and Din [15], Kamali [94], Thambidurai et al. [95], Alizadeh and Sadrameli [96] and, Iten et al. [97]. Therefore, this paper focusses on the application of PCM for free cooling in buildings and is expected to complement and update the previous reviews in this area. The objectives of the present review are;

- To provide a comprehensive discussion on the recent progress and development in free cooling systems incorporated latent heat storage.

- To identify the most significant parameters influencing the thermal performance and application of free cooling based PCM storage systems to get a clear picture of possible opportunities and strategies that can be applied to enhance the efficiency of the technology.

The present paper begins with overviewing the latent heat storage systems and highlighting the classifications and the associated advantages and disadvantages. Section 3 addresses the various methods of PCM application in buildings, highlighting on their merits. Section 4 provides a succinct review in a chronological order for the most recent research in free cooling based PCM storage systems. Section 6 discusses the major factors affecting the performance of free cooling systems and the suitable enhancements that can be applied for the required purpose. This paper concludes by summarising the key achievements of application of PCM energy storage in free cooling, based on the reviewed research work. 


\section{Overview of latent heat storage (LHS) for building application}

Latent heat storages (LHS) aim to use the stored heat by altering the physical state of a substance from one state to another by melting or vaporization (solid to liquid or liquid to gas and vice versa) at desired operating temperature range which is almost constant for pure substances, and this one of the advantages of LHS [98-102]. Fig. 1 shows a variation of latent and sensible heat storage with temperature.

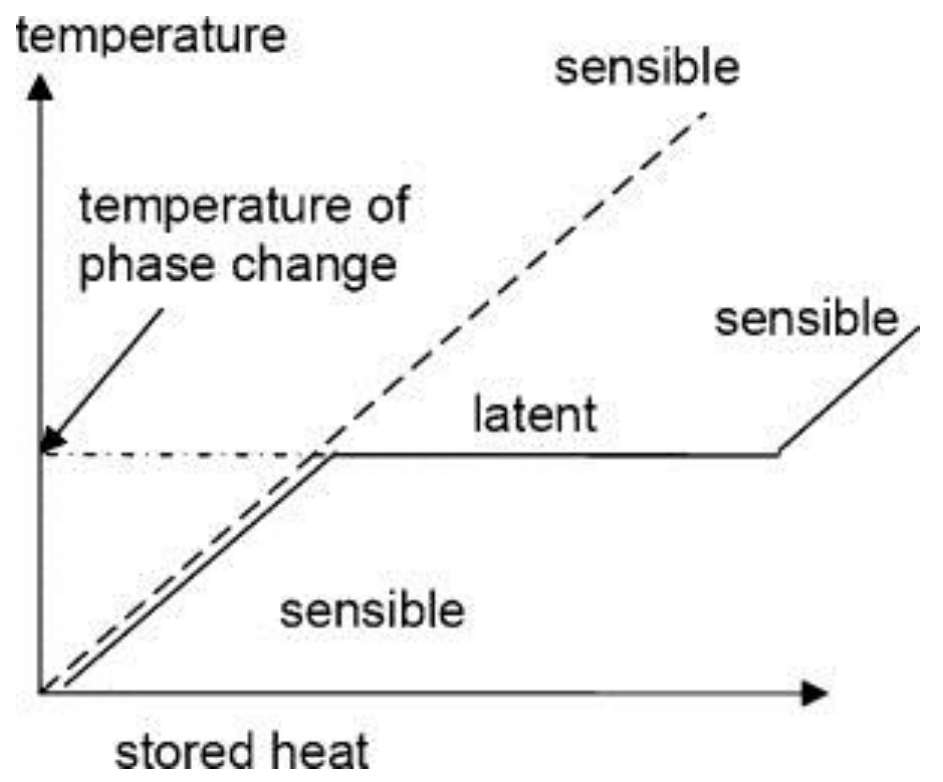

Fig. 1: Latent and sensible heat storage variation with temperature [22:p.3, 103].

The storage capacity of LHS with a solid-liquid PCM $\left(Q_{L H S}\right)$ is given as a function of heat of fusion per unit mass $\left(\Delta h_{m}\right)$ and the specific heat $\left(C_{p}\right)$ by equation $(1)[104]$;

$$
Q_{L H S}=\int_{T i}^{T m} m C_{p i} \Delta T+m a_{m} \Delta h_{m}+\int_{T m}^{T f} m C_{p s} \Delta T
$$

where; $\left(C_{p i}\right)$ is the average specific heat between $T_{m}$ and $T_{i},\left(C_{p s}\right)$ is average specific heat between $T_{f}$ and $T_{m}$, and $\left(a_{m}\right)$ is a fraction of the melted material. 
The selection criteria for latent heat storage substances have been highlighted through several studies $[75,76,105-108]$. All these studies agreed that PCMs should have desirable thermo-physical, chemical, kinetic, and economic properties. In the case of thermo-physical properties, a suitable phase change temperature in the desired operation limit and a high enthalpy of fusion are the two main influential requirements when selecting a PCM for a particular application. A desirable PCM also has to possess other thermo-physical properties including; high thermal conductivity, high specific heat, high density, congruent melting, small volume change during phase transition and low vapour pressure at operational temperatures to minimise the containment defects. Chemically the PCMs should be stable for a long-term usage, non-corrosive to encapsulation, non-toxic, non-flammable, non-explosive, compatible with construction and container materials, and exhibiting no degradation after a large number of cycles. In the case of Kinetic properties, PCMs are required to possess a high nucleation rate to avoid supercooling, a sufficient solidification rate to meet demands of heat retrieval from the storage system, and the melting and the solidification should be at a nearly constant temperature and phase segregation. From the economical side, the PCM should be abundant and cost-effective.

Although there are a large number of PCM products in the market, it is difficult to identify a substance that satisfies all the selection criteria to operate as a superior thermal storage; and this issue should be handled through a careful design of the system.

Latent heat storage can be achieved through Solid-Solid, Solid-Gas, Liquid-Gas, and Solid-Liquid phase transformation. However, solid-liquid and solid-solid PCMs are the only two of practical interest [109]. Characteristics and performance of these classifications are as follow:

\subsection{Solid-Solid PCM}

In Solid-Solid PCM substances, the heat is stored when a substance changes from a crystalline to another form. They appear as an alternative solution to overcome the drawbacks of the most utilised Solid-Liquid PCMs that requires adequate encapsulation to prevent the liquid from leaking, this encapsulation lowers the density of the system and escalates the cost of the product. Solid-Solid PCMs may be used without containers. Another positive side is that they have small volumetric expansion compared to Solid-Liquid PCMs which leads to a less 
stringent container, larger design flexibility, and more effective cost. Unfortunately, SolidSolid PCMs have lower latent heat $[110,111]$. Examples of most promising Solid-Solid LHS used as possible candidates for space heating and process heat applications are; pentaerythritol $\left[\mathrm{C}_{5} \mathrm{H}_{12} \mathrm{O}_{4}\right]$, pentaglycerine $\left[\mathrm{CH}_{3}-\mathrm{C}-\left(\mathrm{CH}_{2}-\mathrm{OH}_{3}\right)\right]$, neopentyl glycol $\left[\left(\mathrm{CH}_{3}\right)_{2}-\mathrm{C}-\right.$ $\left(\mathrm{CH}_{2}-\mathrm{OH}\right)_{2}$ ], and their mixtures [104]. Noting that, trombe wall with such substances can exhibit much better thermal behaviour compared to a customary concrete trombe wall [112].

\subsection{Solid-Gas and Liquid-Gas PCM}

Solid-Gas and Liquid-Gas PCM have the highest latent heat, however, they are limitedly used for heat storage as such systems require large volume containers which lead to a complexity and impracticality, and so they are not widely used for thermal energy storage $[110,113]$.

\subsection{Solid-Liquid PCM}

Solid-Liquid PCMs have relatively smaller latent heat compared to Solid-Gas and Liquid-Gas PCMs. But, their small volume change (10\% or less) makes the system cost effective, and these are commonly applied for thermal energy storage systems [33:p.258]. Solid-Liquid PCMs are the most examined and commercially produced type amongst all the LHS family, and hence, a large number of candidates are available in a wide range of operating temperatures. Abhat [105] in his major study of LHS substances produced a classification for PCM which has largely been used and cited by a number of researchers. Solid-liquid PCMs can be classified based on their chemical composition into three main categories; organic compounds, inorganic compounds, and eutectics as illustrated in Fig. 2. Another general classification of substances that can be used as latent heat storage was given in Mehling and Cabeza $[22,33]$ based on their typical melting temperature range and enthalpy as shown in Fig. 3. 


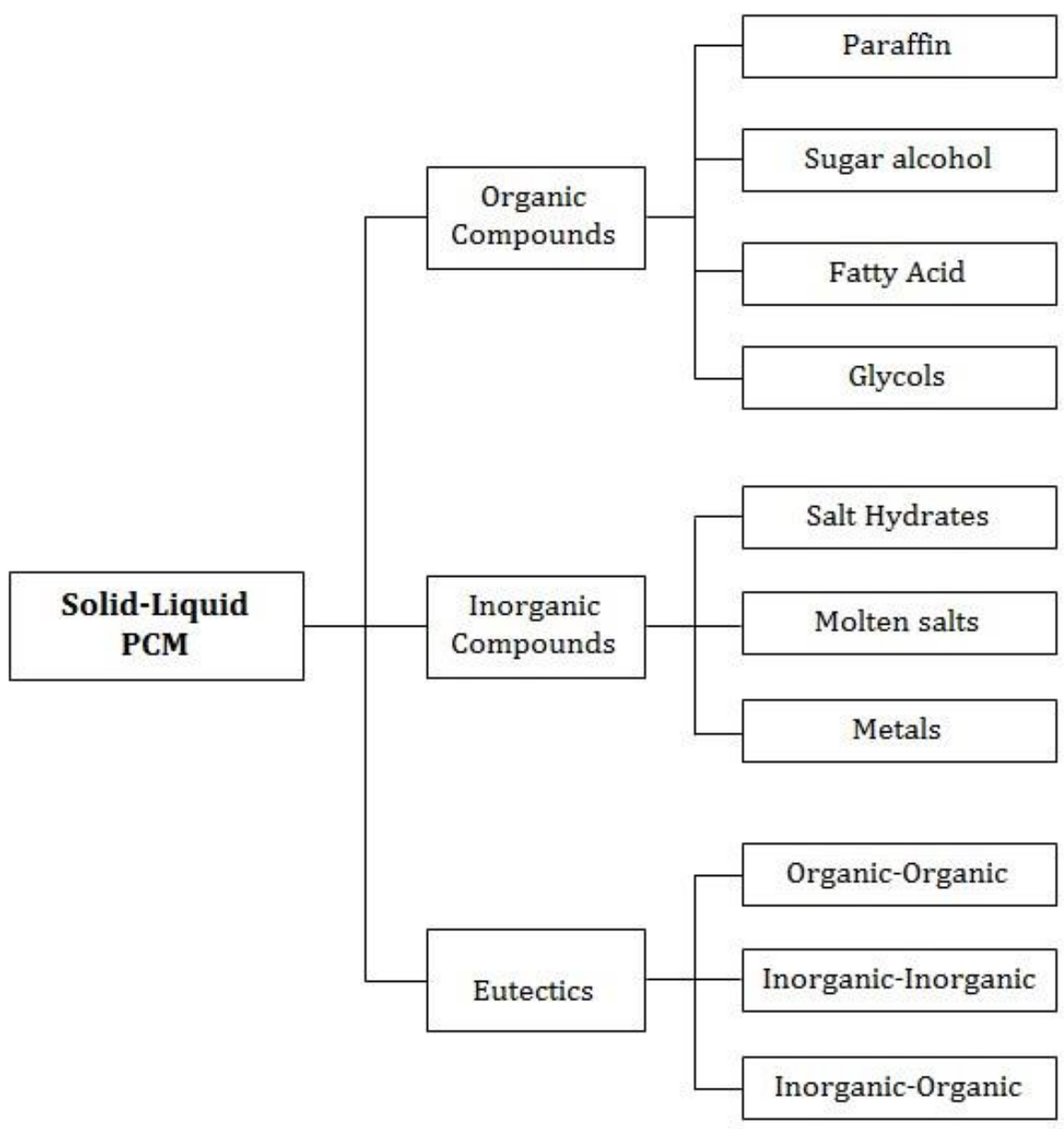

Fig. 2: Classification of the Solid-Liquid PCMs [114].

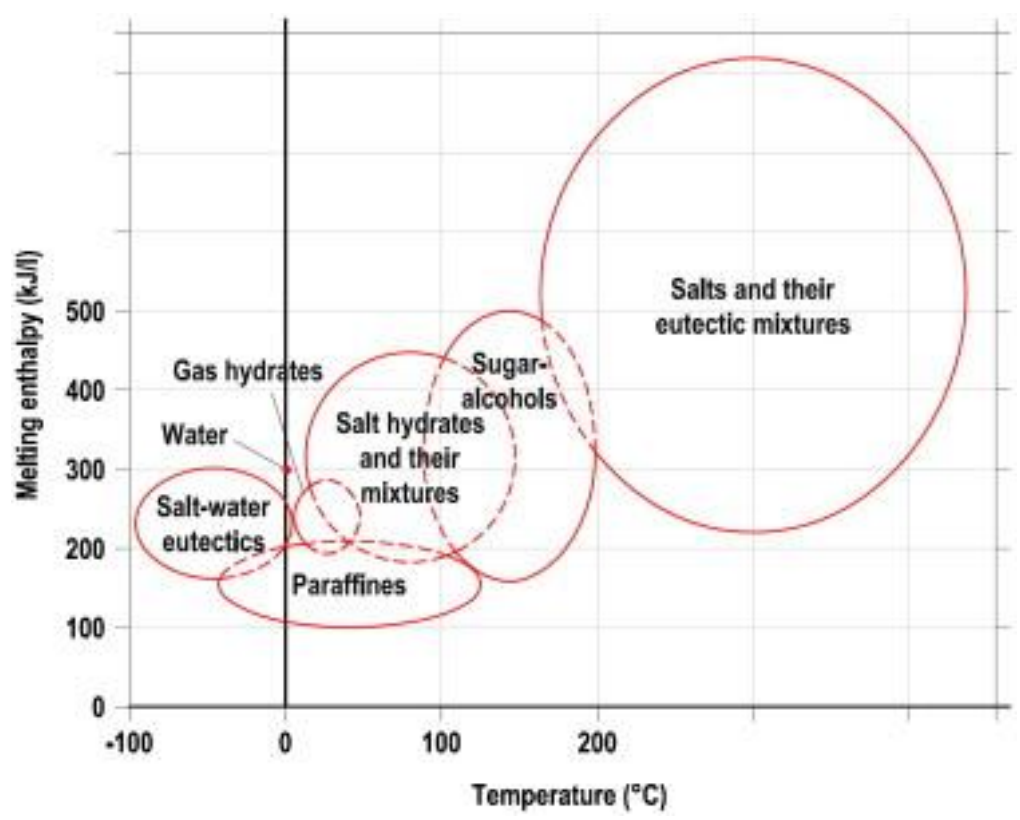

Fig. 3: Classes of available PCMs based on their melting temperatures range and enthalpy [72]. 


\subsubsection{Organic Solid-Liquid PCMs}

The organic Solid-Liquid PCMs are generally chemically stable, available in a wide range of temperature, and having a high latent heat of fusion. In addition, these compounds show almost less or no supercooling during the freezing state. They also show little degradation of latent heat of fusion, congruent melting, and they are non-corrosiveness and are usually compatible with other construction materials. The organic PCMs can be divided into paraffin and non-paraffin [115].

Paraffin organic PCMs belong to a group of saturated hydrocarbons with same characteristics and molecular formulas $\left[\mathrm{C}_{n} \mathrm{H}_{2 n+2}\right]$, which consists of a mixture of straight hydrocarbon chains known as n-alkanes. Noting that, the more the carbon atoms are in the paraffin formula; the higher the melting temperature of the PCM $[114,116]$. Paraffin waxes are safe, inexpensive, reliable, non-corrosiveness and available in a large range of melting temperatures up to around $70{ }^{\circ} \mathrm{C}$. They also have a reasonable storage density ranging from $120 \mathrm{~kJ} / \mathrm{kg}$ to about $210 \mathrm{~kJ} / \mathrm{kg}$, a low vapour pressure, and no segregation throughout the phase change. The Differential Scanning Calorimetry (DSC) analysis carried out by Baetens et al. [72] has shown no any indication for significant degradation of thermal properties of the paraffin waxes after high number of thermal cycles. Conversely, Paraffin waxes show some unfavourable properties including; low thermal conductivity level (around $0.2 \mathrm{~W} / \mathrm{m} \mathrm{K}$ ), relatively large volume alteration, moderate flammability, and incompatibility with the plastic containers.

Non-paraffin organics such as fatty acid, glycols, esters and sugar alcohol have generally favourable thermal properties during both melting and freezing transitions. Amongst all, Fatty acids; which are compounds of carbon $(C)$, hydrate $(H)$, and oxygen $(O)$ with the general formula of $\left[\mathrm{CH}_{3}\left(\mathrm{CH}_{2}\right)_{2 n} . \mathrm{COOH}\right]$ where $\mathrm{n}$ is the atomic numbers; are the most interested type. Fatty acids have a melting/freezing temperature range of approximately 16-65 ${ }^{\circ} \mathrm{C}$ and relatively high heat of fusion between 155 and $180 \mathrm{~kJ} / \mathrm{kg}$. The most widespread fatty acids are sorted into six groups; Caprylic, Capric, Myristic, Palmitic and Stearic with respectively 8 up to 18 carbon atoms per molecule. Although fatty acids are the most commonly used group of non-paraffin family due to their desirable characteristics, they are flammable at high temperatures and there is a shortage of substances with transformation temperature around the human thermal comfort $[72,114,117-119]$. Sugar alcohol organics in particular have a 
phase transformation temperature almost over $100{ }^{\circ} \mathrm{C}$, then, they can be applied in solar plants and for waste heat recovery at temperatures below $200^{\circ} \mathrm{C}$ [111]. Although non-paraffin PCMs represents the largest group of the LHS, they are two to three times more expensive than paraffin. They are also instable at high temperature, having varying toxicity, and mild corrosive $[50,105]$.

Significantly, organic Solid-Liquid PCMs are widely consumed due to their obvious advantages; still, the low thermal conductivity, the large volume alteration, and the moderate flammability have to be handled carefully by an adequate system design and selection of proper container. PCMs having melting/solidification temperature in the range of $20^{\circ} \mathrm{C}$ to $30^{\circ} \mathrm{C}$ are considered suitable for building use in the literature. Examples of some organic Solid-Liquid PCM candidates suitable for space heating and cooling in buildings are tabulated in Table 2.

Table 2: Organic Solid-Liquid PCMs with phase change temperature between 19 and $30^{\circ} \mathrm{C}[73,93$, 120-123].

\begin{tabular}{|c|c|c|}
\hline PCM Compound & Melting Temp. $\left({ }^{\circ} \mathrm{C}\right)$ & Heat of fusion $(\mathrm{kJ} / \mathrm{kg})$ \\
\hline Butyl stearate & 19 & 140 \\
\hline Propyl palmitate & 19 & 186 \\
\hline Paraffin $\mathrm{C}_{16}-\mathrm{C}_{18}$ & $20-22$ & 152 \\
\hline Polyethylene glycol E 600 & $20-25$ & 146 \\
\hline Dimethyl sabacate & 21 & $120-135$ \\
\hline Octadecyl 3-mencaptopropylate & 21 & 143 \\
\hline Paraffin $\mathrm{C}_{17}$ & 21.7 & 213 \\
\hline n-Heptadecane & 22 & 215 \\
\hline Paraffin $\mathrm{C}_{13}-\mathrm{C}_{24}$ & $22-24$ & 189 \\
\hline Octadecyl thioglyate & 26 & 90 \\
\hline Lactic acid & 26 & 184 \\
\hline 1-Dodecanol $\left[\mathrm{CH}_{3}\left(\mathrm{CH}_{2}\right)_{11} \mathrm{OH}\right]$ & 26 & 200 \\
\hline Vinyl stearate & $27-29$ & 122 \\
\hline Paraffin $\mathrm{C}_{18}$ & 28 & 244 \\
\hline n-Octadecane & 28.2 & 245 \\
\hline Methyl palmitate & 29 & 205 \\
\hline Methyl stearate & 29 & 169 \\
\hline Capric acid & 30.1 & 158 \\
\hline
\end{tabular}




\subsubsection{Inorganic Solid-Liquid PCMs}

Inorganic solid-liquid PCMs include salt hydrates, molten salts, and metallic alloys. They normally have a high latent heat of fusion and a volumetric latent heat storage capacity approximately equivalent to a double of the organic compounds [112]. Inorganic compounds also have a small volume alteration during the melting phase, a relatively high thermal conductivity (around $0.5 \mathrm{~W} / \mathrm{m} \mathrm{K}$ ) and an inexpensive cost compared to organic PCMs. However, supercooling, decomposition and corrosion are the common drawbacks which may influence the properties of PCM and hence reducing the system efficiency at the long-term [105]. Table 3 includes some inorganic compounds suitable for space heating and cooling in buildings.

Salt hydrates are the oldest and most investigated PCM group. They can be regarded as mixtures of inorganic salts and water creating a typical crystalline solid of general formula $\left[A . \mathrm{nH}_{2} \mathrm{O}\right]$ where $(A)$ represents the salt component. Varying chemical composition of salts is used to accomplish the required phase change temperature. The solid-liquid transition of salt hydrates is basically a dehydration of hydration of the salt, although this process resembles melting or solidification thermodynamically. At the melting phase, the hydrate salt either melts to salt hydrate and fewer moles of water or to anhydrous salt and water, noting that, the melting manner varies among the compositions and can be regarded as congruent, incongruent or semi congruent melting [114, 124]. Salt hydrates; besides their excellent thermal properties; are generally inflammable, slightly toxic, economical and compatible with plastic containers. However, incongruent melting represents the major problem faced when applying salt hydrates for energy storage. It can be attributed to the insufficiency of the released water of crystallisation to dissolve all the existent crystalline salt. The hydrate or anhydrous salt usually remains at the lower part of the container due to the density difference and hence reduces the opportunity of its recombination with water during the following solidification phase. This may lead to an irreversible melting/freezing of salt hydrate continuation in decreasing with each load-unload cycle. This problem can be treated via different methods including; mechanical stirring, the addition of thickening agents and adjustment of the chemical compositions [105, 112]. Other common problems associated with the application of salt hydrates are supercooling and phase segregation. Supercooling of the liquid phase before the crystallisation occurrence can be minimised by adding nucleating agents, by retaining some crystals in a small cold zone to act as nuclei or by utilising rough heat exchanging surface on container walls to promote 
nucleation. Salt segregation can be avoided via utilising thickening agents, rotating storage devices and direct contact heat exchange [50].

Molten salts and some metallic PCMs have a high heat of fusion per unit volume, a high thermal conductivity, low specific heat, a small volume change and a large phase change temperature [110]. Based on their availability of high transformation temperature, they are usually used for solar power generations applications and for waste heat recovery at temperatures above $200^{\circ} \mathrm{C}[111]$.

Table 3: Inorganic Solid-Liquid PCMs with phase change temperature between 19 and $30{ }^{\circ} \mathrm{C}[52,60$, $73,112]$.

\begin{tabular}{|c|c|c|}
\hline PCM Compound & Melting Temp. $\left({ }^{\circ} \mathrm{C}\right)$ & Heat of fusion $(\mathrm{kJ} / \mathrm{kg})$ \\
\hline $\mathrm{FeBr}_{3} \cdot 6 \mathrm{H}_{2} \mathrm{O}$ & $21-27$ & 105 \\
\hline $\mathrm{Mn}\left(\mathrm{No}_{3}\right)_{2} \cdot 6 \mathrm{H}_{2} \mathrm{O}$ & 25.5 & 148 \\
\hline $\mathrm{CaCl}_{2} \cdot 6 \mathrm{H}_{2} \mathrm{O}$ & 29.7 & 192 \\
\hline $\mathrm{LiNO}_{3} \cdot 3 \mathrm{H}_{2} \mathrm{O}$ & 30 & 189 \\
\hline $\mathrm{LiNO}_{3} \cdot 2 \mathrm{H}_{2} \mathrm{O}$ & 30 & 296 \\
\hline Gallium & 30 & 80.3 \\
\hline
\end{tabular}

\subsubsection{Eutectic PCMs}

Eutectics usually comprise of two or more low melting temperature components which melt and solidify congruently to create a mixture of the components' crystals during the solidification. The key advantage of eutectics over other classes of PCMs is that their melting points can be manipulated via a combination of various weight proportions of components [78]. Eutectic PCMs are largely welcomed in buildings for heating and cooling requirements due to their high volumetric thermal storage density, single melting temperature and to the advantage of melting and freezing congruently. However, there is a limited availability of thermophysical properties data of eutectic PCMs. Also, some fatty eutectics have a very strong odor which makes it undesirable to be operated as PCM wallboard [95]. Examples of commonly used eutectics of organic and inorganic compounds in buildings are listed in Table 4. 
Table 4: Eutectic PCMs with phase change temperature between 19 and $30^{\circ} \mathrm{C}[60,73,112,125]$.

\begin{tabular}{lll}
\hline PCM Compound & $\begin{array}{l}\text { Melting temp. } \\
\left({ }^{\circ} \mathrm{C}\right)\end{array}$ & $\begin{array}{l}\text { Heat of fusion } \\
(\mathrm{kJ} / \mathrm{kg})\end{array}$ \\
\hline 65.5\% Capric + 34.5\% Lauric acid & $18-19.5$ & 140.8 \\
61.5\% Capric acid + 38.5\% Lauric acid & 19.1 & 132 \\
$45 \%$ Capric + 55\% Lauric acid & 21 & 143 \\
$75.2 \%$ Capric acid + 24.8\% Palmitic acid & 22.1 & 153 \\
26.5\% Myristic acid + 73.5\% Capric acid & 22.4 & 152 \\
$34 \% \mathrm{C} 14 \mathrm{H} 28 \mathrm{O} 2+66 \% \mathrm{C} 10 \mathrm{H} 20 \mathrm{O} 2$ & 24 & 147.7 \\
$50 \% \mathrm{CaCl} 2+50 \% \mathrm{MgCl} 26 \mathrm{H} 2 \mathrm{O}$ & 25 & 95 \\
$66.6 \% \mathrm{CaCl} 2 \cdot 6 \mathrm{H} 2 \mathrm{O}+33.3 \% \mathrm{Mgcl} 2 \cdot 6 \mathrm{H} 2 \mathrm{O}$ & 25 & 127 \\
Octadecane + docosane & $25.5-27$ & 203.8 \\
Octadecane + heneicosane & $25.8-26$ & 173.93 \\
$13.4 \% \mathrm{Stearic}$ acid + 86.6\% Capric acid & 26.8 & 160 \\
$48 \% \mathrm{CaCl}+4.3 \% \mathrm{NaCl}+0.4 \% \mathrm{KCl}+47.3 \% \mathrm{H} 2 \mathrm{O}$ & 26.8 & 188 \\
$50 \% \mathrm{CH} 3 \mathrm{CONH} 2+50 \% \mathrm{NH} 2 \mathrm{CONH} 2$ & 27 & 163 \\
Triethylolethane + urea & 29.8 & 218 \\
$47 \% \mathrm{Ca}(\mathrm{NO} 3) 2 \cdot 4 \mathrm{H} 2 \mathrm{O}+53 \% \mathrm{Mg}(\mathrm{NO} 3) 2 \cdot 6 \mathrm{H} 2 \mathrm{O}$ & 30 & 136 \\
$60 \% \mathrm{Na}(\mathrm{CH} 3 \mathrm{COO}) \cdot 3 \mathrm{H} 2 \mathrm{O}+40 \% \mathrm{CO}(\mathrm{NH} 2) 2$ & 30 & 200.5 \\
\hline
\end{tabular}

According to the literature $[15,92,126]$, there are many popular international manufacturing companies produce PCMs across the world such as Rubitherm $\mathrm{GmbH}$ in Germany [127], EPS Ltd in the UK [128], Climator in Sweden [129], PLUSS [130] and TEAP [131] in India, and Cristopia Energy Systems in France [132]. Table 5 includes thermo-physical specifications of various commercial PCMs with melting/solidification temperature within the range of $19-30^{\circ} \mathrm{C}$. 
Table 5: Available commercial PCMs within the phase change temperature range $19-30^{\circ} \mathrm{C}$ [127-130]

\begin{tabular}{|c|c|c|c|c|c|c|c|}
\hline PCM & $\begin{array}{l}\text { Classification of } \\
\text { PCM }\end{array}$ & $\begin{array}{l}\text { Melting } \\
\text { temp. }\left({ }^{\circ} \mathrm{C}\right)\end{array}$ & $\begin{array}{l}\text { Enthalpy } \\
(\mathrm{kJ} / \mathrm{kg})\end{array}$ & $\begin{array}{l}\text { Density } \\
\mathrm{L} / \mathrm{S}(\mathrm{kg} / \mathrm{l})\end{array}$ & $\begin{array}{l}\text { Specific } \\
\text { heat L/S } \\
(\mathrm{kJ} / \mathrm{kg} \mathrm{K})\end{array}$ & $\begin{array}{l}\text { Conductivity } \\
\text { L/S (W/m K) }\end{array}$ & $\begin{array}{l}\text { Maximum } \\
\text { operation } \\
\text { temp. }\left({ }^{\circ} \mathrm{C}\right) \\
\end{array}$ \\
\hline \multicolumn{8}{|c|}{ Rubitherm [127] } \\
\hline RT21 & Paraffin & 21 & 155 & $0.77 / 0.88$ & 2.0 & 0.2 & 40 \\
\hline RT21 HC & Paraffin & 21 & 190 & $0.77 / 0.88$ & 2.0 & 0.6 & 45 \\
\hline RT22 HC & Paraffin & 22 & 190 & $0.70 / 0.76$ & 2.0 & 0.2 & 50 \\
\hline RT24 & Paraffin & 24 & 160 & $0.77 / 0.88$ & 2.0 & 0.2 & 55 \\
\hline RT25 & Paraffin & 25 & 170 & $0.76 / 0.88$ & 2.0 & 0.2 & 55 \\
\hline RT25 HC & Paraffin & 25 & 230 & $0.77 / 0.88$ & 2.0 & 0.2 & 65 \\
\hline RT26 & Paraffin & 26 & 180 & $0.75 / 0.88$ & 2.0 & 0.2 & 60 \\
\hline RT28 HC & Paraffin & 28 & 250 & $0.77 / 0.88$ & 2.0 & 0.2 & 50 \\
\hline SP21 E & Inorganic & $21-23$ & 170 & $1.4 / 1.5$ & 2.0 & 0.6 & 45 \\
\hline SP24 E & Inorganic & $24-25$ & 180 & $1.4 / 1.5$ & 2.0 & 0.6 & 45 \\
\hline SP25 E2 & Inorganic & $24-26$ & 180 & $1.4 / 1.5$ & 2.0 & 0.6 & 45 \\
\hline SP26 E & Inorganic & $25-27$ & 180 & $1.4 / 1.5$ & 2.0 & 0.6 & 45 \\
\hline SP29 Eu & Inorganic & $29-31$ & 200 & $1.5 / 1.55$ & 2.0 & 0.6 & 60 \\
\hline \multicolumn{8}{|c|}{ EPS Ltd. [128] } \\
\hline A22 & Organic & 22 & 145 & 0.785 & 2.22 & 0.18 & 250 \\
\hline $\mathrm{A} 22 \mathrm{H}$ & Organic & 22 & 216 & 0.82 & 2.85 & 0.18 & 400 \\
\hline A23 & Organic & 23 & 145 & 0.785 & 2.22 & 0.18 & 280 \\
\hline A24 & Organic & 24 & 145 & 0.79 & 2.22 & 0.18 & 280 \\
\hline A25 & Organic & 25 & 150 & 0.785 & 2.26 & 0.18 & 280 \\
\hline $\mathrm{A} 25 \mathrm{H}$ & Organic & 25 & 226 & 0.81 & 2.15 & 0.18 & 400 \\
\hline A26 & Organic & 26 & 150 & 0.79 & 2.22 & 0.21 & 280 \\
\hline A28 & Organic & 28 & 155 & 0.789 & 2.22 & 0.21 & 280 \\
\hline A29 & Organic & 29 & 226 & 0.81 & 2.15 & 0.18 & 300 \\
\hline S19 & Salt hydrate & 19 & 160 & 1.52 & 1.9 & 0.43 & 60 \\
\hline S21 & Salt hydrate & 22 & 170 & 1.53 & 2.2 & 0.54 & 60 \\
\hline S23 & Salt hydrate & 23 & 175 & 1.53 & 2.2 & 0.54 & 60 \\
\hline S25 & Salt hydrate & 25 & 180 & 1.53 & 2.2 & 0.54 & 60 \\
\hline S27 & Salt hydrate & 27 & 183 & 1.53 & 2.2 & 0.54 & 60 \\
\hline S30 & Salt hydrate & 30 & 190 & 1.304 & 1.9 & 0.48 & 60 \\
\hline \multicolumn{8}{|c|}{ Climator [129] } \\
\hline ClimSel C21 & Salt hydrate & $21-26$ & 134 & 1.4 & N.A. & $0.75-0.93$ & N.A. \\
\hline ClimSel C24 & Salt hydrate & $24-27$ & 140 & 1.4 & N.A. & $0.75-0.93$ & N.A. \\
\hline ClimSel C28 & Salt hydrate & $27-31$ & 170 & 1.4 & N.A. & $0.72-0.98$ & N.A. \\
\hline \multicolumn{8}{|l|}{ PLUSS [130] } \\
\hline OM21 & Organic & 21 & 250 & $0.924(\mathrm{~S})$ & N.A. & $0.14 / 0.21$ & 120 \\
\hline FS21R & Organic & $20.5-20.7$ & 183 & $0.887(\mathrm{~S})$ & N.A. & $0.10 / 0.30$ & 120 \\
\hline FS21 & Organic & $20-21$ & 130 & $0.87(\mathrm{~S})$ & N.A. & $0.10 / 0.30$ & 120 \\
\hline OM29 & Organic & 29 & 229 & $0.87(\mathrm{~S})$ & $3.9(\mathrm{~L})$ & $0.172 / 0.293$ & 120 \\
\hline FS29 & Organic & $28-29$ & 189 & $0.87(\mathrm{~S})$ & $3.4(\mathrm{~S})$ & $0.45(\mathrm{~S})$ & 120 \\
\hline HS21 & Inorganic & $18-22$ & 185 & $1.40(\mathrm{~L})$ & $3.4(\mathrm{~L})$ & $0.59 / 0.82$ & 80 \\
\hline HS22 & Inorganic & $22-23$ & 185 & $1.54 / 1.84$ & $3.04 / 2.2$ & $0.56 / 1.13$ & 80 \\
\hline HS 24 & Inorganic & $24-25$ & 185 & $1.51 / 1.8$ & $2.3(\mathrm{~L})$ & $0.55 / 1.05$ & 80 \\
\hline HS 29 & Inorganic mix & 29 & 190 & $1.53 / 1.83$ & $2.3(\mathrm{~L})$ & $0.382 / 0.478$ & 80 \\
\hline
\end{tabular}

$\mathrm{S}=$ Solid, L= Liquid, and N.A. = Not Available. 


\section{Methods of PCM application in buildings}

The first studies of exploiting PCM for space cooling and heating have been conducted since $1975[54,55]$. Currently, PCM products are largely available in several forms such as powder, granule or rubber and in a wide range of container types such as tubes, spheres or panels, etc. This diversity provides a variety of integration means in buildings as follows:

\subsection{Impregnation of PCM into the construction materials}

PCMs can be impregnated into the conventional structural components by several methods such as; direct incorporation by simply mixing a powder or a liquid PCM with the construction materials, in this case, no additional equipment is required, but a risk of leakages and decomposition problems is predicted [56, 133-135]. Another procedure is called immersion, which could be achieved via dipping the construction material into a melted PCM and let the PCM penetrates into the object pores, however, some studies showed that this technique may have an insufficient impact on long-term usage due to leakage drawbacks. Moreover, some macro-encapsulated PCMs can be added to the building structures to avoid the material leakage and to reduce the unsafe impression on the structure components [74]. For instance, it was reported that concrete included 5\% microencapsulated PCMs can save energy up to $12 \%$ [136].

\subsection{Integration of PCM into the building envelope}

A wide range of encapsulated PCMs inside different configurations and types of containments such as; plastic bags, aluminium foils, PVC panels, etc. can be integrated into the external and internal fabric of the building such as walls, floors, plaster, ceiling, windows, paint, etc. to increase their thermal mass effect [60, 63]. Several concepts of PCM integration into the building envelope for heating and cooling requirements in the literature are presented in Fig. 4.

The key advantages of using PCMs in building fabric is that no loss and no additional cost results from energy transportation as the PCM storage delivers the energy directly to the targeted space [62:p.126, 137]. Incorporating PCMs into the building fabric has been explored through various configurations in different researches and reported as a potential technique of 
lowering energy consumption in buildings; PCM in walls and wallboards was investigated in $[115,138-146]$. PCM in floors and under floors was handled for heating requirements in [147, 148]. While PCM use in upper ceiling space is also widely applied as it represents the most exposed surface to the internal space, unlike walls and floors which may usually be covered by furniture or other fittings, besides; higher temperatures exist closer to the ceiling above. PCM integration into the building ceiling was examined in the references [149-151]. Another interesting method is to integrate the PCM into windows and shutters to absorb the excess heat and to reduce the direct and indirect solar gains; such concept was considered in [152-157]. PCM panels are also used in ventilated double skin facades to minimise the energy demand of space heating and cooling [158, 159]. According to Akeiber et al. [68], although PCM can be integrated into any component of the building envelope, the wall installation is the most common approach detected in the literature $(80 \%)$ due to ease setup and incorporation.

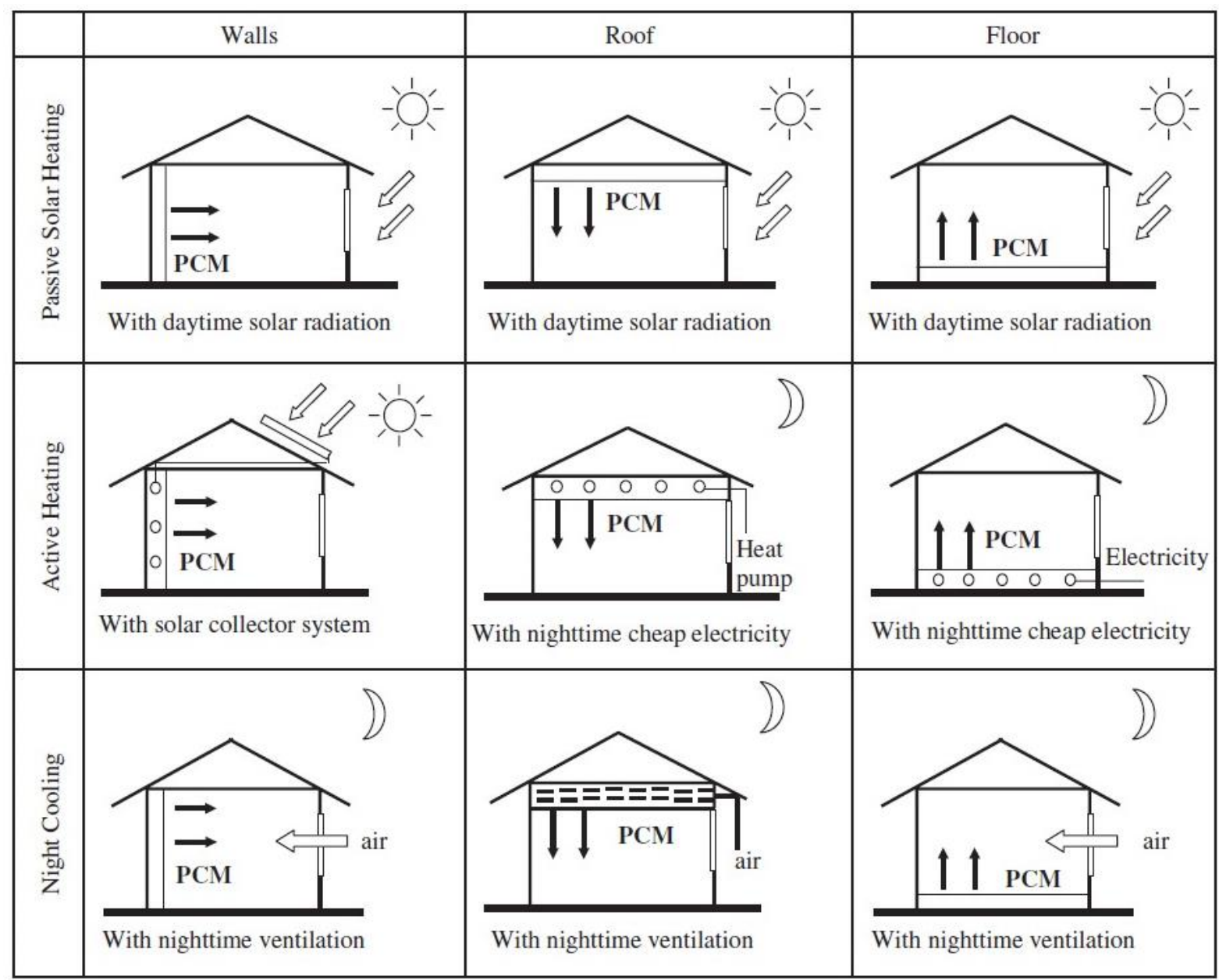

Fig. 4: PCM integration into buildings' envelope for heating and cooling requirements [61]. 


\subsection{Other concepts of PCM applications for building cooling and heating}

There are many other methods of PCM incorporation in buildings for both cooling and heating purposes [160]. PCMs can be used in a trombe wall providing the same performance with much lighter weight. Such studies have been considered in [161-163]. PCMs are usually utilised in solar-PV applications as a passive temperature regulator [164-167]. PCMs can also be incorporated in solar chimneys replacing the conventional storage material and storing the solar energy gained from the absorber [168, 169]. Fig. 5 shows an example of the PCM application in a trombe wall and solar chimneys.

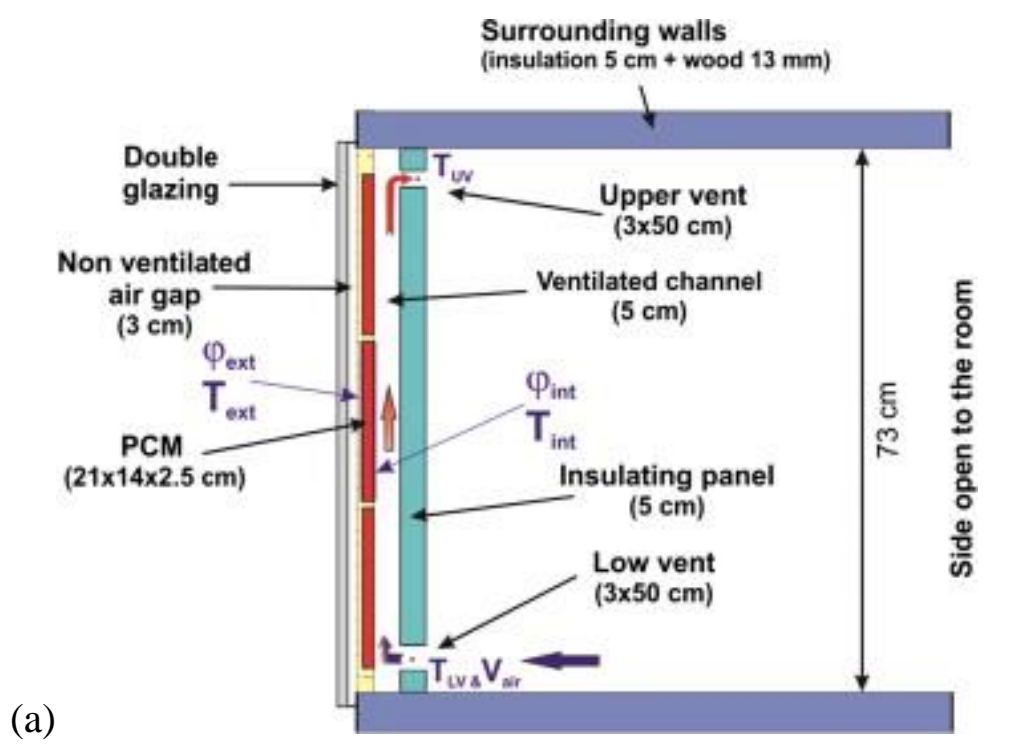

(b)

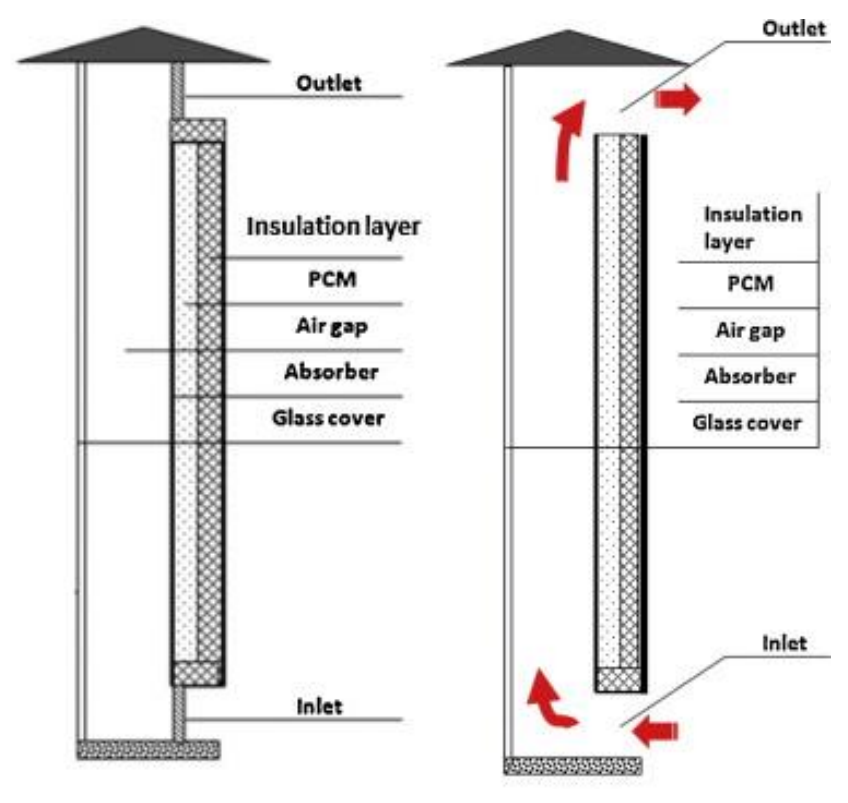

Fig. 5: Incorporation of PCM in (a) a trombe wall [170], and in (b) a solar chimney [168]. 
Another interesting method is the application of PCM as a specialised storage unit located in the room interior envelope. In this case, the storage unit will be combined with any passive or active heating and/or cooling systems by allowing circulation of the heat transfer fluid across the storage unit to store the heat/cold energy in the PCM [62, 97]. Clearly, this concept has the advantage of simple integration into the interior space compared to the other application methods as the PCM unit can easily be added, removed or retrofitted without affecting the building structure. PCM storage medium combined with active systems for space cooling and heating was discussed in [171-175]. PCM specialised storage incorporated in free cooling systems using nocturnal ventilation or combined with other natural cooling strategies will be covered in section 4 . 


\section{Research development on PCM based free cooling of buildings}

Phase change materials are promising sustainable technologies which could be used to store the cold energy available during nights in a sufficient latent heat storage for later utilisation during the daytime. The charging process takes place by circulating the cold ambient air through the PCM storage removing its heat and the PCM starts to freeze. This process continues until the outdoor temperature goes down below the PCM operation temperature (Fig. $6 a)$. On the other hand, the stored cold energy will be discharged once the indoor temperature exceeds the upper limit of the comfort zone through circulation of the hot air through the PCM storage. The passing air rejects the heat to the PCM which begins to melt. The exit air becomes cooler and then will be introduced into the indoor space (Fig. 6b).

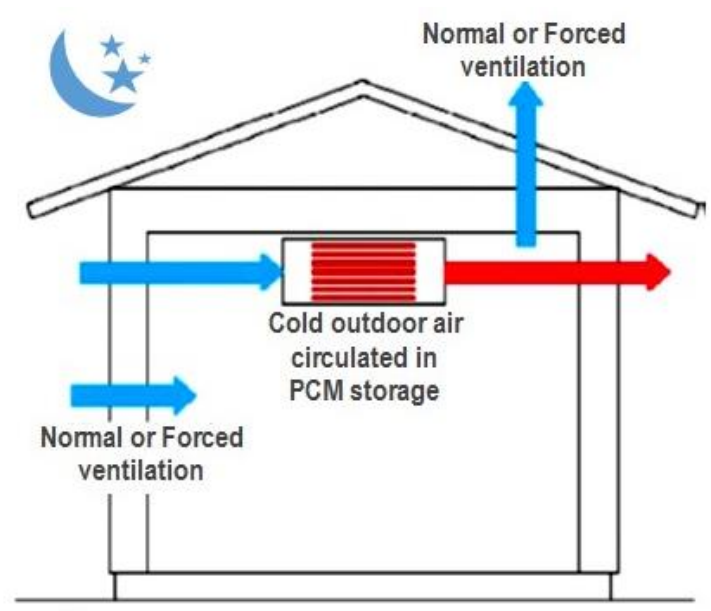

(a)

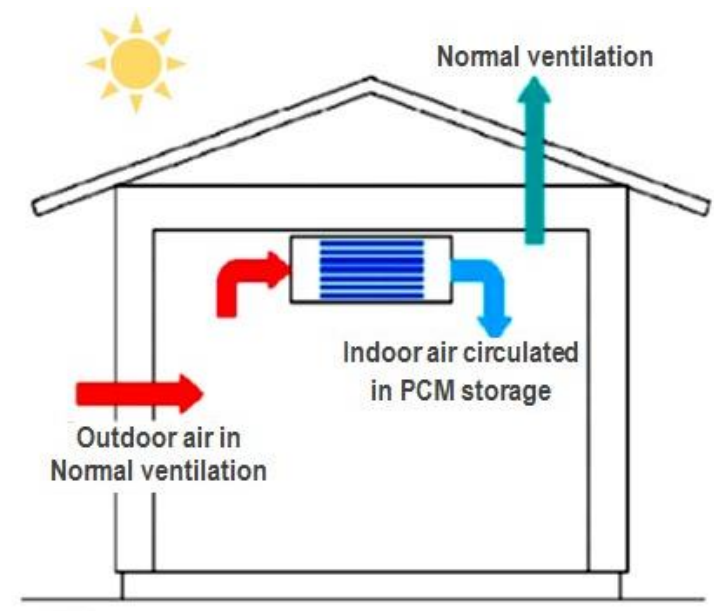

(b)

Fig. 6: A typical operation of free cooling systems incorporated PCM storage; (a) charging, and (b) discharging [176].

LHS systems based free cooling of buildings have been investigated by the researchers for over 25 years. Various designs of cooling and ventilation systems have been developed using different types of PCMs and a wide range of heat exchanger configurations. Any PCM heat exchanger utilised in free cooling contains these following three main components; an appropriate PCM with a phase change temperature within the desired range where most of the absorbed heat will be stored as a latent heat, a convenient container for the storage medium for adopting the volume alteration throughout the phase change process, and a proper heat exchange surface to transmit the heat from the energy supply to the PCM and from the PCM to the load [112]. 
The first serious discussions on free cooling technique incorporating LHS was carried out in 2000 by Turnpenny et al. [177]. In this work, a system with embedded heat pipes inside the PCM units was designed and developed for storing the night coolness to be discharged throughout the next daytime. A low powered fan located below the storage unit was used to draw the air from the room over the exposed part of the heat pipes as shown in Fig. 7. A salt hydrate $\mathrm{Na}_{2} \mathrm{SO}_{4} 10 \mathrm{H}_{2} \mathrm{O}$ with $21^{\circ} \mathrm{C}$ freezing/melting temperature was used for this research, and $1.5 \%$ borax nucleating agents were added to reduce the super-cooling effect. The heat pipes with attached fins were applied to enhance the heat exchange between the air and the PCM and hence avoiding the need for complex heat exchange configurations on the outer surface of the PCM, as this allows simple retrofitting for the system. Theoretical modelling and experimental work were performed to assess the potential of this design. An average heat transfer rate of 40 $\mathrm{W}$ from air to PCM was obtained over a melting duration of $19 \mathrm{~h}$ when the temperature difference between air and the PCM melting point was $5 \mathrm{~K}$. Accordingly, the authors suggested an alternative design for the fins attached to the heat pipes inside the PCM unit in order to increase the heat exchange rate and to shorten the transformation period, hence decreasing the number of PCM units needed to cool one room.

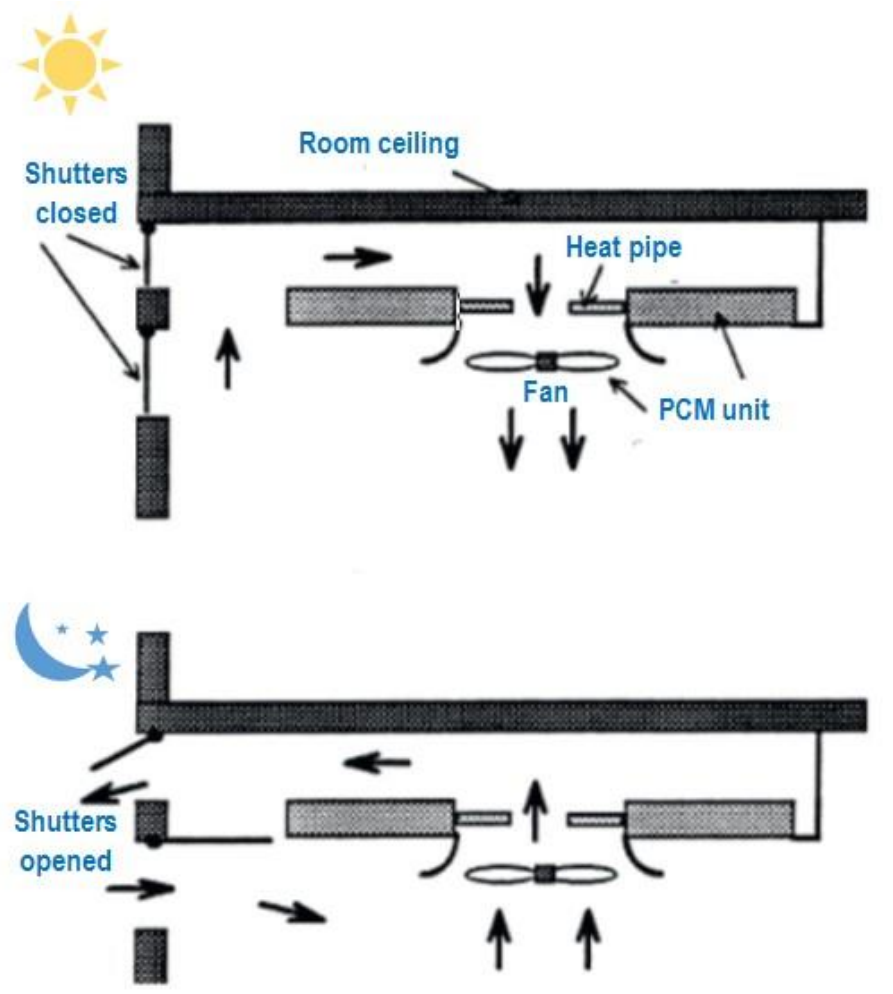

Fig. 7: (a) Charging, and (b) discharging of the heat pipe/PCM cooling system proposed by Turnpenny et al. [177]. 
Turnpenny et al. [178] improved the same system that provided in their previous study [177]. The authors assessed the potential of a full-scale prototype cooling system to cool a room under UK summer conditions. A ceiling fan with $1.20 \mathrm{~m}$ sweep diameter was used over a series of PCM units with embedded heat pipes arranged in a circular layout (Fig. 8). At night, the cold ambient air is directed through the heat pipes by the ceiling fan, the air becomes hotter and then exhausted to the outdoors. During the day, vents are closed and the ceiling fan is kept "ON" in order to enhance the room air convection with the PCM storage. The results showed that the developed storage system combined with night ventilation has provided a heat transfer rate of $200 \mathrm{~W}$, which is sufficient for cooling demand in typical UK summer conditions as stated by the authors. It is also mentioned that the system is able to deliver substantial energy saving and cost benefits compared to conventional air conditioning systems and to other alternatives such as chilled beams. In addition, a fundamental decrease in the percentage of $\mathrm{CO}_{2}$ emissions can be achieved by exchanging the $\mathrm{AC}$ devices by free cooling units. A reduction in the $\mathrm{CO}_{2}$ emissions by around 430 tons per year was predicted by fitting the proposed free cooling system in 2000 office buildings in the UK, as the applied HVAC systems utilise around $10 \%$ of the total fossil fuel [178].

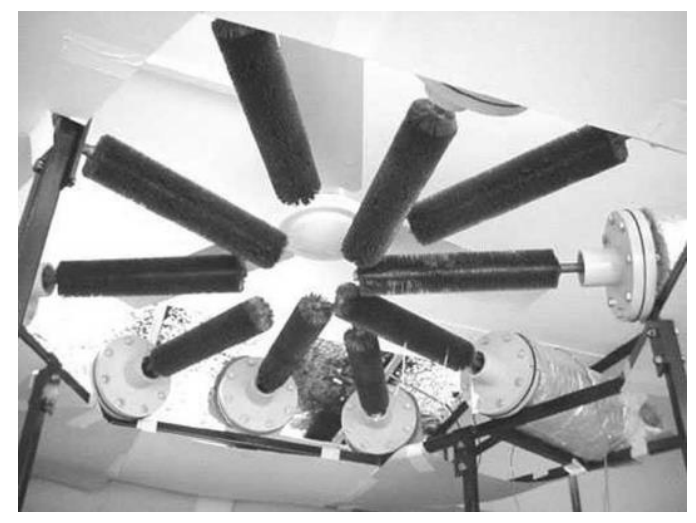

Fig. 8: An arrangement of the heat pipe/PCM units below a ceiling fan proposed by Turnpenny et al. [178].

In another major study, Yanbing et al. [179] have developed a mathematical model in order to examine the thermal performance of a proposed night ventilation with the PCM packed bed storage (NVP) system (Fig. 9). The mathematical results were validated using an experimental work carried out for a real test room during a summer period of Beijing/China. The utilised PCM is a type of fatty acid compounds developed by the authors. It has a melting temperature range of $22-26^{\circ} \mathrm{C}$ and a latent heat capacity $190 \mathrm{~kJ} / \mathrm{kg}$. A total mass of $150 \mathrm{~kg}$ was 
used in this test. An acceptable reduction in indoor temperature to the comfort limit was achieved throughout the test period ( 24 June to 4 July) compared to a similar room without a cooling system. Cooling discharging rates up to $1000 \mathrm{~W}$ during night-time and up to $300 \mathrm{~W}$ during the daytime were obtained. The overall coefficient of performance (COP) of the experimental installation was 80 .

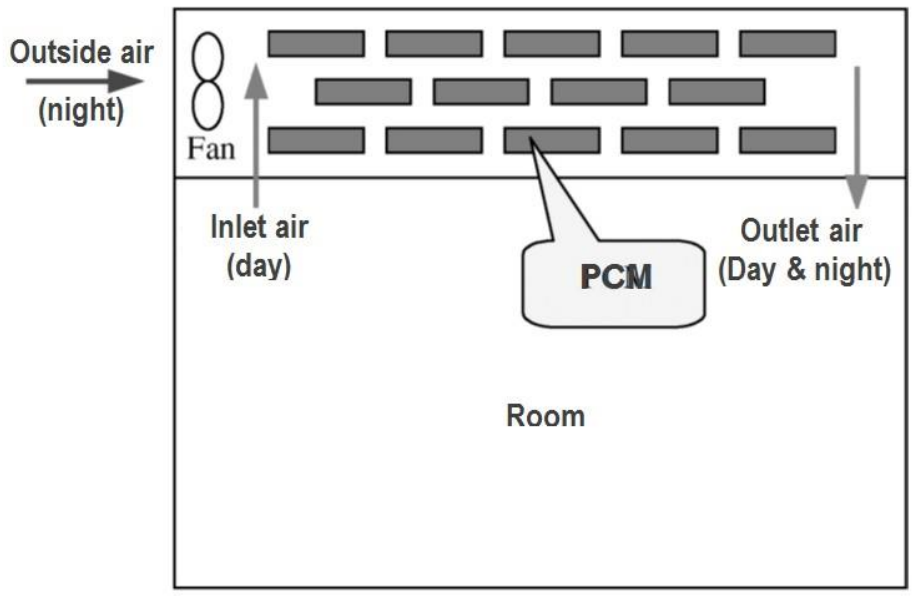

Fig. 9: Schematic of the NVP system proposed by Yanbing et al. [179].

An experimental prototype for free cooling applications was constructed and investigated by Zalba et al. [180]. The authors used a commercially available flat plate PCM packs with a melting temperature range $20-25^{\circ} \mathrm{C}$ incorporated inside a shell created with a couple of plates of polystyrene material with an air cavity in between to ensure lowest thermal losses (Fig. 10a). A parametric study was performed to investigate the performance of the empirical model under different parameters and best results were then utilised to design an actual free cooling system. The statistical analysis demonstrated that; lower thickness of encapsulation, higher flow rate and larger variation between the inlet air temperature and the phase change temperature, all together have a great impact on solidifying the PCM in a short period of time. Also, all these parameters have an obvious influence on the PCM melting but the inlet temperature has the dominant control rather than the encapsulation thickness while augmenting the air flow diminishes the melting time substantially. Based on the best results obtained from the parametric study, the authors designed a cooling system with a mean loading capacity of $3000 \mathrm{~W}$ using 8 tested modules of RT25 and C22 PCMs to cool an industrial room (Fig. 10b). The changes in air temperature throughout the PCM modules are presented in Fig. 
10c. A feasibility evaluation proved that the proposed system is technically feasible and the economically beneficial compared to conventional cooling systems.

(a)
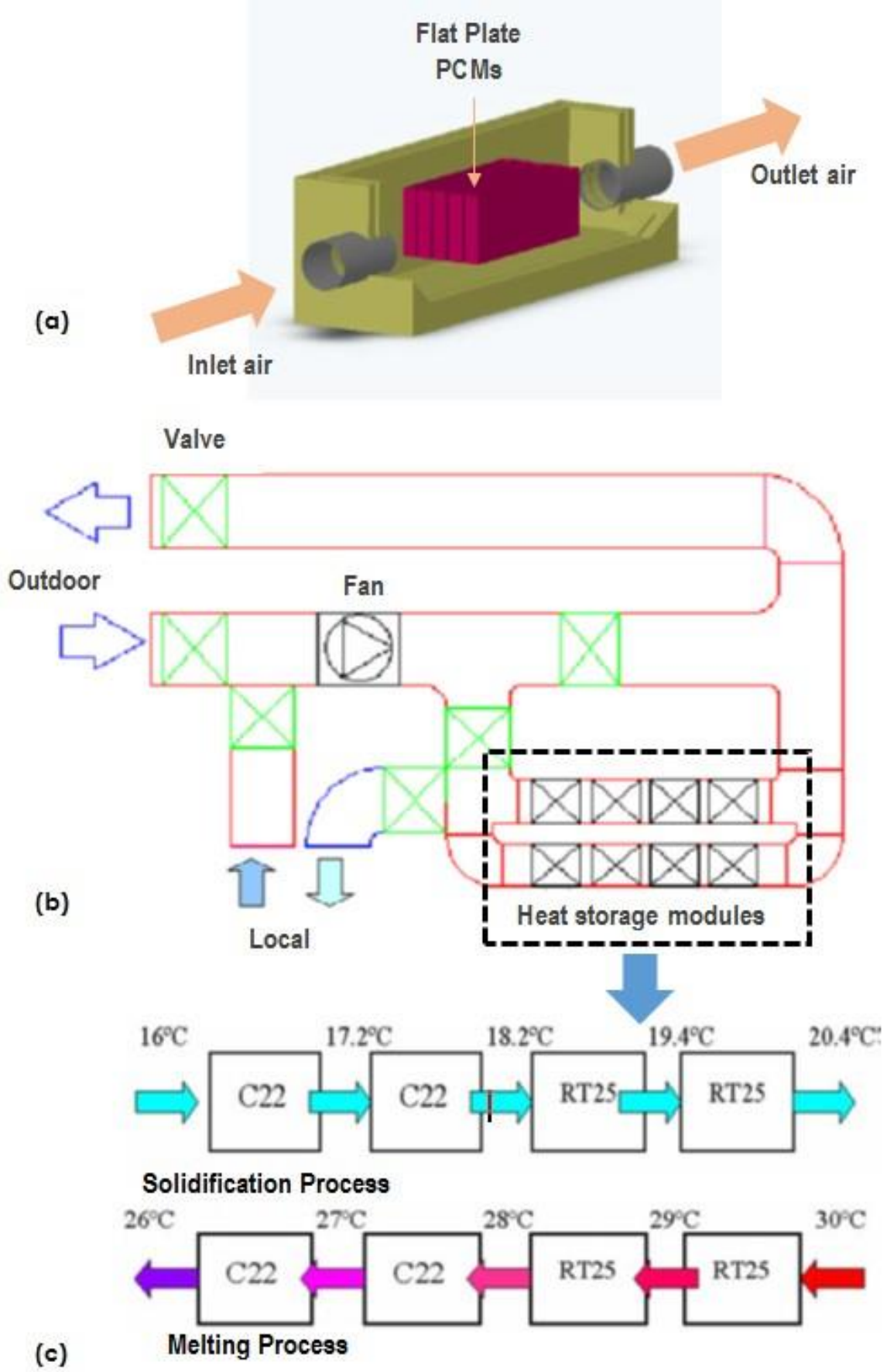

Fig. 10: The free cooling system proposed by Zalba et al. [180]; (a) the TES unit configuration, (b) schematic of a real installation, and (c) the temperature change during solidification and melting process. 
Marín et al. [181] have examined the same experimental setup developed by Zalba et al. [180], but instead of using pure PCM, graphite matrixes were embedded with the PCM inside the flat plate container in order to enhance the heat transfer rate. The system was analysed using a numerical model and validated experimentally. The results were compared to other from a system without graphite matrix. The findings revealed that; reducing the thickness of the PCM with graphite components by $30 \%$ has provided similar solidification/melting response time to that provided by the pure PCM by only half of the fan power consumption. Furthermore, a significant decrease of the PCM phase change time up to 50\% was achieved in the enhanced design with a very small reduction in energy storage approximated by $12-20 \%$.

Takeda et al. [17] also have developed a full-size experimental ventilation apparatus based on a system proposed by Nagano et al. [182]. The system consists of a rectangular duct $140 \mathrm{~mm} \times 140 \mathrm{~mm} \times 900 \mathrm{~mm}$ built to allow direct heat exchange between the ventilation air and the contained packed bed of PCM granules as shown in Fig. 11. The PCM granules are commercially available Rubitherm GR of 1-3 mm particle diameter and comprise $65 \%$ ceramic materials and 35\% paraffinic hydrocarbon by weight. The phase change temperature of the PCM is within the range of $22.5-25^{\circ} \mathrm{C}$. The outlet air temperature from the storage system was measured for various inlet temperatures to simulate the alteration of ambient air temperature. The results showed that the exit air temperature always remains consistent within the limit of PCM phase change during the discharging phase. Moreover, the proposed cooling device was integrated into a household ventilation system and the room temperature was set at $26{ }^{\circ} \mathrm{C}$. The ventilation load was calculated via a simulation tool for a summer season of eight cities in Japan to explore the influence of air temperature on the system performance. A decrease in ventilation load ranged from $42.8 \%$ to $62.8 \%$ was achieved. The authors also have stated that the benefits from the system depend greatly on diurnal temperature variation rather than on average temperature [17]. 


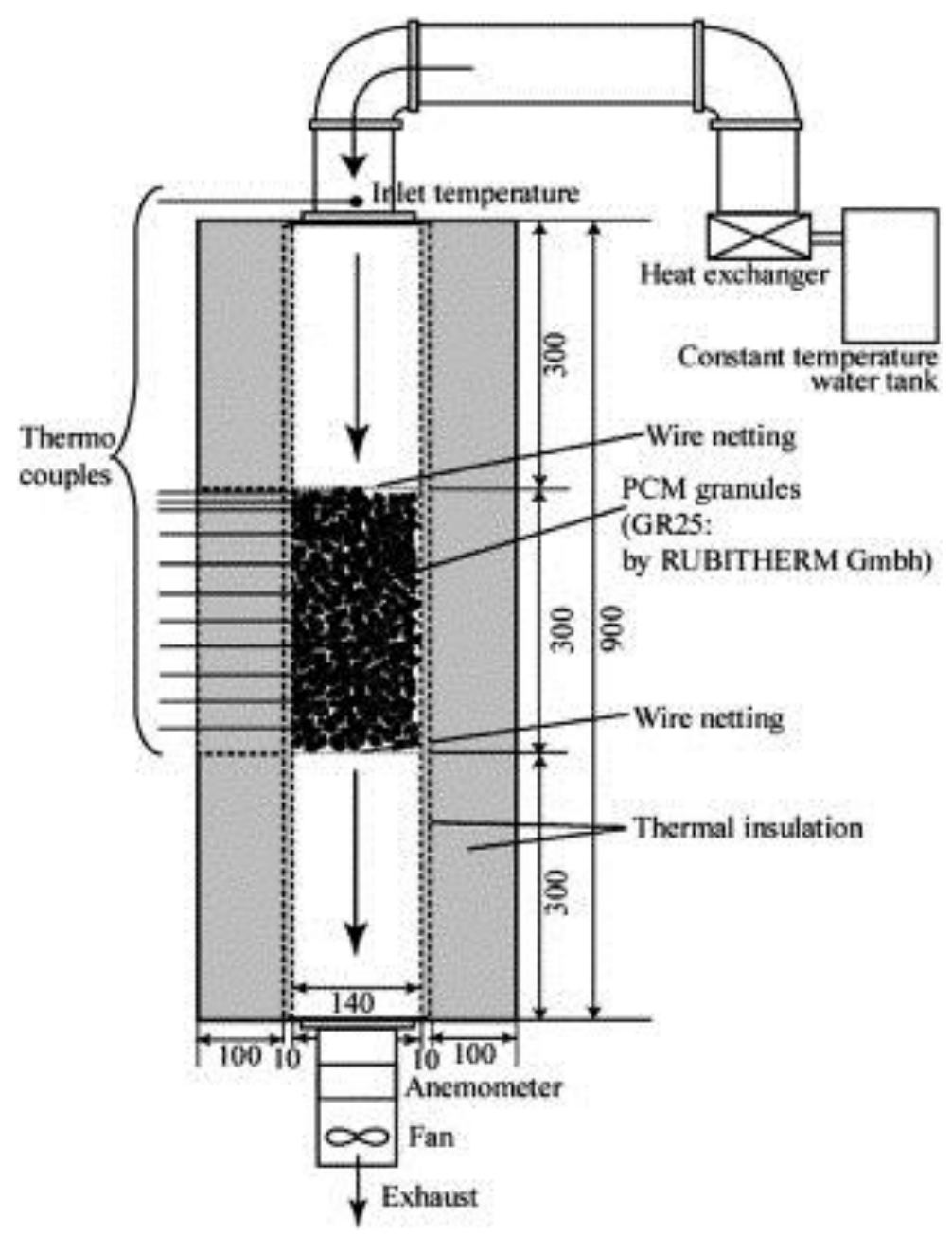

Fig. 11: Experimental apparatus of the free cooling system proposed by Takeda et al. [17].

Nagano et al. [183, 184] have proposed a floor supply air conditioning system via impregnating a packed bed latent heat storage into the building mass to enlarge its thermal storage capacity (Fig. 12). A small-scale experimental model with a floor area of $0.5 \mathrm{~m}^{2}$ was built for this study, and a $30 \mathrm{~mm}$ depth of granules containing PCMs were embedded directly in the room floor. The utilised PCM was made of foamed glass beads and paraffin wax and has a melting/solidification temperature around $20{ }^{\circ} \mathrm{C}$. During the night, cool air from an air conditioner is circulated inside the cavity below the floor which allows charging of cold energy to the floorboard, concrete slab, and PCM packed bed. During the daytime, the accumulated cold energy is released to the interior space through the porous of the floor board. The charging and discharging were performed similarly to a schedule of air conditioning operation over 24 $\mathrm{h}$ duration in a typical office building, and the indoor temperature was set at $28^{\circ} \mathrm{C}$. Each night the system has stored about $1.79 \mathrm{MJ} / \mathrm{m}^{2}$ of cooling energy which is capable of limiting the operation of the AC system for only three hours throughout the daytime and lowering the daily 
cooling load by $89 \%$. The authors stated that increasing the amount of PCM can fulfil the whole daytime cooling demand of the tested office space.

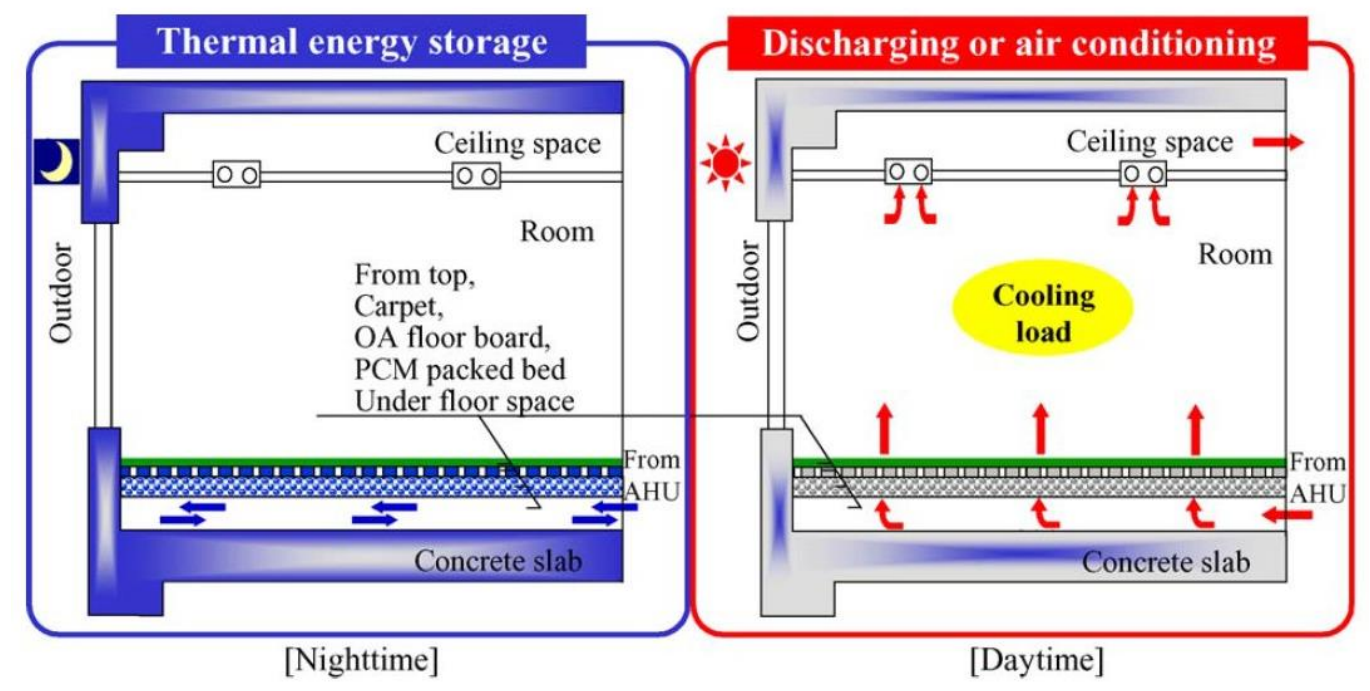

Fig. 12. An underfloor cooling system incorporated packed bed PCM granules proposed by Nagano et al. $[183,184]$.

An experimental setup was designed by Stritih and Butala $[185,186]$ to evaluate the heat transfer within a proposed PCM cold storage system based on free cooling as shown in Fig. 13a. About $3.6 \mathrm{~kg}$ of commercially available PCM (paraffin Rubitherm RT20) with a melting temperature of $22{ }^{\circ} \mathrm{C}$ was placed inside a metal box designed with a configuration to allow simple integration into the building ceiling. The metal duct was externally insulated to suppress the surrounding cold transfer. Aluminium fins were used externally and internally at both top and bottom sides of the metal box to enhance the thermal performance (Fig. 13b). Air temperatures and heat flux as a function of time were calculated for several air speeds and inlet temperatures utilising a numerical model. The experimental measurements and modelling results showed a good agreement. The indoor air temperature was reduced from $27^{\circ} \mathrm{C}$ to $24^{\circ} \mathrm{C}$ for more than $2.5 \mathrm{~h}$ with at $7.8 \mathrm{l} / \mathrm{s}$ flow rate. Moreover, energy savings between $14 \%$ and $87 \%$ were predicted based on the selected parameters. 


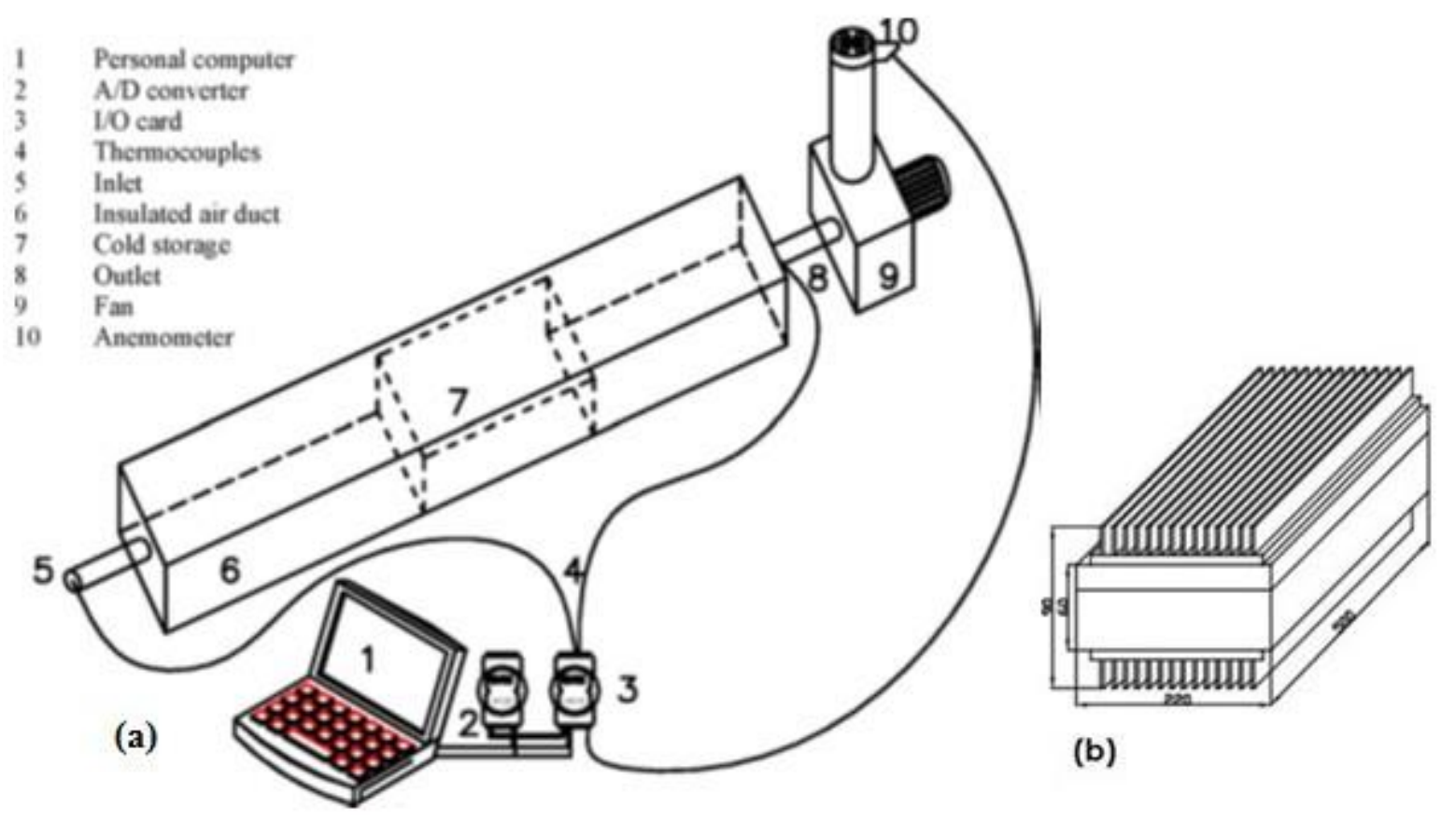

Fig. 13: The free cooling system proposed by Stritih and Butala [185]; (a) the experimental setup, and (b) the PCM storage configuration with fins.

For the purpose of eliminating and lowering the use of conventional air conditioning systems in buildings; Arkar and Medved [187] proposed a free cooling system which consists of a cylindrical latent heat thermal energy storage (LHTES) device filled with spherical balls of paraffin PCM. The authors introduced a numerical model considering the inconsistency of the spaces among the spheres and the velocity of the fluid due to a small tube to sphere diameter proportion. The proposed LHTES device was investigated by integrating it into a mechanical ventilation system of an existing house in Slovenia [188, 189]. The concept was tested and compared to other cooling techniques using TRNSYS simulation tool. The findings indicated that better comfort conditions and noticeable reduction in the size of the mechanical system can be accomplished by the free cooling device. A $6.4 \mathrm{~kg}$ of the PCM per square metre of floor area is sufficient to achieve the thermal comfort in the tested house. The authors also mentioned that the developed LHTES device can be utilised for winter heating when it is combined with an air solar collector or a ventilated facade.

Another major study was conducted by Medved and Arkar [190] who assessed the free cooling potential under different climatic conditions of six European cities. The same packed bed cylindrical LHTES device that developed in [188, 189] was applied to a building mechanical ventilation system. The utilised PCM was commercially available RT20 paraffin 
with a relatively large phase change temperature range $(12 \mathrm{~K})$. The size of the LHTES system was optimised according to the cooling degree hours (CDH) which represents the maximum free cooling potential estimated by the following formula;

$$
C D H=\sum_{i=0}^{2208}\left(T_{a}-T_{o}\right) \delta
$$

where $\delta=1 \mathrm{~h}$, when $T_{a}>T_{o}$, and $\delta=0 \mathrm{~h}$, when $T_{a} \leq T_{o}$. The air flow is fully regulated by a control unit based on the inlet ambient air temperature $\left(T_{a}\right)$ and the outlet air temperature $\left(T_{o}\right)$. When $T_{o}>T_{a}$; often during the night; the interior space was ventilated directly by the ambient air which is within the thermal comfort range for the selected cities, and a separate air circulation was provided to solidify the PCM (Fig. 14b). While in the case of $T_{a}>T_{o}$; mostly during the daytime; the room was ventilated through the PCM unit extracting the accumulated cold (Fig. 14a). For the studied climates (continental) it is found that the PCM with a larger phase change temperature range $(12 \mathrm{~K})$ is more advantageous than the PCM with a narrow temperature range $(4 \mathrm{~K})$. The authors also stated that the optimal melting temperature of PCM is almost equivalent to the average temperature of the hottest month or only $\pm 2{ }^{\circ} \mathrm{C}$ to guarantee an effective performance. The ideal ratio between the mass of the PCM and the air flow rate has to be between 1.0 and $1.5 \mathrm{~kg} / \mathrm{m}^{3} / \mathrm{h}$ in order to meet around $85 \%-95 \%$ of the maximum $\mathrm{CDH}$.

(a)

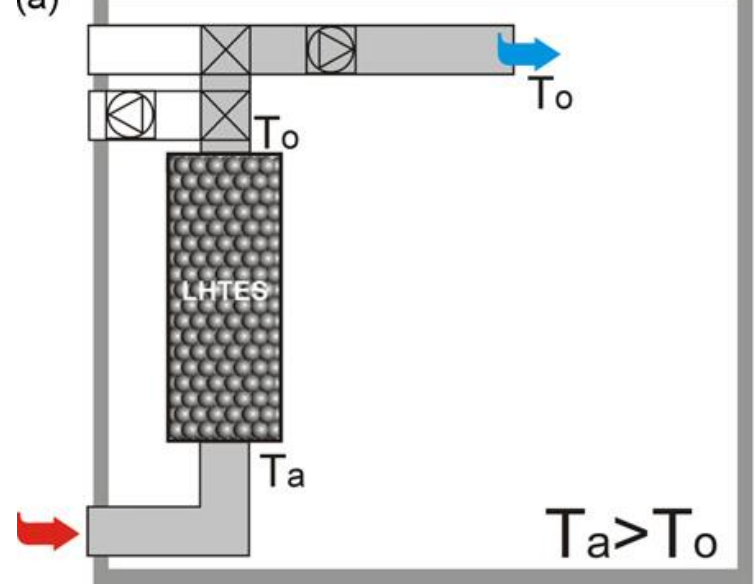

(b)

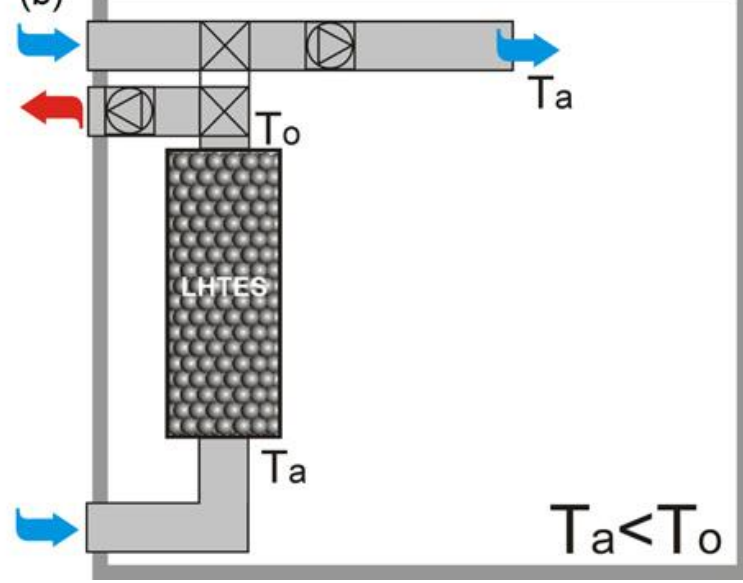

Fig. 14: Operational principles of the free cooling system proposed by Arkar and Medved [190]. 
Based on the results obtained by Zalba et al. [180], an experimental setup was designed by Lazaro et al. [191] to examine the thermal behaviour of two real-scale prototypes of PCMair heat exchanger for free cooling purposes; one was designed utilising aluminium pouches filled with inorganic PCM (Fig. 15a), and the other type was designed utilising aluminium panels filled with organic PCM (Fig. 15b). An air conditioner was employed to simulate various operation modes. A feasibility study was performed for different inlet air temperatures and air flow rates. The results indicated that, although the aluminium panels with organic PCM have a lower conductivity and a smaller stored energy, a higher cooling power and a shorter melting time (nearly half) was obtained due to the thickness stability, in contrast to the aluminium pouches which displayed high container expansions and PCM leakage during the phase change. Based on these findings the authors proved that it is better to enhance the heat exchanger design rather than escalating the conductivity level to ensure satisfactory outcomes, as increasing the conductivity in most cases results in additional costs.

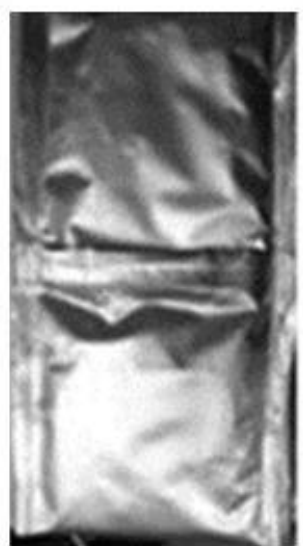

(a)

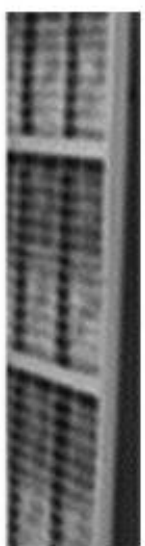

(a)

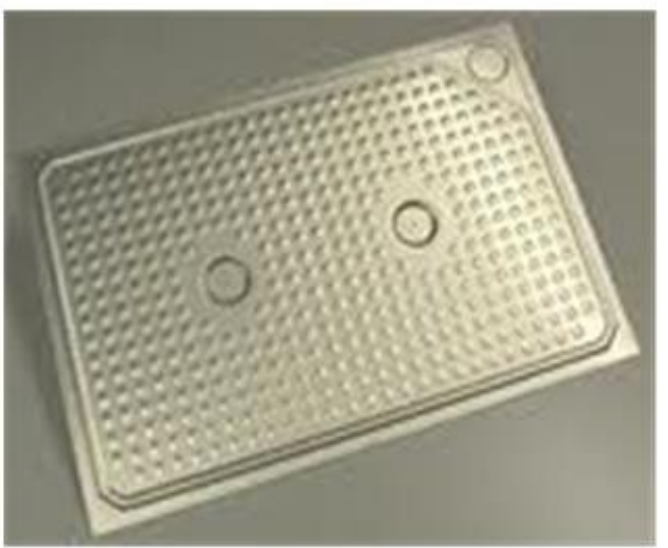

(b)

Fig. 15: The real-scale PCM prototypes investigated by Lazaro et al. [191]; (a) aluminium pouches filled with an inorganic PCM, and (b) aluminium panels filled with organic PCM.

Based on the satisfactory performance of the second prototype (aluminium panel with organic PCM) that evaluated in [191], it was selected for further implementation by Lazaro et al. [192]. An empirical model consists of 18 PCM modules was built to evaluate the technical viability of the proposed cooling system. The authors reported that utilising a modular design concept is beneficial to assess the technical viability of the tested configuration for different applications, as it is possible to size the number of PCM modules and the average phase change temperature based on the needed cooling power, favourable indoor temperature and duration 
required to maintain this temperature. Moreover, a selection criterion for PCM melting temperature was investigated according to the cooling load; it was found that PCM with a melting point lower than the required indoor temperature should be selected in case of high cooling demands, while PCM with a melting point closer to indoor objective temperature is suitable for the low cooling demands.

An experimental setup used to investigate the full thermal cycling of a real-scale PCMair heat exchanger was developed by Dolado et al. [193]. Commercially available macroencapsulated paraffin RT27 in aluminium rigid slabs was used. Fig. 16 shows the experimental setup of the conducted study. The key findings showed that the continuous thermal cycling of the designed storage unit is a repetitive procedure and no deterioration was observed regarding the properties of the PCM. A full solidification of the PCM was realised in less than $3 \mathrm{~h}$ for a temperature variation of $8 \mathrm{~K}$ between the inlet air and the PCM average phase change point with an air mass flow between 0.4 and $0.5 \mathrm{~kg} / \mathrm{s}$. Average heat flux up to $4.5 \mathrm{~kW}$ and $3.5 \mathrm{~kW}$ for $1 \mathrm{~h}$ were achieved for the melting and solidification phases respectively. Another work related to this study had been carried out in parallel by the same authors in [194]. The computed results of the experimental study were utilised to validate results of a developed numerical model for the tested PCM-air heat exchanger. The authors reported that the developed numerical model will be employed as a designing tool for these sorts of PCM-air heat exchangers in various applications.

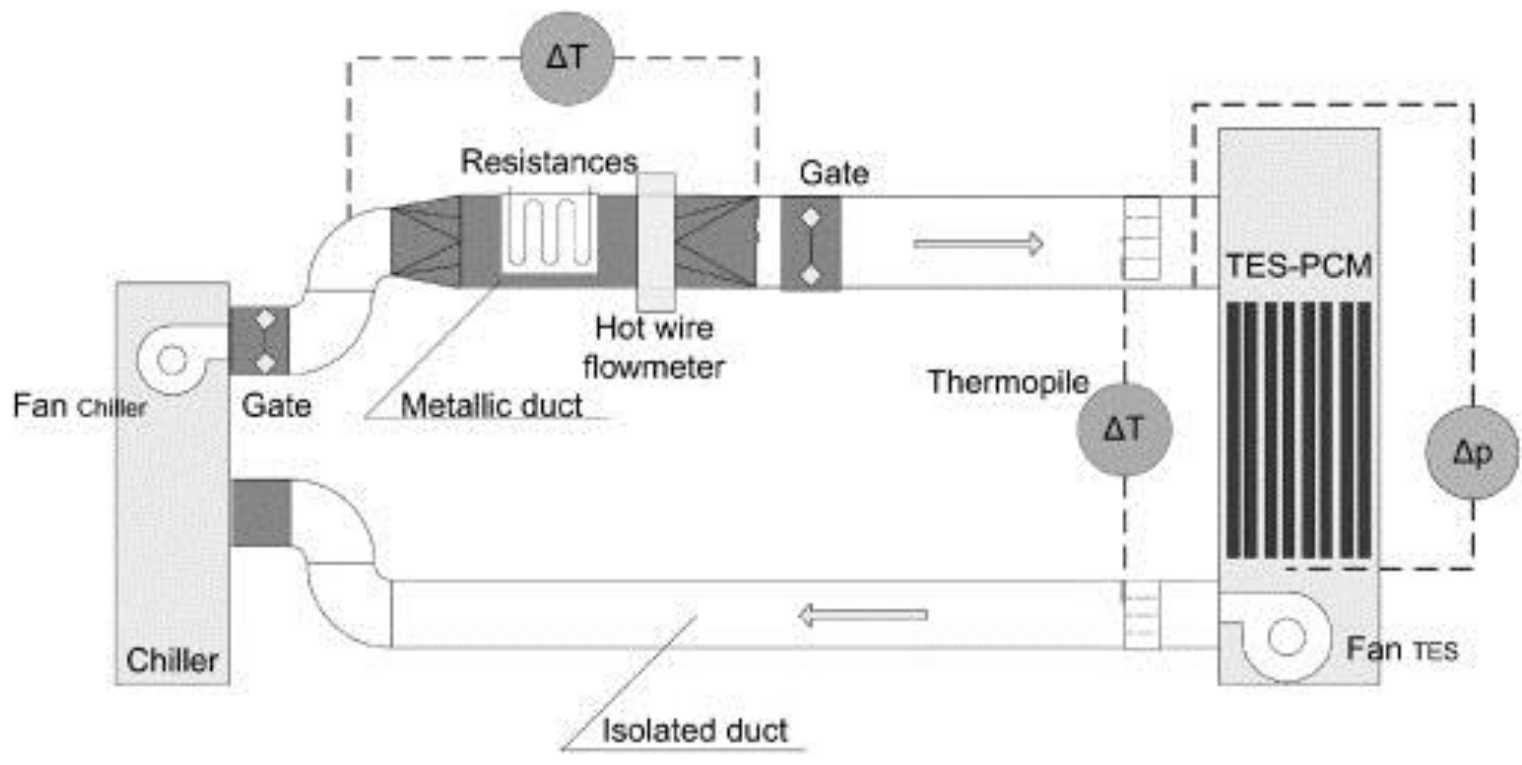

Fig. 16: Experimental setup of the PCM-air heat exchanger with rigid panels developed by Dolado et al. [193]. 
The first investigation of free cooling systems under hot and arid climate conditions was carried out in 2011 by Waqas and Kumar [195]. A prototype storage unit was built using three PCM containers and tested inside a controlled environmental chamber as illustrated in Fig. 17. The utilised PCM was a commercialised type of salt hydrates (SP29, Rubitherm $\mathrm{GmbH}$ ) with a phase change temperature range of $28-29^{\circ} \mathrm{C}$, encapsulated inside a galvanized steel container $(0.5 \mathrm{~m} \times 0.5 \mathrm{~m} \times 0.01 \mathrm{~m})$. Three inlet air temperatures $20^{\circ} \mathrm{C}, 22^{\circ} \mathrm{C}$ and $24{ }^{\circ} \mathrm{C}$ were tried for the charging of the PCM and $36^{\circ} \mathrm{C}, 38^{\circ} \mathrm{C}$ and $40{ }^{\circ} \mathrm{C}$ for the discharging phase. The key findings indicated that; the examined PCM storage can be allocated to maintain the indoor daytime temperature within the acceptable ranges via extraction of the accumulated cold energy at night. Moreover, increasing the inlet charging temperature from $22{ }^{\circ} \mathrm{C}$ to $24{ }^{\circ} \mathrm{C}$ has led to an approximately 55\% extra time required for full solidification of the PCM, while decreasing the inlet temperature from $22^{\circ} \mathrm{C}$ to $20^{\circ} \mathrm{C}$ saved about $33 \%$ of the required time for the complete solidification. Augmenting the air flow rate from 4.0 to $5.0 \mathrm{~m}^{3} / \mathrm{h}$ lowered the solidification period by around $16 \%$. The authors also concluded that low inlet air temperature and high flow rates are useful during the charging phase to assure a complete solidification of the PCM in a short time, while, lower flow rates are beneficial for the cold energy discharge throughout the daytime.

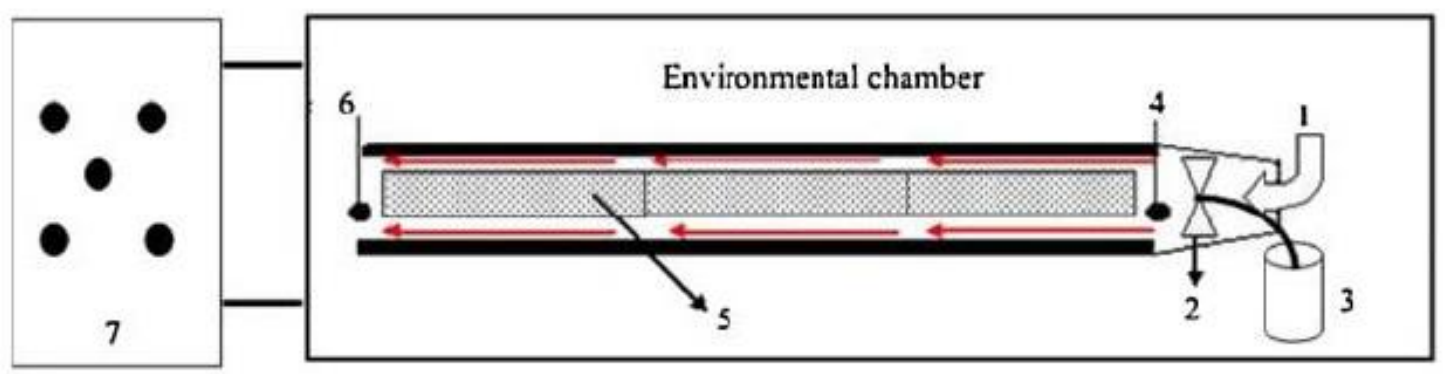

1: Air inlet to storage unit. 2: Fan. 3: Fan speed controller. 4: Air inlet temperature sensor. 5: storage material (PCM). 6: Air outlet temperature sensor. 7: Control panel for chamber $\mathrm{AC}$, heater and fan.

Fig. 17: Experimental setup of the PCM storage proposed by Waqas and Kumar [195].

Using a numerical method, Waqas and Kumar [196] have assessed the behaviour of a flat plate air-based PCM storage system for free cooling in the summer season of Islamabad, Pakistan. The modelling results were validated with results of a previous experimental study conducted by Halawa et al. [197] considering the use of the same inlet temperature data and the simulation time. The findings generally showed close agreement between both approaches. 
However, the numerical model predicts higher outlet air temperatures at the start time of the melting phase simulation and lower values at the rest time. Also, the numerical calculations indicated early completion of the solidification process than that appeared during the experiment. The authors came out with these conclusions; the proposed cooling system is capable of bringing the hot daytime temperature well to the comfort range in the investigated hot and dry region. The cooling capacity was maximised when selecting a PCM with a melting point equal to the comfort temperature of the hottest summer month and the melting temperature seems to be the most influential parameter on the system manner than the air flow rate.

Raj and Velraj [198] have developed a modular heat exchanger for free cooling application in locations with low diurnal temperature variation. The thermal storage consists of a number of modules placed vertically over each other with spacers above and below each module. The designed module was a PCM encapsulated inside a $750 \mathrm{~mm}$ diameter shell containing several tubes for air flow (Fig. 18a). CFD modelling was performed for one module and two air spacers to study the temperature distribution, air flow, and heat transfer phenomena in the proposed heat exchanger. Temperature contours in Fig. 18b indicated that uniform temperatures about $295 \mathrm{~K}$ are dominant at the inlet side of the spacer, constant temperature around $299 \mathrm{~K}$ was maintained around the PCM walls of the inner tube, and the temperature increase is higher at the lower velocity $0.1 \mathrm{~m} / \mathrm{s}$ compared to that of $2.0 \mathrm{~m} / \mathrm{s}$ due to increase in air mass flow. A steady state analysis was performed to determine the pressure drop throughout the module and spacers and to recognise the flow and temperature variation of the passing air across the module, this analysis is useful to select the geometrical and flow parameters for a given surface temperature and inlet conditions. A transient analysis was also carried out to determine both; the solidification features of the PCM and the geometrical dimensions of the modular design. Comparing the output of CFD simulations to the experimental findings indicated that, the scanning rate of the DSC analysis should be made according to the cooling/heating rate of the selected application to attain the accurate phase change temperature range for the selected PCM; otherwise, incompatible results of phase change temperature between theoretical and practical applications may be expected. The authors also noticed that the provided spacers enhanced the retention time of the air and resulted in better heat transfer, especially at lower air speeds. A sub-cooling was observed on the PCM adjacent to the inner ring of the tubes when the area between the two tubes reaches the solidus temperature, which 
was attributed to the diminution of the heat transfer surface area for the given PCM module, accordingly, lessening the distances between the tubes is suggested. In addition, incomplete phase change at the outer boundaries of the PCM module was detected. Thus, reducing the outer diameter of the module design is advocated by the authors.

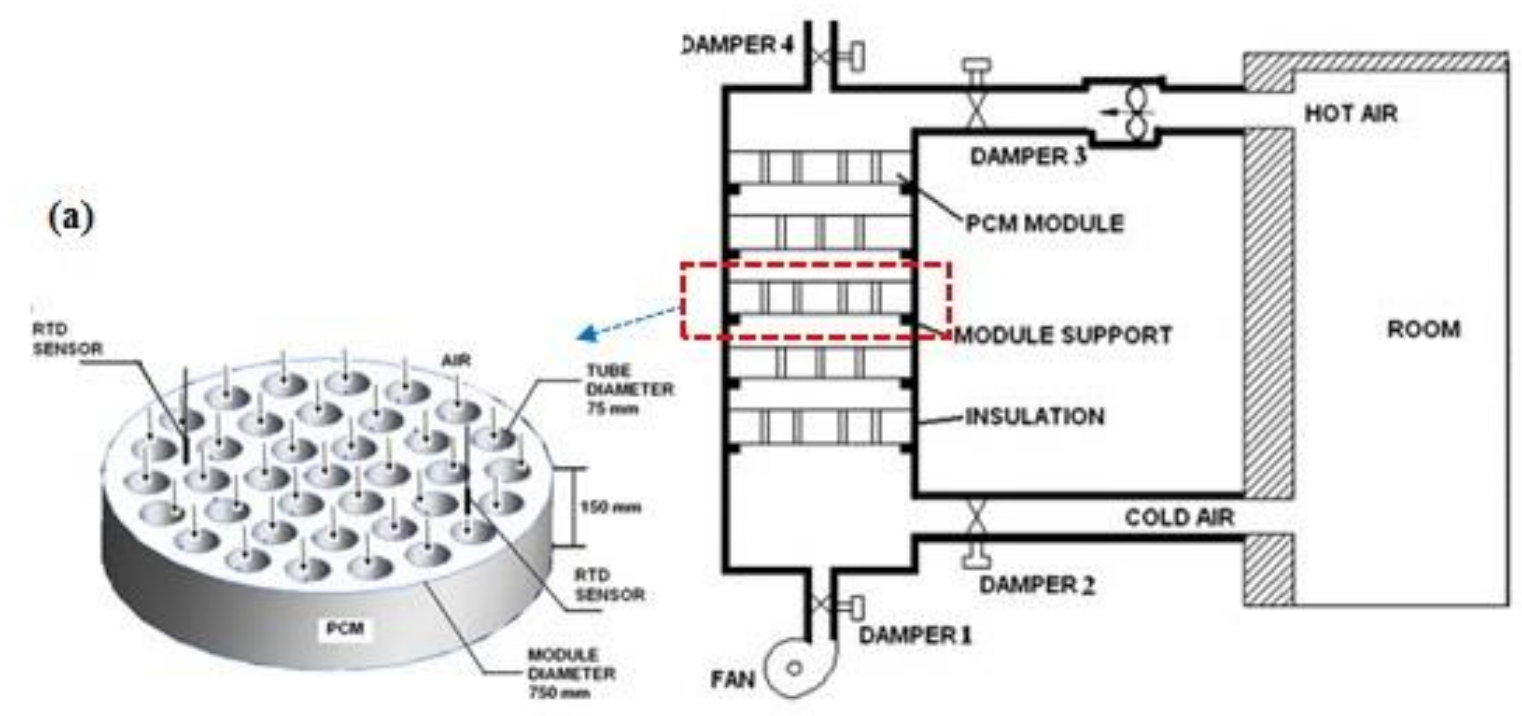

(b)

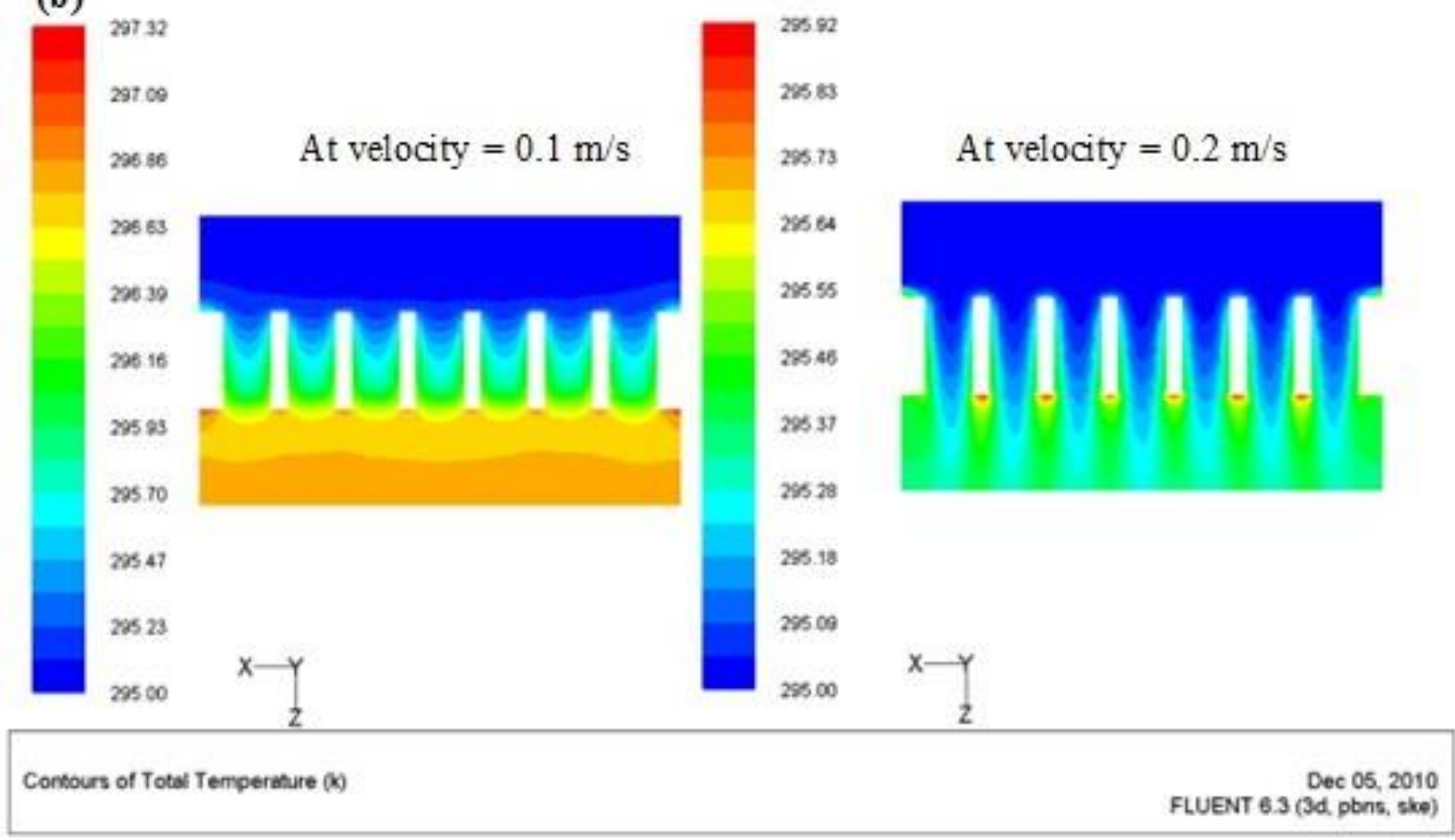

Fig. 18: (a) Schematic of the modular PCM heat exchanger developed by Raj and Velraj [198], and (b) the temperature contours computed by CFD modelling. 
Bulut and Aktacir [199] have thought on free cooling as a supportive application for the air conditioning device. They investigated the potential of free cooling for an all-air HVAC system under climate conditions of Istanbul, Turkey, via analysing the hourly dry-bulb temperature data of 16 years period. The authors reported that free cooling or so-called economiser cycle can be used as a part of the HVAC system to supply comfort temperature with minimum operation costs. This can be accomplished when benefiting from the available natural coolness to fulfil part of the energy load during favourable outdoor climate conditions. It was found that free cooling capacity in the meant location varies with the supply air temperature and months. Significant energy savings can be realised during the transition months; yet, the free cooling concept seems to be non-beneficial during summer months excluding durations in which outside temperatures are less or equal to the high supply air temperature.

A novel cooling using PCM named Indirect Evaporative and Storage Unit (IESU) was developed and optimised by Jaber and Ajib [200] for domestic application under a Mediterranean climate of Amman, Jordan. The proposed cooling system comprises an indirect air cooler combined with a PCM heat exchanger as shown in Fig. 19a. The heat exchanger was made of a rectangular corrugated flat tube filled with PCM layers and passages for air flow from two directions were created (Fig. 19b). The utilised PCM was a commercial type of salt hydrates with a phase change temperature $20^{\circ} \mathrm{C}$. A parametric study was carried out to investigate the effect of various parameters related to the PCM storage configuration and to the operating conditions on the IESU thermal behaviour. It was found that the influence of heat exchanger length is greater than the width effect and the cooling load increases as distances between plates increased due to decreasing number of PCM modules. An optimised design was found and is able to provide a total savings of $80 \%$ of the annual cooling demand with a payback period of 7.8 years. 


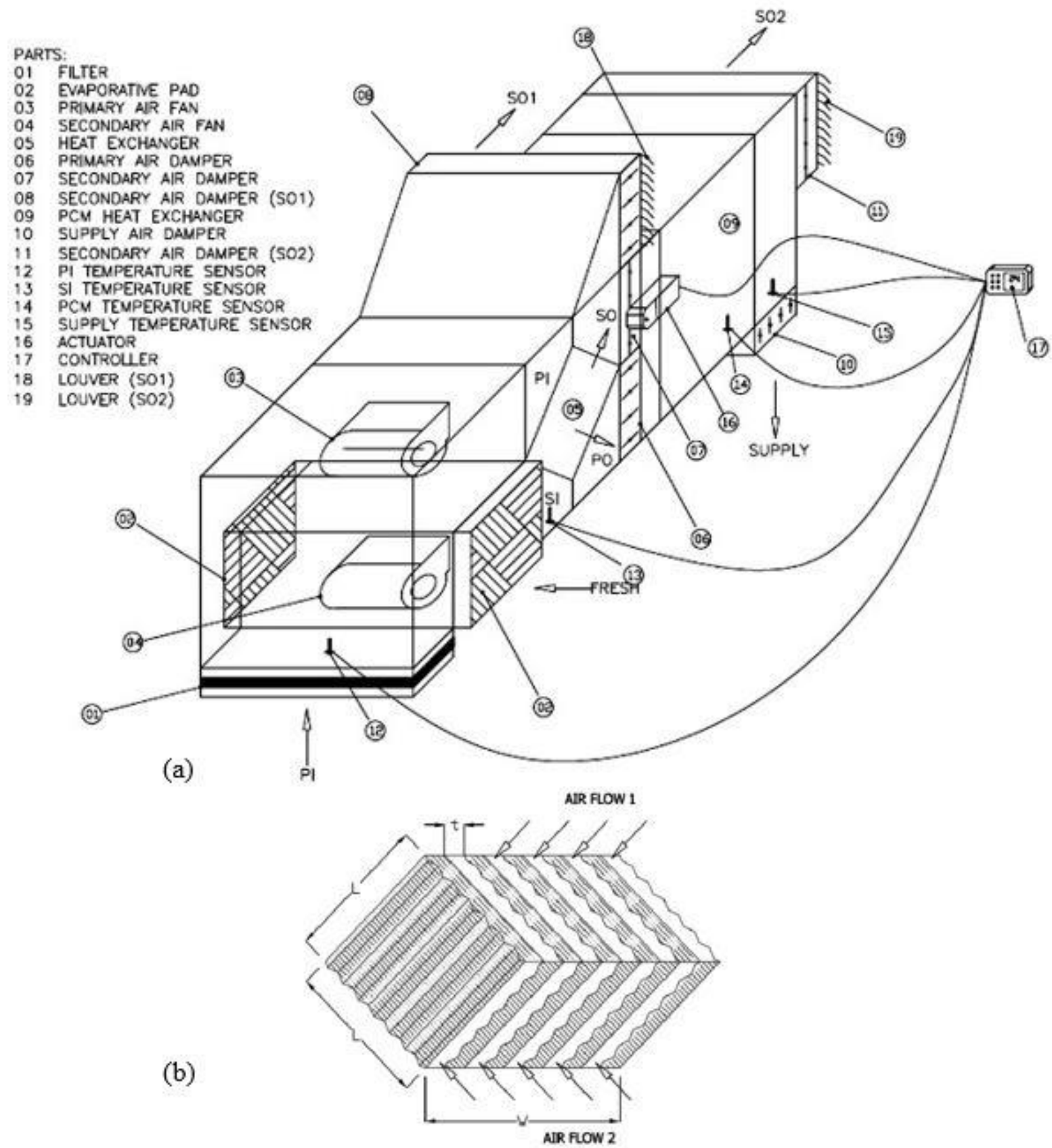

Fig. 19: (a) Experimental setup, and (b) the PCM heat exchanger model proposed by Jaber and Ajib [200].

Mosaffa et al. [201, 202] have studied the thermal behaviour of a multiple PCMs for the free cooling application (employing more than one PCM type to store and release the heat). The storage medium comprises several slab units of PCM, each unit includes multiple PCMs, and these units were arranged parallel to each other creating rectangular tunnels in between for the air flow (Fig. 20a). The schematic of the whole proposed system is shown in Fig. 20b. During the charging phase, the circulation of the ambient air occurs from the side of the PCM 
with the lowest phase change temperature to the higher ones, while reverse flow takes place during the discharging phase in order to enhance the heat transfer between the PCM and the stream of air flow. A two-dimensional mathematical investigation using the effective heat capacity method was performed to study the thermal performance of the cooling system and the computed results were validated experimentally showing a satisfactory agreement. The thermal comfort was accomplished by the system for the climate of both; Tabriz/Iran [202] and Eindhoven/Netherlands [201] with a COP above 7.0 which is considerably better than that for conventional air conditioners. From the feasibility study; the highest COP was achieved for the PCM slab with a shorter length and a thinner thickness, and the optimal design parameters to maintain the outlet air temperature below $20^{\circ} \mathrm{C}$ for around $8 \mathrm{~h}$ were determined by the authors to be $3.2 \mathrm{~mm}$ high and 1.30 meter long for the air channel, and $9 \mathrm{~mm}$ thickness for the PCM slab.

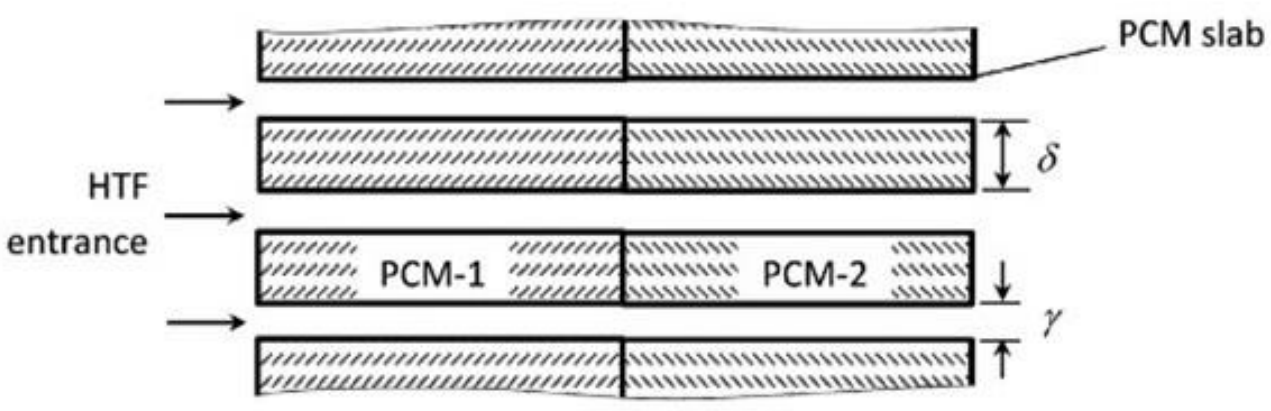

(a)
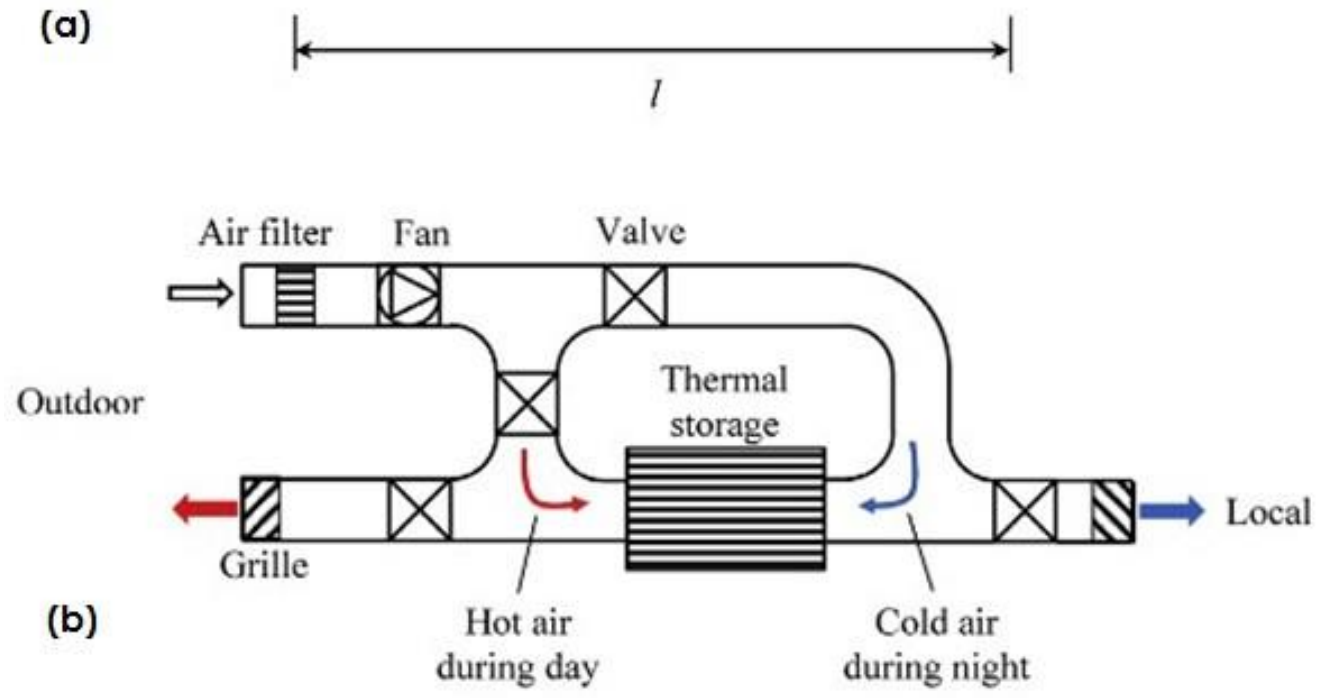

Fig. 20: (a) Arrangement of multiple PCM slabs, and (b) schematic of the free cooling system proposed by Mosaffa et al. [202, 203]. 
A TES system consisted of a bundle of rectangular tubes filled with a commercial RT28HC PCM was developed by Rouault et al. [204] for free cooling application in buildings (Fig. 21). The system was investigated numerically to analyse the effect of the arrangement of the PCM tubes on the system efficiency. The feasibility study revealed that tubes of vertical section slightly displayed better performance compared to horizontal ones, the authors also stated that heat exchange improvement techniques are required to enhance the cooling power of the system.

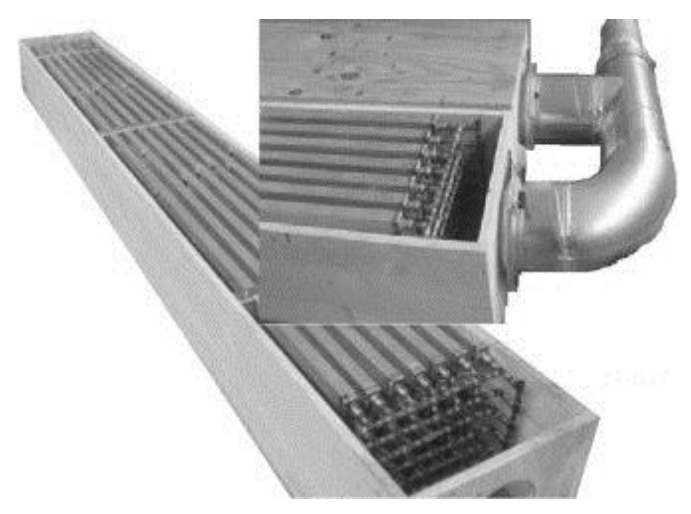

Fig. 21: The TES system of rectangular tubes filled with PCM developed by Rouault et al. [204].

Darzi et al. [205] have studied the impact of mass flow rate and thickness of PCM plates under different indoor room temperatures (i.e. different Stefan number) for free cooling application in buildings. The schematic of the system is shown in Fig. 22. A commercially available kind of salt hydrates PCM (SP22A17) produced by Rubitherm was used. The authors used a numerical simulation to monitor the developments of melt fraction and temperature distribution inside the PCM plates in respect of time, as it is difficult to monitor these parameters experimentally. The heat flux $(Q)$ at each time step $(j)$ was calculated using the following expression;

$$
Q_{j}=\dot{m}_{j} C_{p}\left(T_{i, j}-T_{o, j}\right)=\rho v_{j} A C_{p}\left(T_{i, j}-T_{o, j}\right)
$$

where $(m)$ is air mass flow rate, $\left(C_{p}\right)$ is air specific heat, $(\rho)$ is air density, $(v)$ is velocity of the air, $A$ is the area of the inlet side, and $\left(T_{i}\right)$ and $\left(T_{o}\right)$ are inlet and outlet air temperature respectively. The findings revealed that increasing the Stefan number $(S t)$; computed from equation (4); causes the increase of the cooling power and the exit air temperature from the storage unit, while, increasing the mass flow rate maximises the cooling power and allows 
faster melting process. It was also stated that the thickness of the PCM plates has a significant impact on the thermal behaviour of the PCM heat exchanger and it has a linear relation with the PCM melting duration for the considered configuration.

$$
S t=\frac{C_{p}\left(T_{i}-T_{m}\right)}{L}
$$

where; $\left(T_{m}\right)$ is average melting temperature, $\left(T_{i}\right)$ is inlet temperature, and $(L)$ is latent heat of fusion of the PCM. The Stefan number varies only with inlet temperature for the same PCM.

(a)

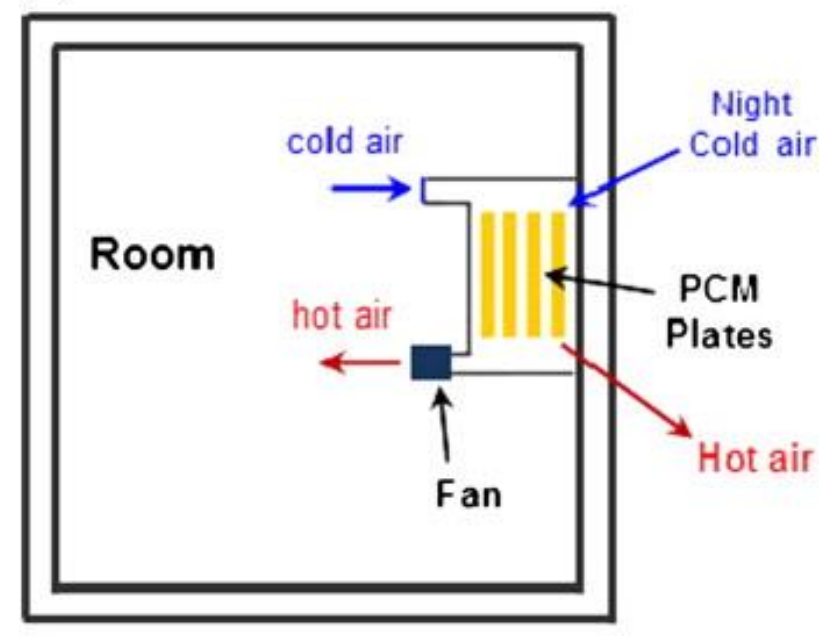

(b)

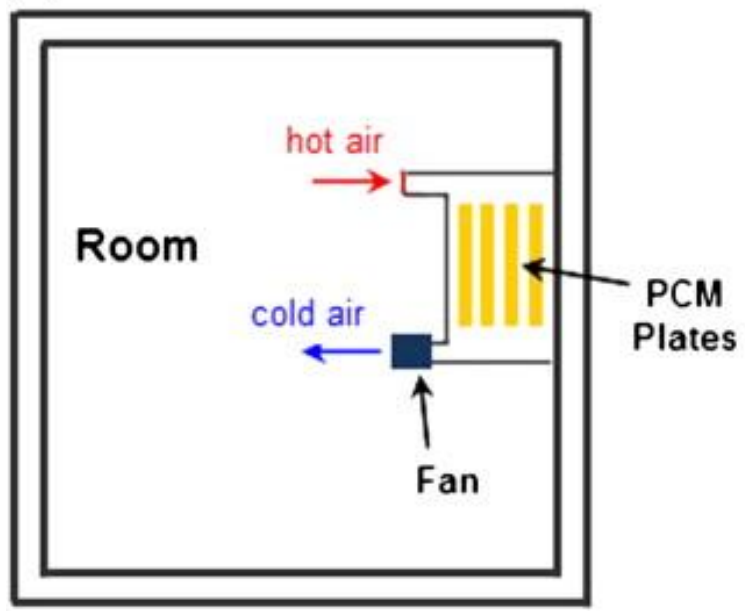

Fig. 22: (a) Night and (b) daytime operation of the free cooling system proposed by Darzi et al. [205].

Rajagopal et al. [206] have studied the potential of free cooling technology in Bangalore city in India based on weather data analysis of the city for a period of one year, and on the 
estimated cooling load of a considered 10 storeys commercial building. The main objective was to come out with some recommendations to get the most out of the free cooling strategy. The study revealed that free cooling is capable of maintaining the year-round thermal comfort in the considered building and location without any need for supportive mechanical systems.

In 2015, Waqas et al. [207] have published a paper in which they coupled the free cooling system that investigated in [196] with a stand-alone solar air collector to allow operation of the PCM heat exchanger for both summer cooling and winter heating in buildings in hot dry and cold dry climate of Islamabad, Pakistan. A commercial PCM of salt and paraffin mixture with a phase change range $23-27{ }^{\circ} \mathrm{C}$ was utilised. For heating requirements, the received solar energy during winter daytime was absorbed using a flat-plate glazed solar air collector. The collector heats up the air before it is being directed by a fan through the PCM storage to be extracted during the cold night hours. The configuration of the solar air collector and the PCM storage is shown in Fig. 23. The authors have found that a PCM with a transformation point approximately $27.5^{\circ} \mathrm{C}$ in the middle of the summer comfort represents the appropriate solution for the whole year comfort in the considered location. The optimum performance achieved in summer is when utilising a PCM with a melting temperature of 29 ${ }^{\circ} \mathrm{C}$; this increases the cooling capacity by $15 \%$ and reduces the heating capacity by only $3 \%$ compared to a PCM with a $27.5^{\circ} \mathrm{C}$ melting point. While a PCM with a melting temperature 21 ${ }^{\circ} \mathrm{C}$ was found suitable for enhancing the system performance in winter conditions. Bearing in mind that; the melting temperature of the PCM $\left(29^{\circ} \mathrm{C}\right)$ which supplies the maximum cooling in summer can be used in winter but not vice versa.

(a)

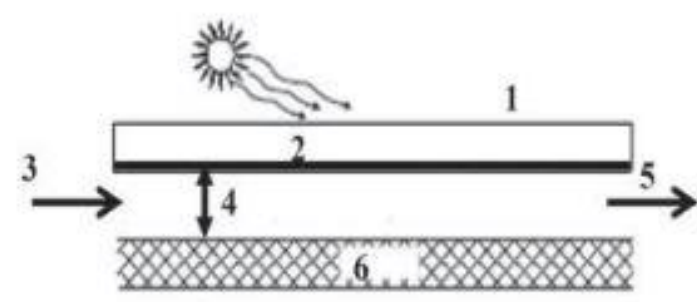

1: Glass Cover. 2: Absorber Plate. 3 Air inlet. 4: Air flow channel. 5:Air outlet 6: Insulation (b)

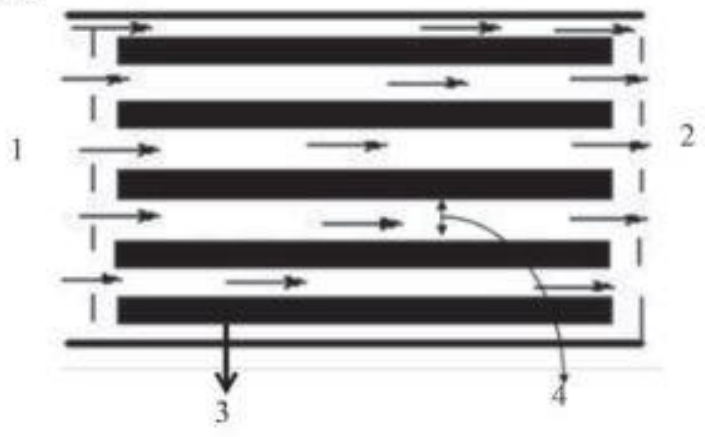

1: Air inlet to PCM storage. 2:Air outlet from PCM storage. 3: Storage material slabs 4: Air flow channel

Fig. 23: The configuration of the proposed solar air collector and the PCM storage investigated by Waqas et al. [207]. 
Borderon et al. [208] have carried out a numerical simulation to investigate the thermal behaviour of a flat plate PCM storage incorporated in a ventilation system for summer comfort in a retrofitted house under a climate of four cites in France (Trappes, Lyon, Nice, and Carpentras). A paraffin based PCM of a latent heat of fusion $170 \mathrm{~J} / \mathrm{g}$ was considered and tested under different melting temperatures between 21 and $25^{\circ} \mathrm{C}$. TRNSYS software was used to model the house and this has been coupled with MATLAB simulations for the PCM/air system modelling. The results showed that the crystallisation of the PCM at night is only partial in most of the studied cases, which indicates a non-optimal use of the system. Therefore, air flow enhancement was recommended to achieve a better performance. Making use of $700 \mathrm{~kg}$ of PCM and considering a comfort temperature of $26^{\circ} \mathrm{C}$, the number of discomfort hours in the summer season can be reduced to only $2.6 \%$ for Trappes city and less than $8 \%$ for Lyon city. The results are less impressive in Nice due to the small daily amplitude of the temperature experienced under this climate which results in a low charging process. In the case of Carpentras city, a significant improvement on summer comfort was accomplished, however, an additional amount of PCM is required and thus a system feasibility analysis must be considered.

An experimental study for a PCM storage incorporated into a ventilation system was conducted by Iten and Liu [209] for summer comfort in buildings in Mediterranean countries, namely Portugal. The storage unit contains three rectangular metallic modules filled with R25 PCM and kept inside an insulated wooden duct, in addition, a cooling/heating unit was used as a climate controller (Fig. 24). The effect of temperature and velocity of the inlet air was evaluated for the both transformation phases. Under their test conditions, the authors have found for all tested cases that the inlet air velocity has the dominant impact on both phases. Enhancing the inlet air velocity linearly decreases the solidification time and non-linearly decreases the melting time. On the contrary, the impact of the inlet air temperature is more visible during the melting process. Accordingly, the temperature and velocity of the air inlet have to be carefully optimised for the entire running cycle of both charging and discharging phases. 

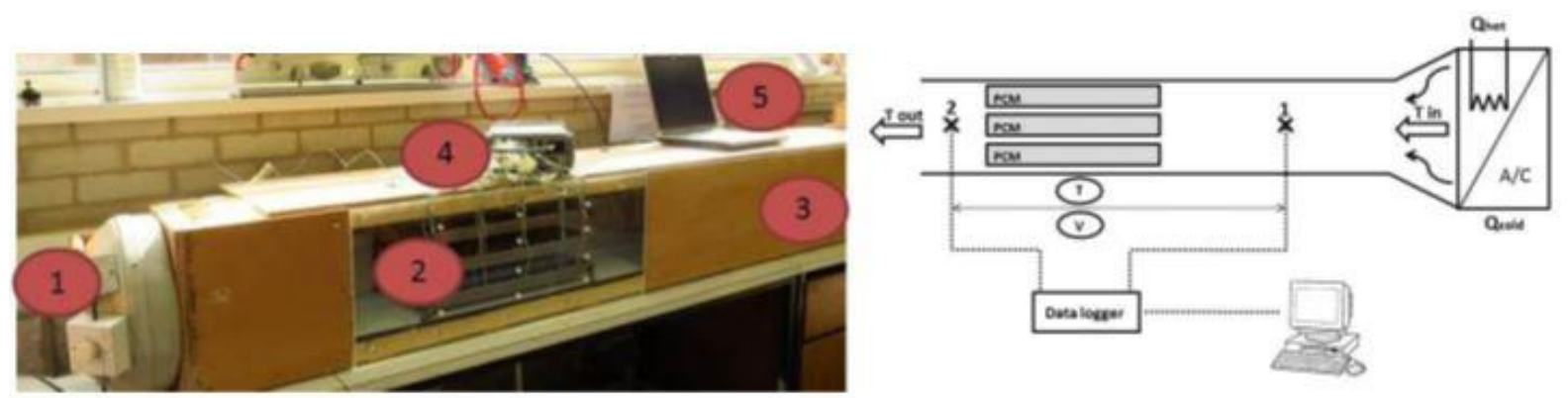

(1) Exhaust fan; (2) PCM modules; (3) Heating/Cooling unit; (4) Data acquisition; (5) PC

Fig. 24: Experimental setup of the system proposed by Iten and Liu [209].

Osterman et al. [210] have performed a parametric study to evaluate the heat transfer of a PCM storage system for free summer cooling of buildings. The system was also adjusted by adding a solar collector to evaluate its capability for winter heating [211]. Compact storage modules (CSM) plates filled with paraffin RT 22HC PCM by Rubitherm was used for the analysis. The PCM modules were investigated in both vertical and horizontal arrangements, and a perforated plate was placed in front of the plates to keep a uniform air circulation among the plates as shown in Fig. 25a. The TES system was investigated numerically using Fluent and the obtained data were validated with experimental results. The air flow was measured by an anemometer and also monitored through visual monitoring of smoke streaming among the modules as shown in Fig. 25b. The results confirm the satisfactory design of the perforated plate for flow regulation. The pressure drop varied from $2.1 \mathrm{mbar}$ to $13.3 \mathrm{mbar}$, which denotes that the spacing between the modules does not have a substantial influence on the fan power consumption. Based on the analysis, the authors advised decreasing the module thickness to enhance the required time for the phase change. 


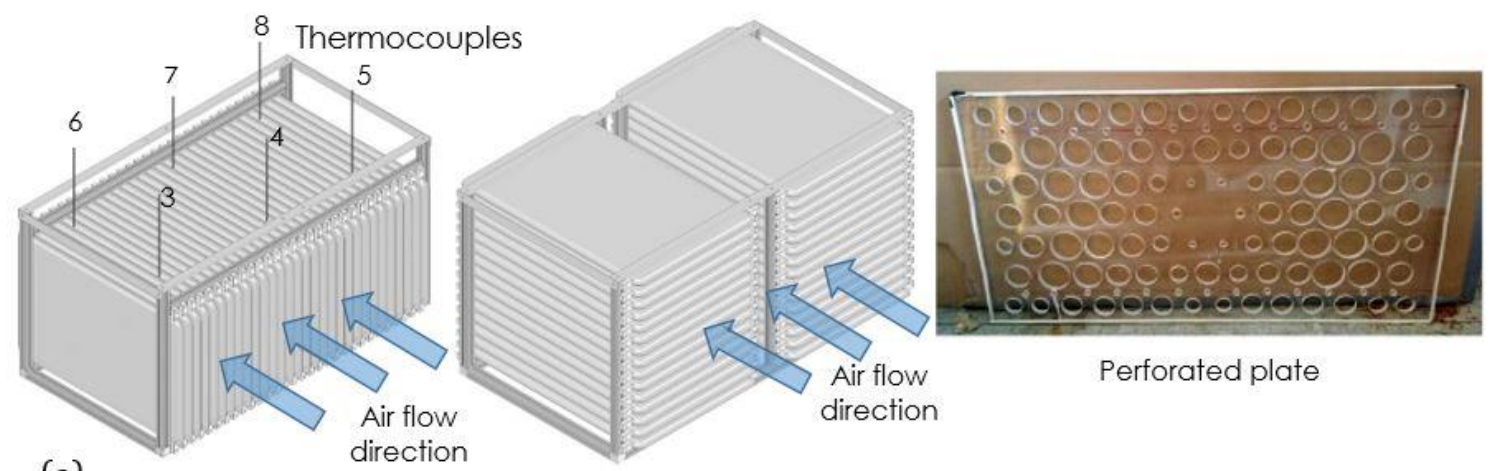

(a)

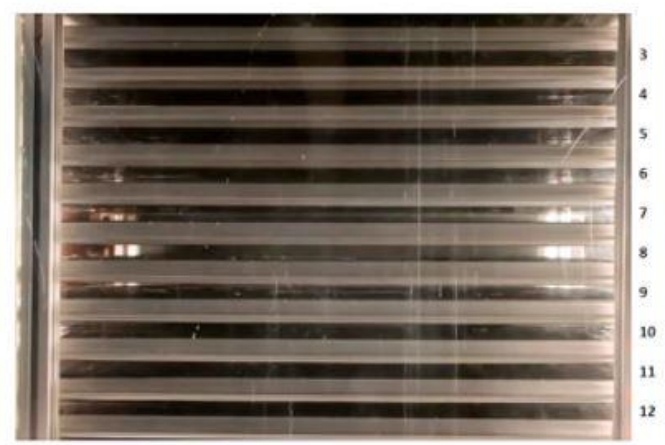

At $0 \mathrm{~s}$

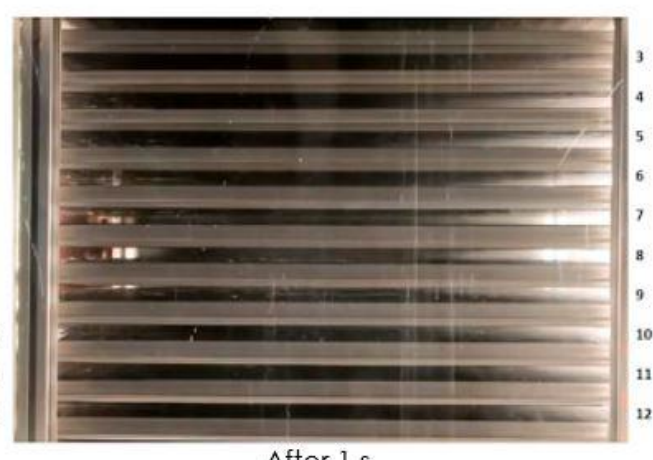

After $1 \mathrm{~s}$

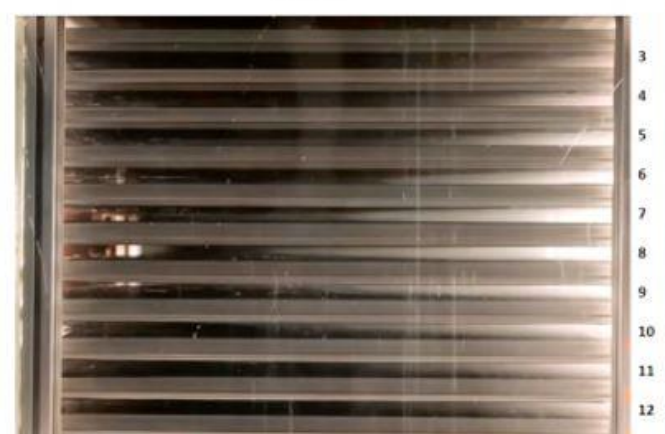

(b)

After $3 \mathrm{~s}$

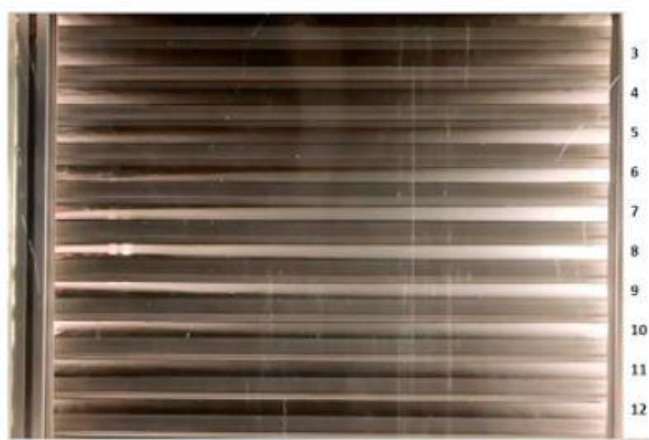

After $5 \mathrm{~s}$

Fig. 25: (a) Tested configurations, and (b) flow visualisation results of the system developed by

Osterman et al. [210].

A small-scale PCM heat exchanger unit was investigated numerically and experimentally by Mirahamad et al. [212] for controlling the indoor temperature fluctuation inside a greenhouse prototype. The proposed latent heat storage system contains flat slab arrangement of 200g of PEG1000 PCM was encapsulated inside aluminium pouches with different dimensions corresponding to the PVC tunnel of circular cross-section that packed in it (Fig. 26). The effect of inlet air temperature and velocity was studied finding that higher temperature variation between the inlet air and the PCM can shorten the phase termination and improve the efficiency, whereas, higher air velocities can reduce the phase duration and 
efficiency. Applying the considered LHS cooling device into a greenhouse decreased the indoor temperature by around $10 \mathrm{~K}$ during the hottest hours of the day.

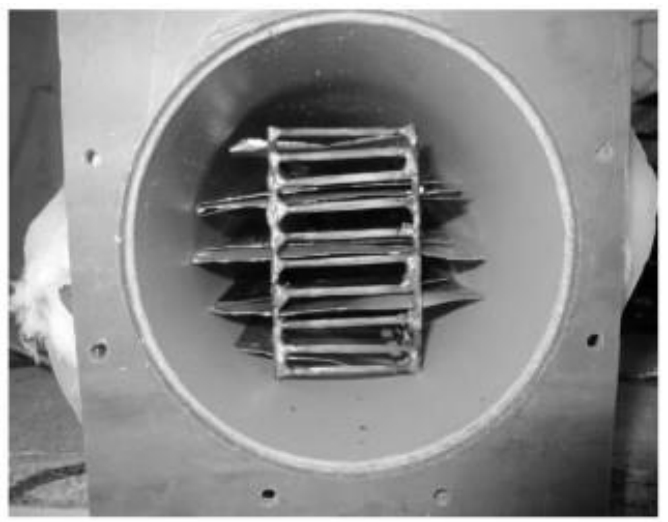

Fig. 26: Configuration of the LHTES apparatus designed by Mirahamad et al. [212].

Muthuvelan et al. [213] have also carried out an experimental investigation to evaluate the thermal performance of a flat plate modular PCM heat exchanger for free cooling application in Pune city in India. The heat exchanger comprises 10 modules of PCM with an overall weight of $76 \mathrm{~kg}$ made of a commercial HS 29 PCM with a phase change range 17-29 ${ }^{\circ} \mathrm{C}$. The outer housing was insulated with polystyrene of a $25 \mathrm{~mm}$ thickness. The system was designed for a free cooling capacity of $0.5 \mathrm{~kW}$. A room with dimensions $2.5 \mathrm{~m} \times 2.5 \mathrm{~m} \times 2.5$ $\mathrm{m}$ was constructed to monitor the indoor temperature based on air supplied by the system. The schematic of the PCM heat exchanger and view of the system along with cabin is demonstrated in Fig. 27. The required air flow rate $\left(\dot{m}_{\text {air }}\right)$ to charge the PCM was estimated using equation (5).

$$
\dot{m}_{\text {air }}=\frac{m_{P C M} \times(L)}{C_{p} \times \Delta T \times d t^{\prime}}
$$

where; $\left(m_{P C M}\right)$ is the mass of the PCM, $(L)$ is latent heat of fusion of the PCM, $\left(C_{p}\right)$ is the air specific heat, $(\Delta T)$ is the temperature difference between the PCM and ambient air, and $\left(d t^{\prime}\right)$ is the duration expected for the full charging. The findings indicated that an average temperature drop of $2.5 \mathrm{~K}$ inside the cabin can be obtained. The design is only applicable for locations with ambient temperature above the comfort by about $5 \mathrm{~K}$ during the discharging period. However, the use of air conditioning is still needed in the considered location. The authors suggested reducing the heat losses to enhance the performance, and if the system is 
combined with an evaporative or a nocturnal radiant cooling mean may entirely eliminate the usage of air conditioning systems.

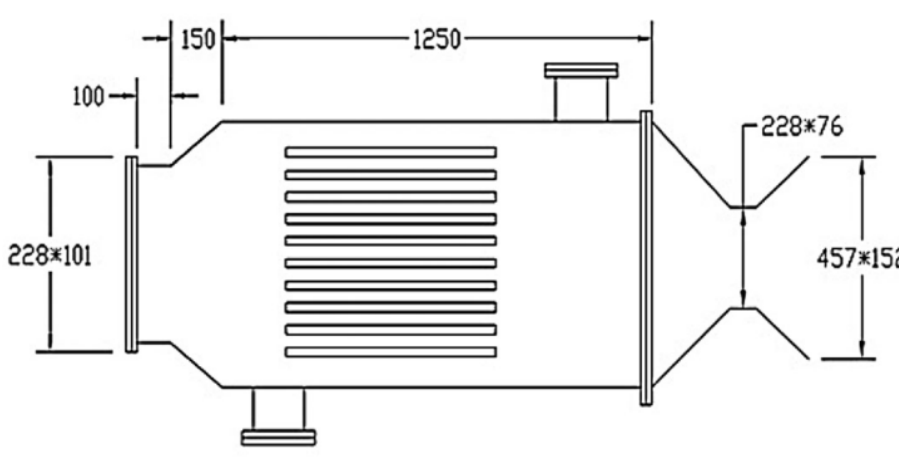

All dimensions are in ' $m m$ '

(a)

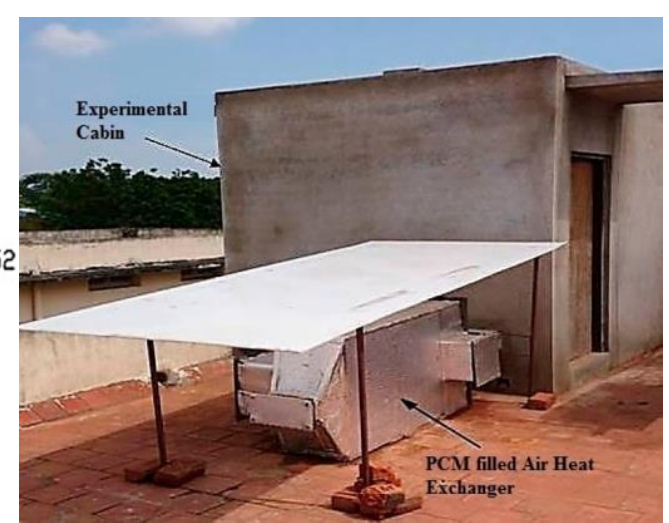

(b)

Fig. 27: (a) Schematic and (b) view of the free cooling system proposed by Muthuvelan et al. [213].

Rajagopal et al. [214] have analysed the thermal behaviour of a fabricated PCM heat exchanger device $(1.20 \mathrm{~m} \times 0.415 \mathrm{~m} \times 0.410 \mathrm{~m})$ with $11 \mathrm{PCM}$ modules for free cooling application in Bangalore city, India. The system was used to fulfil the cooling load of the commercial building considered in [206]. A commercial RT27 paraffin PCM of a melting temperature range of $25-28{ }^{\circ} \mathrm{C}$ was selected according to the available diurnal temperature variation on the site. During the charging phase; various inlet temperatures (19, 20, 21, and 22 ${ }^{\circ} \mathrm{C}$ ) and inlet air velocities (3.0, 4.0 and $5.0 \mathrm{~m} / \mathrm{s}$ ) were considered using an environmental chamber. While during the discharging phase different internal loads between $0.5 \mathrm{~kW}$ and 3.0 $\mathrm{kW}$ were tried to vary the temperature of the indoor air used for cold extraction. The system was evaluated experimentally and numerically using CFD simulation. The experimental setup and configuration of the heat exchanger are illustrated in Fig. 28. The authors found that augmenting inlet temperature from $19^{\circ} \mathrm{C}$ to $22^{\circ} \mathrm{C}$ increased the charging duration by around $60 \%$ with an only small variation of air velocity. Thus, it is advisable to accelerate the charging at a time of lower temperatures rather than using high air velocities as it will be ineffective after a certain level. This is will offer the advantage of a lower power consumption by the fan. A reduction of 2.0-3.5 $\mathrm{K}$ in air temperature inside the room equipped with the free cooling device was achieved, compared to a room without cooling system when the internal heat load was maintained at the lowest $(0.5 \mathrm{~kW})$ level and the highest level $(3.0 \mathrm{~kW})$ respectively. Thus, the internal heat load appears to have a strong impact on the performance, and it is advised to be reduced to the lowest level. 


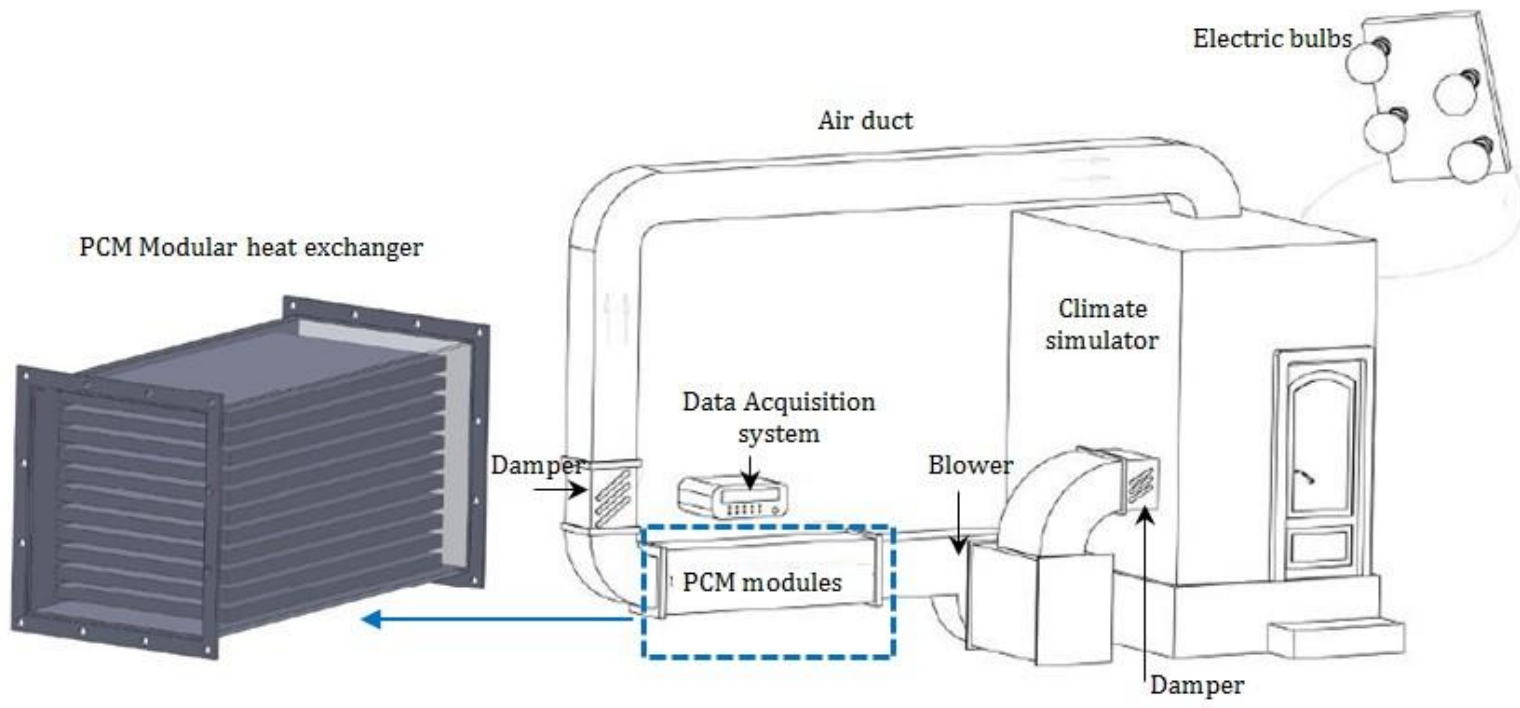

Fig. 28: Experimental setup of the free cooling system proposed by Rajagopal et al. [214, 215].

A comparative study has been carried out by Alam et al. [216] to evaluate the efficiency of two means of PCM application in buildings; a ceiling integrated PCM for passive cooling, and a separate PCM storage unit for free cooling applications as shown in Fig. 29. The study was performed using Energy-Plus and CFD simulation tools and the results were validated with relevant experimental data. The results indicated that the free cooling application of the PCM is more efficient in decreasing the indoor temperature by up to $1.8^{\circ} \mathrm{C}$ than the ceiling application which resulted in a temperature drop by only $0.5^{\circ} \mathrm{C}$ for a considered residential building under typical summer conditions of Melbourne, Australia. The authors have also reported that more than the required amount of the PCM was utilised in this study.

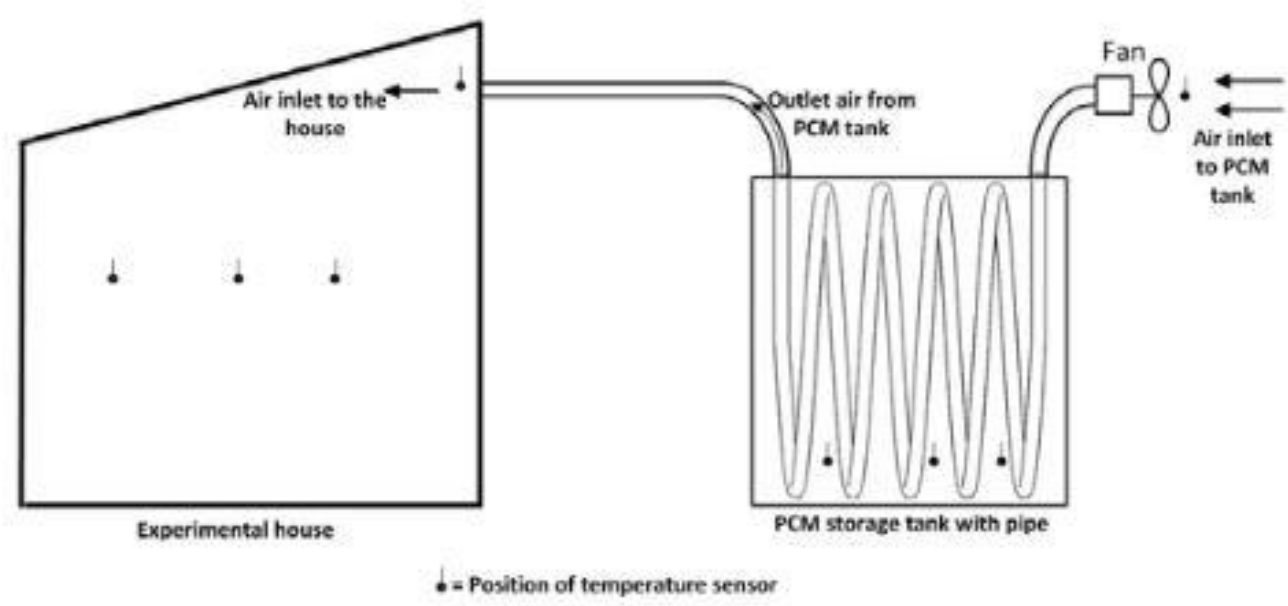

Fig. 29: Experimental setup of the free cooling system proposed by Alam et al. [216]. 


\section{Discussion of the factors affecting performance and application of PCM in free cooling systems}

Based on the current review, this section highlights some critical observations regarding factors with major impact on thermal performance and application of free cooling technologies. These factors include; climate conditions, PCM transformation temperature, encapsulation of the PCM, heat transfer problems (due to low thermal conductivity, incongruent melting, and supercooling of PCMs) and the stability of the PCM. The economic feasibility of the free cooling systems is also an important factor and should be taken into consideration. Discussion of these factors allows researchers to get a clear picture of potential opportunities to tackle the challenges and possible strategies to enhance the performance of the technology, and accordingly, areas for future research are suggested.

\subsection{Climate conditions}

The free cooling concept is site specific and climate dependent. In any location, nocturnal ventilative cooling depends largely on the amplitude of diurnal temperature variation rather than the average outdoor temperature. It is well established that, free cooling based latent heat storage performs effectively in locations with diurnal temperature swing ranging between 12 and $15 \mathrm{~K}$, a typical of desert climates [93]. Any diurnal temperature variation below this necessitates careful design considerations coupled with a proper selection of the PCM properties [180]. It should be stressed that coupling of PCM storage with other passive ventilation systems such as wind catchers or with other natural cooling strategies such as evaporative cooling and ground cooling may represent an interesting area for future research.

\subsection{PCM switching temperature}

Several approaches regarding the selection criteria of PCM transformation temperatures for free cooling technology have been reported in the literature [64, 93, 190, 217]. The phase change temperature of a PCM considered for the free cooling system should be in the range to provide maximum and quick crystallisation of the PCM throughout the night charging, and in the same way, should be closer to the indoor design temperature [179]. 
Raj and Velraj [93] have stated that PCM with a certain phase change temperature may not fit well in the outdoor temperature swing throughout the entire year for some climates, and in particular, the hot climate. This suggestion is also supported by Medved and Arkar [190] who mentioned that a PCM with a range of transformation temperatures is recommended due to its capability of absorbing heat in a variety of inlet air temperatures, and accordingly able to operate throughout the outdoor temperature swing for a longer period of the year. For buildings in hot regions, PCMs with a higher melting/solidification temperatures are much appropriate for cooling enhancement. It has been added that the optimum phase change temperature can be estimated as a function of PCM peak melting temperature $\left(T_{p}\right)$ and the average outdoor temperature $\left(T_{a}\right)$ from this simple equation;

$$
T_{p}=T_{a}+2 K
$$

Butala and Stritih [217] have proposed a temperature range between 19 and $24{ }^{\circ} \mathrm{C}$ for the PCM application in hotter climates. They have stated that this range will result in a temperature between 23 and $27^{\circ} \mathrm{C}$ for the exit air from the storage medium during the discharging period, which is considered acceptable for the hottest summer period. Osterman et al. [64] have recommended that, most of the PCMs utilised as thermal energy storage in buildings should possess phase change temperatures within the range of $20-32{ }^{\circ} \mathrm{C}$ to maintain the comfort conditions in most climates, and the proper selection of the PCM transformation temperature must be coupled with the existing appropriate passive or active heating/cooling systems.

In general, it is difficult to find a single PCM that suits the whole year comfort requirements due to the large seasonal variation predicted in most locations. Thus, a switching temperature within the comfort limit of the overheating period can be an appropriate solution for different climates, otherwise, a combination of phase change materials may be used to provide a larger operating temperature range.

\subsection{Encapsulation of PCMs}

PCM encapsulation is one of the ways which enables integration of PCM into buildings, and also prevents PCM leakage as well as protecting the PCM from interaction with the 
external environment and hence determines its long-term operation. In addition, PCM containers can assist avoiding some PCM drawbacks such as flammability in the case of paraffin [218].

The properties of PCM container play a central role in the performance of the storage system. PCM encapsulation influences the thermal conductivity and hence the time lapse of the freezing/melting phase. The PCM container should be strong, corrosion resistant, thermally and structurally stable, have easy handling features and have a sufficient surface area for heat transfer $[121,219]$.

There are a variety of PCM encapsulation techniques proposed and utilised by different researchers $[73,220]$, and offered by companies with various configurations and manufacturing materials. Some of these include aluminium panels, aluminium pouches, metal or plastic spherical balls, flat plates, plastic bags, different forms of plastic tubes, cylindrical pipes, PVC panels, shells, granules, etc. as illustrated in Error! Reference source not found.

PCMs encapsulation can be classified into micro and macro-encapsulations according to the container size. In microencapsulation; very small particles varying from 1 to $1000 \mu \mathrm{m}$ in size will be contained inside solid and thin shells. These micro-components can be combined in any matrix compatible with the enclosed shell. In the case of macro-encapsulation, PCM from millilitres to numerous litres will be packaged in various containers' configurations such as aluminium panels and pouches, and in most cases, the container itself acts as a heat exchanger surface $[15,221]$.

Micro-encapsulation is capable of providing more application opportunities in buildings, enhancing the heat transfer through enlarging the heat exchange surface, reducing the interaction between the PCM and the outer environment and controlling the volume alteration. However, the cost of micro-encapsulated PCMs is higher than macro-encapsulated ones, and some micro-encapsulations may influence the mechanical strength of the construction materials [222-225].

On the other hand, macro-encapsulation has the advantage of preventing the leaking of PCM and suits application of the PCM inside walls and partitions of the building. Conversely, some macro-encapsulations may reduce the heat transfer rate during the solidification process $[218,226]$. 


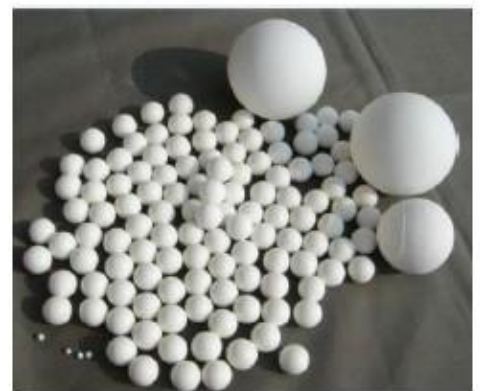

Spherical PCM balls (different sizes)

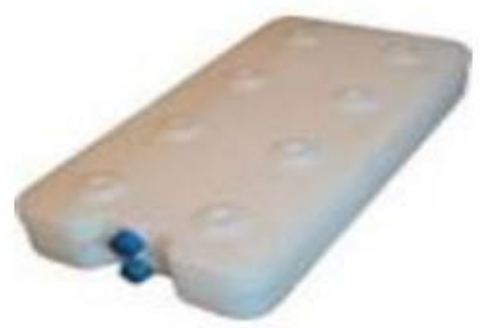

PCM HDPE plastic containers

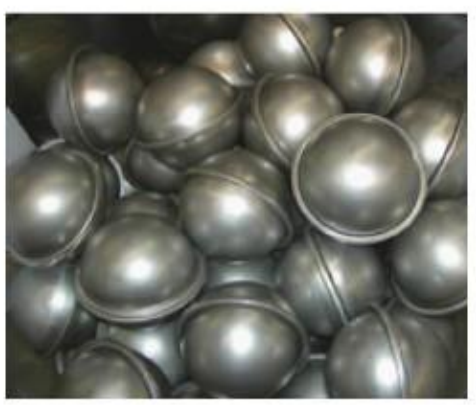

Stainless ball capsule

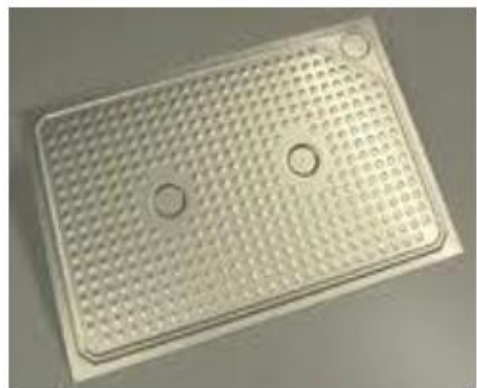

PCM Aluminium panel

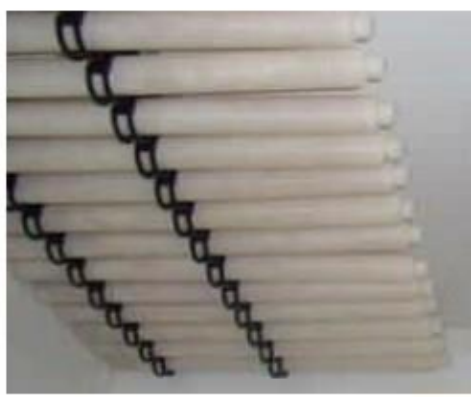

PCM plastic tubes containers

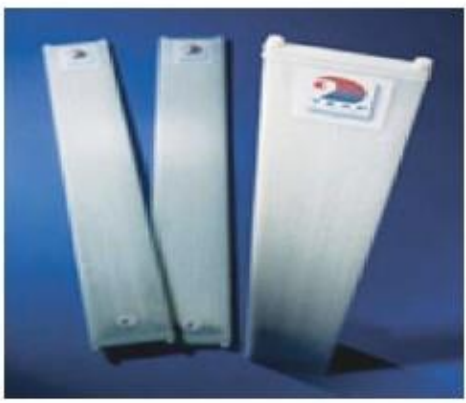

PCM flat panel

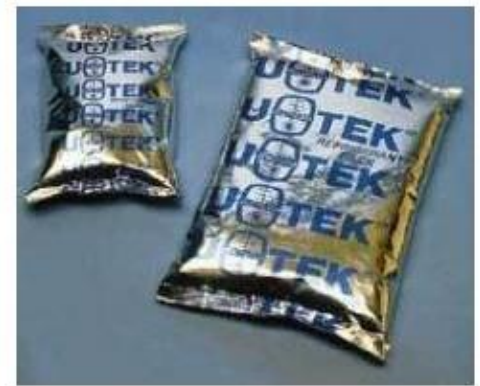

PCM Aluminium pouches

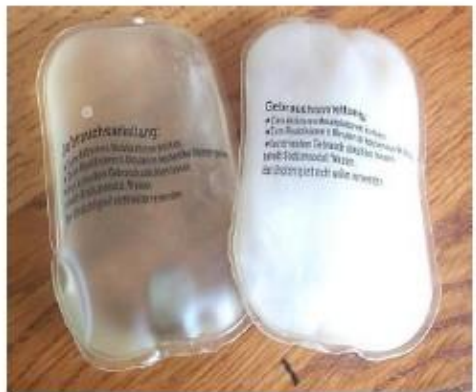

PCM plastic bags

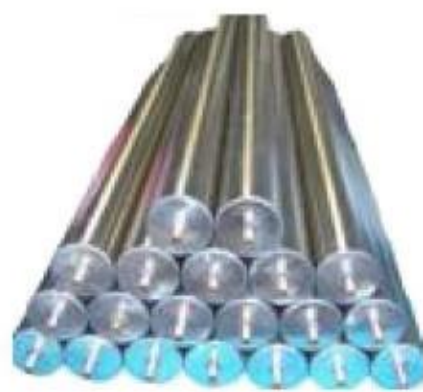

Module beam

(Cylindrical)

Fig. 30: Some of the PCM encapsulation techniques available in the market.

\subsection{Heat transfer of the PCM heat exchangers}

There are many factors that limit the utilisation of PCMs for cooling and heating in buildings, including the low thermal conductivity of the most available PCMs, the incongruent melting, and the supercooling problems. Accordingly, comprehensive research has currently been carried out by a number of researchers and PCM companies to overcome these drawbacks and enhance the thermal behaviour of the PCMs. 
The majority of studies carried out on phase change materials have reported poor thermal conductivities [92], and therefore, the heat transfer performance used in free cooling is low [227, 228]. Promoting the conductivity level to enhance the melting and crystallisation process during the charging and discharging periods has been investigated widely in the literature $[229,230]$. A review of theoretical and experimental research to advance the PCM conductivity was presented in [231]. Adding substances with large thermal conductivities; such as copper, aluminium, nickel, stainless steel and carbon fibre in different configurations such as fins, honeycomb, wool, brush, etc.; is considered as one of the effective techniques for enhancing the heat transfer rate (Error! Reference source not found.) [232]. For instance; a eries of axial metal planes perpendicular to the longitudinal pipe to increase the heat transmission between the air and the PCM unit were utilised by Abhat [105]. Application of finned tubes has been reported by Costa et al. [233]. Aluminium fins used inside and outside upper and lower metal box filled with PCM was investigated by Butala and Stritih [217, 234]. Metal matrix structures with PCMs were extensively investigated in $[181,235,236]$ to increase the conductivity level with a minimum reduction of energy stored. Furthermore, other benefits such as diminishing the supercooling of salt hydrates and lowering the volume alteration of paraffin can also be realised as well by this method.

Another effective method for enhancement of heat exchange rate is utilising arrangements with multiple PCMs which depends mainly on the temperature difference between the circulated air and the PCM melting temperature. When using a single PCM, this variance has reduced in the direction of the air flow, however, packing multiple PCMs with melting temperature in a decreasing order during the discharging phase and in an increasing order throughout the charging phase can keep an appropriate or nearly constant temperature difference in the flow directions. This concept leads to approximately steady heat flux, hence, enhancing the performance of the storage system [202, 237]. For example, a significant increase in heat transfer rate with multiple PCMs was achieved by Farid and Kanzawa [238] and Gong and Mujumdar [239] relative to a single PCM.

In conclusion, although these methods have enhanced the heat transfer within the storage system, they may generally increase the weight of the PCM and cost of the system. 


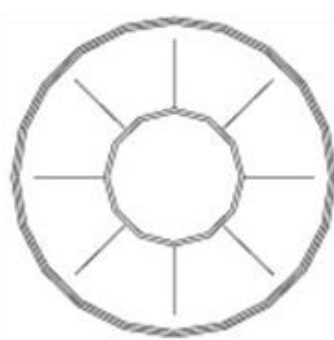

(i) Longitudinal or axial fins

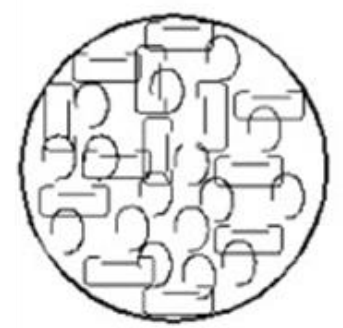

(v) Metal Ri ngs

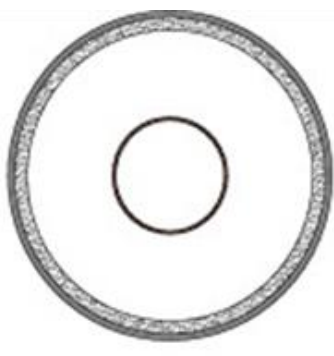

(ii) Circular fins

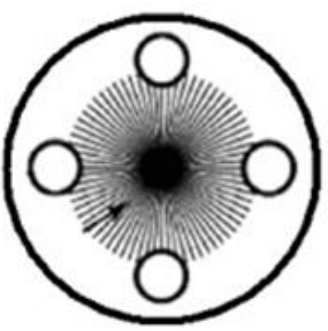

(vi) Multitubes and carbon brushes

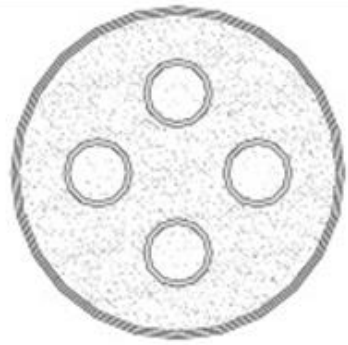

(iii) Multitubes or shell and tube

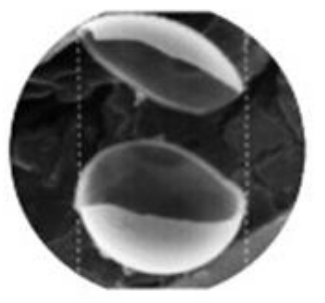

(vii) Encapsulation

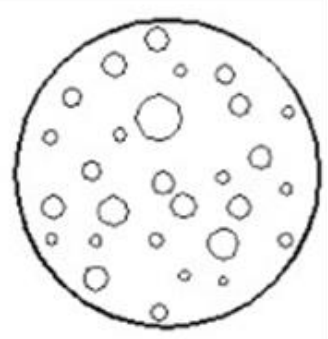

(iv) Bubble agitation

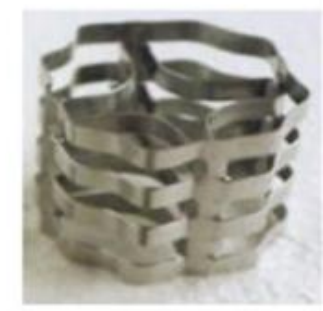

(ix) Metal Matrix

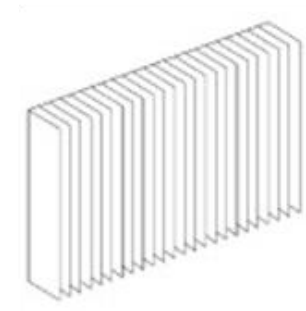

(x) Finned Re ctangular Container

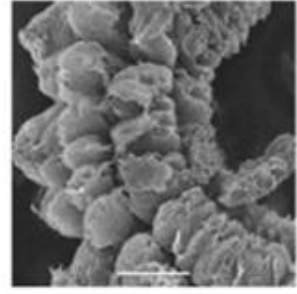

(xi) Graphite flakes

Fig. 31: Methods utilised for heat transfer enhancements in PCM applications [92].

\subsection{Stability of PCMs}

Stability of the PCM materials is another important factor that affects the operation of PCMs for a long-term duration in buildings. The stability problem could be attributed to two key factors; insufficient stability of the PCM properties as a result of thermal cycling and/or the corrosion between the substance and the container [240]. Thermal stability of PCMs can be recognised by assessing the thermo-physical properties of the PCM after a number of repeated thermal cycles. Therefore, this factor has to be considered when selecting a PCM for a given purpose in order to avoid any system deterioration. A comprehensive review on thermal stability for various PCM groups can be found in [241]. Numerous researches have been carried out to examine the durability of some organic and inorganic materials including; Zhou et al. 
[74], Sharma et al. [242], Silakhori et al. [243], Solé et al. [244], Shukla et al. [245]. For example, thermal cycling tests were performed to assess the stability of some chosen organic and inorganic PCMs by Shukla et al. [245]. Their findings indicate that the inorganic PCMs show inappropriate performance after some cycles compared to the organic types which demonstrate good thermal properties after up to1000 cycles.

\subsection{Economic aspect of free cooling systems}

The economic feasibility is a major issue that has not been adequately addressed in most of the studies conducted in the free cooling application, though it was reported that most of the developed storage systems have exhibited high energy efficiency and promising outcomes. According to Kamali [94], the initial cost of a PCM based free cooling system is estimated to be around $10 \%$ higher than a conventional air conditioning system of equivalent capacity, despite the fact that the technology has not yet been fully commercialised. However, running costs may be far lower, if the system is appropriately sized.

Jaber and Ajib [200] have assessed the technical and economic feasibility of a free cooling system shown in Fig. 19 in comparison to an operation of a standard air conditioning system. A free cooling system with an initial cost of $€ 5671$ was developed to fulfil the entire annual cooling demand of a typical residential building in Jordan (Mediterranean climate). However, its running cost exceeded the annual energy saving i.e., the size of the system is not economically feasible. An optimised design based on a conducted parametric study was then introduced covering around $80 \%$ of the total cooling load with an initial cost decreasing to around $€ 1195$. The Payback Period (PB) for the optimised system was estimated at 7.8 years. It is important to underline that the high initial cost may be attributed to the usage of two fans as an indirect evaporative cooling is incorporated. The PCM share in the initial cost is not known, as a cost breakdown has not been provided by the authors.

An economic analysis has been carried out by Zalba et al. [180] for their developed free cooling system. The pie chart in Fig. 32a shows the ratio of each component from the total cost. It is clear that about $17 \%$ of the whole cost goes to the storage material (PCM). It is also reported that the power consumption by the free cooling system is almost lower by $94 \%$ compared to conventional air conditioning systems with similar capacity. However, 9\% additional cost is required for the storage unit with an approximate payback period of 3-4 years. 
Osterman et al. [211] have presented the cost details of their TES system that utilised for both heating and cooling in buildings. A reference office building with $4 \mathrm{~m} \times 3 \mathrm{~m} \times 2.8 \mathrm{~m}$ was considered. According to the authors, the overall initial cost was estimated at $€ 1140$ which is approximately double of that for a conventional air-conditioner. The share of all equipment in the entire cost is presented in Fig. 32b. It is clear that half of the cost goes to the PCM panels (Aluminium containers filled with $40 \mathrm{~kg}$ of paraffin RT22HC PCM). However, if the system is operated for cooling purpose only, the capital cost can be lowered by nearly $20 \%$ compared to that of the solar collector.

(a)

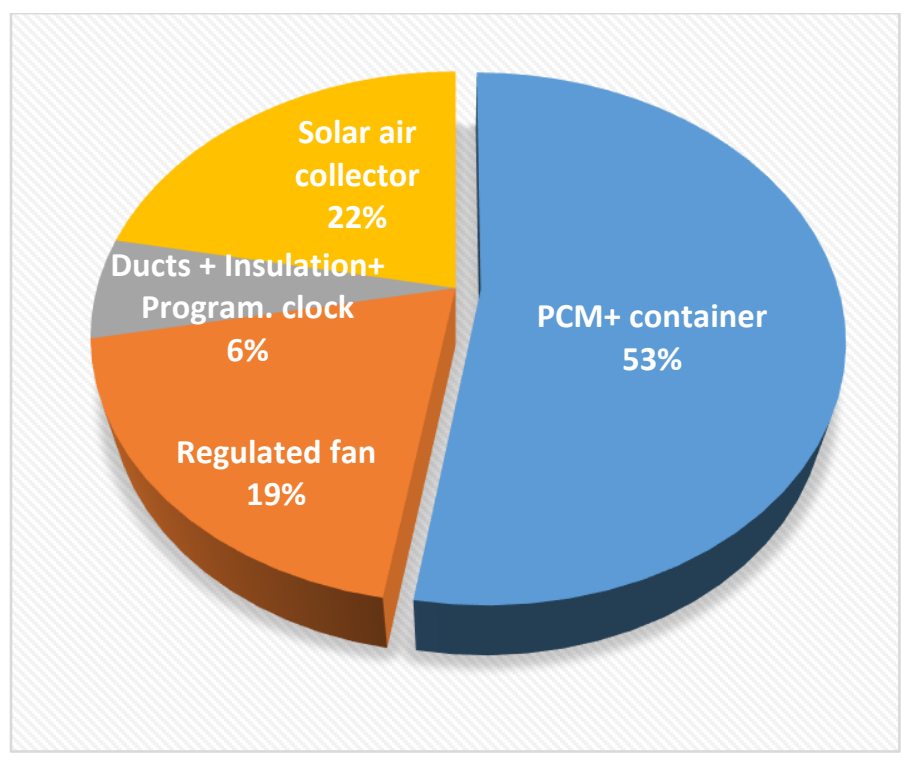

(b)

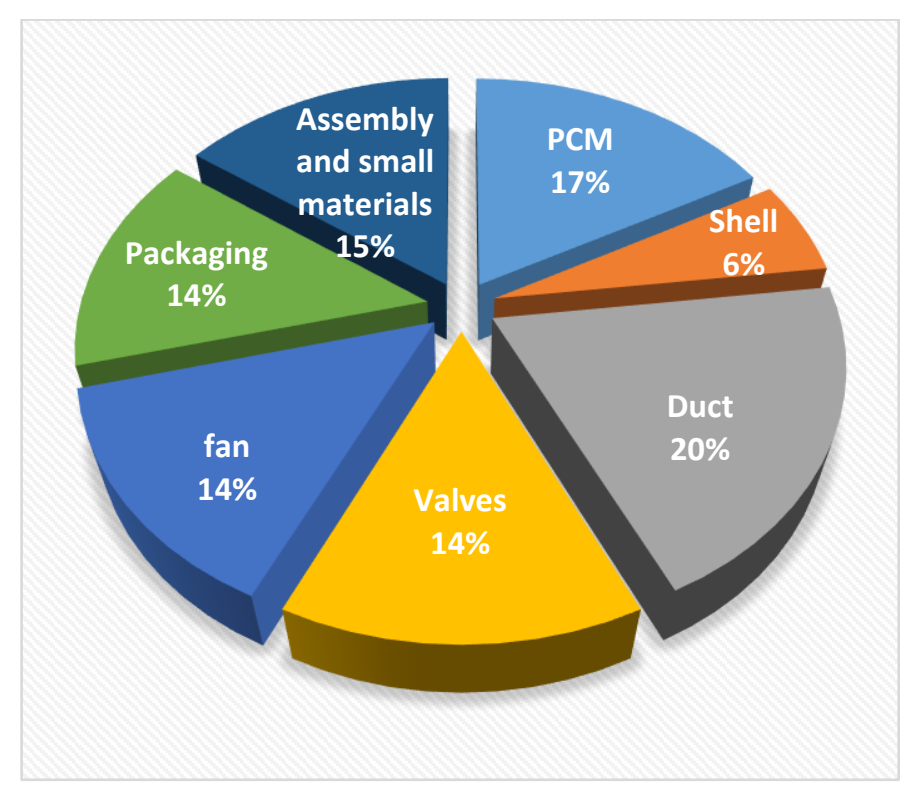

Fig. 32: Cost breakdown for the free cooling systems developed by (a) Zalba et al. [180], and (b) Osterman et al. [211]. 
Both studies reported in [180] and [211] agreed that the largest fraction of the capital cost has been expended in PCM substance and its encapsulation. The variation in percentages can be attributed to many other factors including differences in size of the systems and type of PCM utilised. Additionally, the costs of free cooling systems could be decreased, if the PCM production was largely commercialised. Osterman et al. [211] said that the reduction in PCM price can take place if TES is mass fabricated. 


\section{Conclusions}

Free cooling incorporated latent heat storage system is a promising sustainable technique best applicable for locations with diurnal temperature variation between 12 and $15 \mathrm{~K}$. Most of the reviewed studies indicated that such systems are capable of bringing the indoor temperature well to the comfort zone, and significant energy savings exceeding $50 \%$ could be realised in all investigated climates compared to conventional air conditioning systems. The major conclusions drawn from this review are:

- The most critical parameter that affects the free cooling performance is the PCM transformation temperature, as any improper selection of the phase change temperature neither completely solidifies nor melts the PCM during charging and discharging phases, resulting in an inadequate cold store. The low thermal conductivity of PCMs is another factor that represents a key barrier for application as it slows down the solidification and melting processes. Consequently, PCMs with higher thermal conductivities must be chosen and use of heat transfer enhancements is highly advised.

- In all proposed systems air was the heat transfer fluid. Most of the studies recommend enhancing the air flow rate during the charging period to accelerate the PCM solidification, which can also be enhanced by enlarging the surface area per unit volume of the PCM. An air flow rate 3 or 4 times higher for charging than that for discharging was found appropriate for sufficient cooling storage.

- The magnitude of the utilised PCM storage has varied significantly among most of the studies; PCM weights range from 6.4 to $30 \mathrm{~kg} / \mathrm{m}^{2}$ of floor area have been reported based on the local climate conditions, cooling load, proposed system, etc.

- The majority of the free cooling studies have been conducted in moderate and continental climates and very limited in hot and arid regions where the demand for cooling is extremely high. This draws attention to the need for conducting more research on free cooling technologies in hot arid climate conditions.

- Despite a large number of research on the PCM application for energy storage in buildings, the real case applications documenting the potential and behaviour of PCMs in real operation conditions are quite rare. It should also be noted that there are no studies being 
performed to evaluate the long-term performance of the technology. The barrier to the PCM application in actual buildings may be attributed to their major drawbacks such as; segregation, supercooling, low thermal conductivity, high cost and to the limited number of PCM manufacturers available around the world. Accordingly, the concept of free cooling using PCM energy storage is still under development and more research is needed to convey the concept from the theoretical and experimental stage to the real implementation phase.

\section{Acknowledgments}

The authors acknowledge the University of Nottingham in the UK, University of Khartoum in Sudan, and the Ministry of Higher Education and Scientific Research of Sudan for the financial support of this research. 


\section{References:}

1. Quadrelli, R. and S. Peterson, The energy-climate challenge: Recent trends in $\mathrm{CO} 2$ emissions from fuel combustion. Energy Policy, 2007. 35(11): p. 5938-5952.

2. Schneider, S.H., The greenhouse effect: Science and policy. Science, 1989. 243(4892): p. 771-781.

3. IEA, $\mathrm{CO} 2$ emissions from fuel combustion-highlights, in IEA Statistics, Paris https://www.iea.org/media/statistics/CO2highlights.pdf. Cited July. 2011.

4. Cuce, E., D. Harjunowibowo, and P.M. Cuce, Renewable and sustainable energy saving strategies for greenhouse systems: A comprehensive review. Renewable and Sustainable Energy Reviews, 2016. 64: p. 34-59.

5. Yang, L., H. Yan, and J.C. Lam, Thermal comfort and building energy consumption implications-a review. Applied Energy, 2014. 115: p. 164-173.

6. Pérez-Lombard, L., J. Ortiz, and C. Pout, A review on buildings energy consumption information. Energy and buildings, 2008. 40(3): p. 394-398.

7. Boyle, G., Renewable energy. 2004: OXFORD university press.

8. Lefebvre, D. and F.H. Tezel, A review of energy storage technologies with a focus on adsorption thermal energy storage processes for heating applications. Renewable and Sustainable Energy Reviews, 2017. 67: p. 116-125.

9. Sharma, R., P. Ganesan, and V. Tyagi, Long-term thermal and chemical reliability study of different organic phase change materials for thermal energy storage applications. Journal of Thermal Analysis and Calorimetry, 2016. 124(3): p. 13571366.

10. Anisur, M.R., et al., Curbing global warming with phase change materials for energy storage. Renewable and Sustainable Energy Reviews, 2013. 18: p. 23-30.

11. Kuznik, F., J. Virgone, and K. Johannes, In-situ study of thermal comfort enhancement in a renovated building equipped with phase change material wallboard. Renewable Energy, 2011. 36(5): p. 1458-1462.

12. Evola, G., L. Marletta, and F. Sicurella, A methodology for investigating the effectiveness of PCM wallboards for summer thermal comfort in buildings. Building and Environment, 2013. 59: p. 517-527.

13. Arzamendia Lopez, J.P., et al., Numerical modeling and experimental validation of a PCM to air heat exchanger. Energy and Buildings, 2013. 64: p. 415-422.

14. Carrilho da Graça, G., et al., Simulation of wind-driven ventilative cooling systems for an apartment building in Beijing and Shanghai. Energy and buildings, 2002. 34(1): p. 1-11.

15. Waqas, A. and Z.U. Din, Phase change material (PCM) storage for free cooling of buildings-a review. Renewable and sustainable energy reviews, 2013. 18: p. 607625.

16. Givoni, B., Passive low energy cooling of buildings. 1994: John Wiley \& Sons. 
17. Takeda, S., et al., Development of a ventilation system utilizing thermal energy storage for granules containing phase change material. Solar Energy, 2004. 77(3): p. 329-338.

18. Dincer, I. and S. Dost, A perspective on thermal energy storage systems for solar energy applications. International Journal of Energy Research, 1996. 20(6): p. 547-557.

19. Dincer, I., S. Dost, and X. Li, Performance analyses of sensible heat storage systems for thermal applications. International Journal of Energy Research, 1997. 21(12): p. 1157-1171.

20. Pinel, P., et al., A review of available methods for seasonal storage of solar thermal energy in residential applications. Renewable and Sustainable Energy Reviews, 2011. 15(7): p. 3341-3359.

21. Baylin, F., Low temperature thermal energy storage: a state-of-the-art survey. 1979, Solar Energy Research Inst., Golden, CO (USA).

22. Mehling, H. and L.F. Cabeza, Heat and cold storage with PCM. 2008: Springer.

23. Tatsidjodoung, P., N. Le Pierrès, and L. Luo, A review of potential materials for thermal energy storage in building applications. Renewable and Sustainable Energy Reviews, 2013. 18: p. 327-349.

24. Hariri, A.S. and I.C. Ward, A review of thermal storage systems used in building applications. Building and Environment, 1988. 23(1): p. 1-10.

25. Prieto, C., et al., Review of technology: Thermochemical energy storage for concentrated solar power plants. Renewable and Sustainable Energy Reviews, 2016. 60: p. 909-929.

26. Kerskes, H., Thermochemical Energy Storage. Storing Energy: with Special Reference to Renewable Energy Sources, 2016: p. 345.

27. Cot-Gores, J., A. Castell, and L.F. Cabeza, Thermochemical energy storage and conversion: A-state-of-the-art review of the experimental research under practical conditions. Renewable and Sustainable Energy Reviews, 2012. 16(7): p. 52075224.

28. Ding, Y. and S. Riffat, Thermochemical energy storage technologies for building applications: a state-of-the-art review. International Journal of Low-Carbon Technologies, 2013. 8(2): p. 106-116.

29. Kalaiselvam, S. and R. Parameshwaran, Thermal Energy Storage Technologies for Sustainability: Systems Design, Assessment and Applications. 2014: Elsevier.

30. H Abedin, A. and M. A Rosen, A critical review of thermochemical energy storage systems. The Open Renewable Energy Journal, 2011. 4(1).

31. Zhang, $\mathrm{H}_{\text {., }}$ et al., Thermal energy storage: Recent developments and practical aspects. Progress in Energy and Combustion Science, 2016. 53: p. 1-40.

32. Paksoy, H.Ö., Thermal energy storage for sustainable energy consumption: fundamentals, case studies and design. Vol. 234. 2007: Springer Science \& Business Media. 
33. Mehling, H. and L.F. Cabeza, Phase change materials and their basic properties, in Thermal energy storage for sustainable energy consumption. 2007, Springer. p. 257-277.

34. Baggs, D. and N. Mortensen, Thermal mass in building design. Environmental Design Guide, 2006.

35. Szokolay, S.V., Introduction to architectural science: the basis of sustainable design. 2014: Routledge.

36. Dincer, I., On thermal energy storage systems and applications in buildings. Energy and Buildings, 2002. 34(4): p. 377-388.

37. Chiras, D.D., The solar house: passive heating and cooling. 2002: Chelsea Green Publishing.

38. Agyenim, F.B., The development of medium temperature thermal energy storage for cooling applications. 2007, University of Ulster.

39. Ding, Y., Investigation of high capacity heat energy storage for building applications. 2014, University of Nottingham.

40. Dincer, I. and M. Rosen, Thermal energy storage: systems and applications. 2002: John Wiley \& Sons.

41. Mohamed, S.A., et al., A review on current status and challenges of inorganic phase change materials for thermal energy storage systems. Renewable and Sustainable Energy Reviews.

42. Fang, D., et al., Preparation, microstructure and thermal properties of MgBi alloys as phase change materials for thermal energy storage. Applied Thermal Engineering, 2016. 92: p. 187-193.

43. Liu, M., et al., Review on concentrating solar power plants and new developments in high temperature thermal energy storage technologies. Renewable and Sustainable Energy Reviews, 2016. 53: p. 1411-1432.

44. Pardo, P., et al., A review on high temperature thermochemical heat energy storage. Renewable and Sustainable Energy Reviews, 2014. 32: p. 591-610.

45. Fernandez, A., et al., Selection of materials with potential in sensible thermal energy storage. Solar Energy Materials and Solar Cells, 2010. 94(10): p. 17231729.

46. Regin, A.F., S. Solanki, and J. Saini, Heat transfer characteristics of thermal energy storage system using PCM capsules: a review. Renewable and Sustainable Energy Reviews, 2008. 12(9): p. 2438-2458.

47. Pielichowska, K. and K. Pielichowski, Phase change materials for thermal energy storage. Progress in materials science, 2014. 65: p. 67-123.

48. Brun, A., et al., Summer comfort in a low-inertia building with a new free-cooling system. Applied energy, 2013. 112: p. 338-349.

49. Cui, Y.Q. and S. Riffat. Review on Phase Change Materials for Building Applications. in Applied Mechanics and Materials. 2011. Trans Tech Publ. 
50. Hasnain, S., Review on sustainable thermal energy storage technologies, part I: heat storage materials and techniques. Energy Conversion and Management, 1998. 39(11): p. 1127-1138.

51. Khadiran, T., et al., Advanced energy storage materials for building applications and their thermal performance characterization: $A$ review. Renewable and Sustainable Energy Reviews, 2016. 57: p. 916-928.

52. Pasupathy, A., R. Velraj, and R. Seeniraj, Phase change material-based building architecture for thermal management in residential and commercial establishments. Renewable and Sustainable Energy Reviews, 2008. 12(1): p. 3964.

53. Zhang, P., X. Xiao, and Z.W. Ma, A review of the composite phase change materials: Fabrication, characterization, mathematical modeling and application to performance enhancement. Applied Energy, 2016. 165: p. 472-510.

54. Telkes, M. Thermal storage for solar heating and cooling. in Proceedings of the Workshop on Solar Energy Storage Subsystems for the Heating and Cooling of Buildings, Charlottesville (Virginia, USA). 1975.

55. Barkmann, H.G. and F. Wessling. Use of buildings structural components for thermal storage. in Proceedings of the Workshop on Solar Energy Storage Subsystems for the Heating and Cooling of Buildings, Charlottesville (Virginia, USA). 1975.

56. Hawes, D., D. Feldman, and D. Banu, Latent heat storage in building materials. Energy and buildings, 1993. 20(1): p. 77-86.

57. Zhang, Z., et al., Thermal energy storage cement mortar containing $n$ octadecane/expanded graphite composite phase change material. Renewable energy, 2013. 50: p. 670-675.

58. Ramakrishnan, S., et al., Thermal energy storage enhancement of lightweight cement mortars with the application of phase change materials. 2017.

59. Ling, T.-C. and C.-S. Poon, Use of phase change materials for thermal energy storage in concrete: An overview. Construction and Building Materials, 2013. 46: p. 55-62.

60. Zalba, B., et al., Review on thermal energy storage with phase change: materials, heat transfer analysis and applications. Applied thermal engineering, 2003. 23(3): p. 251-283.

61. Zhang, Y., et al., Application of latent heat thermal energy storage in buildings: state-of-the-art and outlook. Building and Environment, 2007. 42(6): p. 21972209.

62. Rodrigues, L.T., An Investigation Into the Use of Thermal Mass to Improve Comfort in British Housing. 2009.

63. Pomianowski, M., P. Heiselberg, and Y. Zhang, Review of thermal energy storage technologies based on PCM application in buildings. Energy and Buildings, 2013. 67: p. 56-69. 
64. Osterman, E., et al., Review of PCM based cooling technologies for buildings. Energy and Buildings, 2012. 49: p. 37-49.

65. Parameshwaran, R., et al., Sustainable thermal energy storage technologies for buildings: a review. Renewable and Sustainable Energy Reviews, 2012. 16(5): p. 2394-2433.

66. Kalnæs, S.E. and B.P. Jelle, Phase change materials and products for building applications: a state-of-the-art review and future research opportunities. Energy and Buildings, 2015. 94: p. 150-176.

67. Konuklu, Y., et al., Review on using microencapsulated phase change materials (PCM) in building applications. Energy and Buildings, 2015. 106: p. 134-155.

68. Akeiber, $\mathrm{H}$., et al., A review on phase change material (PCM) for sustainable passive cooling in building envelopes. Renewable and Sustainable Energy Reviews, 2016. 60: p. $1470-1497$.

69. Souayfane, F., F. Fardoun, and P.-H. Biwole, Phase change materials (PCM) for cooling applications in buildings: A review. Energy and Buildings, 2016. 129: p. 396-431.

70. Navarro, L., et al., Thermal energy storage in building integrated thermal systems: A review. Part 1. active storage systems. Renewable Energy, 2016. 88: p. 526547.

71. Kenisarin, M. and K. Mahkamov, Passive thermal control in residential buildings using phase change materials. Renewable and sustainable energy reviews, 2016. 55: p. 371-398.

72. Baetens, R., B.P. Jelle, and A. Gustavsen, Phase change materials for building applications: a state-of-the-art review. Energy and Buildings, 2010. 42(9): p. 1361-1368.

73. Cabeza, L., et al., Materials used as PCM in thermal energy storage in buildings: a review. Renewable and Sustainable Energy Reviews, 2011. 15(3): p. 1675-1695.

74. Zhou, D., C.-Y. Zhao, and Y. Tian, Review on thermal energy storage with phase change materials (PCMs) in building applications. Applied Energy, 2012. 92: p. 593-605.

75. Soares, N., et al., Review of passive PCM latent heat thermal energy storage systems towards buildings' energy efficiency. Energy and buildings, 2013. 59: p. 82-103.

76. SOCACIU, L., et al., Review on phase change materials for building applications. Leonardo Electronic Journal of Practices and Technologies, 2014(25): p. 179-194.

77. Wahid, M.A., et al., An overview of phase change materials for construction architecture thermal management in hot and dry climate region. Applied Thermal Engineering, 2017. 112: p. 1240-1259.

78. Sharma, S.D. and K. Sagara, Latent heat storage materials and systems: a review. International Journal of Green Energy, 2005. 2(1): p. 1-56. 
79. Pasupathy, A.V. and R. Velraj, Phase Change Material Based ThermalStorage for Energy Conservation inBuilding Architecture. International Energy Journal, 2006. 7(2).

80. Wang, X., et al., Review on thermal performance of phase change energy storage building envelope. Chinese science bulletin, 2009. 54(6): p. 920-928.

81. Zhu, N., Z. Ma, and S. Wang, Dynamic characteristics and energy performance of buildings using phase change materials: A review. Energy Conversion and Management, 2009. 50(12): p. 3169-3181.

82. Dutil, Y., et al., A review on phase-change materials: Mathematical modeling and simulations. Renewable and Sustainable Energy Reviews, 2011. 15(1): p. 112-130.

83. Rao, Z., S. Wang, and Z. Zhang, Energy saving latent heat storage and environmental friendly humidity-controlled materials for indoor climate. Renewable and Sustainable Energy Reviews, 2012. 16(5): p. 3136-3145.

84. Al-Saadi, S.N. and Z. Zhai, Modeling phase change materials embedded in building enclosure: A review. Renewable and Sustainable Energy Reviews, 2013. 21: p. 659-673.

85. Patel, J.H., P. Darji, and M. Qureshi, Phase Change Material with Thermal Energy Storage System and Its Applications: A Systematic Review. Indian Journal of Science and Technology, 2017. 8(1).

86. Al-Abidi, A.A., et al., Review of thermal energy storage for air conditioning systems. Renewable and Sustainable Energy Reviews, 2012. 16(8): p. 5802-5819.

87. Saffari, M., et al., Passive cooling of buildings with phase change materials using whole-building energy simulation tools: A review. Renewable and Sustainable Energy Reviews, 2017. 80: p. 1239-1255.

88. Navarro, L., et al., Thermal energy storage in building integrated thermal systems: A review. Part 2. Integration as passive system. Renewable Energy, 2016. 85: p. 1334-1356.

89. Liu, M., W. Saman, and F. Bruno, Review on storage materials and thermal performance enhancement techniques for high temperature phase change thermal storage systems. Renewable and Sustainable Energy Reviews, 2012. 16(4): p. 2118-2132.

90. Milián, Y.E., et al., A review on encapsulation techniques for inorganic phase change materials and the influence on their thermophysical properties. Renewable and Sustainable Energy Reviews, 2017. 73: p. 983-999.

91. Kylili, A. and P.A. Fokaides, Numerical simulation of phase change materials for building applications: a review. Advances in Building Energy Research, 2017. 11(1): p. 1-25.

92. Agyenim, F., et al., A review of materials, heat transfer and phase change problem formulation for latent heat thermal energy storage systems (LHTESS). Renewable and Sustainable Energy Reviews, 2010. 14(2): p. 615-628. 
93. Raj, V.A.A. and R. Velraj, Review on free cooling of buildings using phase change materials. Renewable and Sustainable Energy Reviews, 2010. 14(9): p. 28192829.

94. Kamali, S., Review of free cooling system using phase change material for building. Energy and Buildings, 2014. 80: p. 131-136.

95. Thambidurai, M., K. Panchabikesan, and V. Ramalingam, Review on phase change material based free cooling of buildings-The way toward sustainability. Journal of Energy Storage, 2015. 4: p. 74-88.

96. Alizadeh, M. and S.M. Sadrameli, Development of free cooling based ventilation technology for buildings: Thermal energy storage (TES) unit, performance enhancement techniques and design considerations - A review. Renewable and Sustainable Energy Reviews, 2016. 58: p. 619-645.

97. Iten, M., S. Liu, and A. Shukla, A review on the air-PCM-TES application for free cooling and heating in the buildings. Renewable and Sustainable Energy Reviews, 2016. 61: p. 175-186.

98. Mahlia, T.M.I., et al., A review of available methods and development on energy storage; technology update. Renewable and Sustainable Energy Reviews, 2014. 33: p. 532-545.

99. Xu, J., R.Z. Wang, and Y. Li, A review of available technologies for seasonal thermal energy storage. Solar Energy, 2014. 103: p. 610-638.

100. Mondal, S., Phase change materials for smart textiles - An overview. Applied Thermal Engineering, 2008. 28(11): p. 1536-1550.

101. Jacob, R. and F. Bruno, Review on shell materials used in the encapsulation of phase change materials for high temperature thermal energy storage. Renewable and Sustainable Energy Reviews, 2015. 48: p. 79-87.

102. Abhat, A., Short term thermal energy storage. Revue de physique appliquee, 1980. 15(3): p. 477-501.

103. Gil, A., et al., State of the art on high temperature thermal energy storage for power generation. Part 1-Concepts, materials and modellization. Renewable and Sustainable Energy Reviews, 2010. 14(1): p. 31-55.

104. Lane, G.A. and N. Shamsundar, Solar heat storage: Latent heat materials, Vol. I: Background and scientific principles. 1983, American Society of Mechanical Engineers.

105. Abhat, A., Low temperature latent heat thermal energy storage: heat storage materials. Solar energy, 1983. 30(4): p. 313-332.

106. Lorsch, H.G., K.W. Kauffman, and J.C. Denton, Thermal energy storage for solar heating and off-peak air conditioning. Energy conversion, 1975. 15(1): p. 1-8.

107. Vats, G. and R. Vaish, Phase change materials selection for latent heat thermal energy storage systems (LHTESS): an industrial engineering initiative towards materials science. Advanced Science Focus, 2014. 2(2): p. 140-147. 
108. Alva, G., et al., Thermal energy storage materials and systems for solar energy applications. Renewable and Sustainable Energy Reviews, 2017. 68, Part 1: p. 693-706.

109. Wang, X., et al., Heat storage performance of the binary systems neopentyl glycol/pentaerythritol and neopentyl glycol/trihydroxy methyl-aminomethane as solid-solid phase change materials. Energy conversion and management, 2000. 41(2): p. 129-134.

110. Cárdenas, B. and N. León, High temperature latent heat thermal energy storage: Phase change materials, design considerations and performance enhancement techniques. Renewable and Sustainable Energy Reviews, 2013. 27: p. 724-737.

111. Nomura, T., N. Okinaka, and T. Akiyama, Technology of latent heat storage for high temperature application: a review. ISIJ international, 2010. 50(9): p. 12291239.

112. Sharma, A., et al., Review on thermal energy storage with phase change materials and applications. Renewable and Sustainable energy reviews, 2009. 13(2): p. 318345.

113. Liu, C., et al., Advanced materials for energy storage. Advanced Materials, 2010. 22(8): p. E28-E62.

114. Su, W., J. Darkwa, and G. Kokogiannakis, Review of solid-liquid phase change materials and their encapsulation technologies. Renewable and Sustainable Energy Reviews, 2015. 48: p. 373-391.

115. Kuznik, F., et al., A review on phase change materials integrated in building walls. Renewable and Sustainable Energy Reviews, 2011. 15(1): p. 379-391.

116. Shao, J., J. Darkwa, and G. Kokogiannakis, Review of phase change emulsions (PCMEs) and their applications in HVAC systems. Energy and Buildings, 2015. 94: p. 200-217.

117. Rozanna, D., et al., Fatty acids as phase change materials (PCMs) for thermal energy storage: a review. International Journal of Green Energy, 2005. 1(4): p. 495-513.

118. Yuan, Y., et al., Fatty acids as phase change materials: A review. Renewable and Sustainable Energy Reviews, 2014. 29: p. 482-498.

119. Feldman, D., et al., Fatty acids and their mixtures as phase-change materials for thermal energy storage. Solar Energy Materials, 1989. 18(3): p. 201-216.

120. Tyagi, V.V. and D. Buddhi, PCM thermal storage in buildings: a state of art. Renewable and Sustainable Energy Reviews, 2007. 11(6): p. 1146-1166.

121. Riffat, S., B. Mempouo, and W. Fang, Phase change material developments: a review. International Journal of Ambient Energy, 2013(ahead-of-print): p. 1-14.

122. Kenisarin, M. and K. Mahkamov, Solar energy storage using phase change materials. Renewable and Sustainable Energy Reviews, 2007. 11(9): p. 19131965. 
123. Verma, P. and S. Singal, Review of mathematical modeling on latent heat thermal energy storage systems using phase-change material. Renewable and Sustainable Energy Reviews, 2008. 12(4): p. 999-1031.

124. RBiradar, N. and C.A. CHOUGALE, Review on Thermal Energy Storage using Phase Change Materials and Applications. 2015.

125. Veerakumar, C. and A. Sreekumar, Phase change material based cold thermal energy storage: Materials, techniques and applications-A review. international journal of refrigeration, 2016. 67: p. 271-289.

126. Kousksou, T., et al., Energy storage: Applications and challenges. Solar Energy Materials and Solar Cells, 2014. 120, Part A: p. 59-80.

127. Rubitherm. 2017 [cited 2017, 09/11]; Available from: [<https://www.rubitherm.eu/>].

128. EPS. [cited 2017, 06/07]; Available from: [<http://www.pcmproducts.net/>].

129. Climator. [cited 2017, 06/07]; Available from: [<http://climator.com/?lang=en>].

130. PLUSS. [cited 2017, 06/07]; Available from: [<http://www.pluss.co.in/>].

131. TEAP. [cited 2017, 06/07]; Available from: [<http://www.teappcm.com/>].

132. Cristopia. [cited 2017, 06/07]; Available from: [<http://www.cristopia.com/>].

133. Voelker, C., O. Kornadt, and M. Ostry, Temperature reduction due to the application of phase change materials. Energy and Buildings, 2008. 40(5): p. 937-944.

134. Karaipekli, A., A. Sarı, and A. Biçer, Thermal regulating performance of gypsum/(C18-C24) composite phase change material (CPCM) for building energy storage applications. Applied Thermal Engineering, 2016. 107: p. 55-62.

135. Ascione, F., et al., Energy refurbishment of existing buildings through the use of phase change materials: Energy savings and indoor comfort in the cooling season. Applied Energy, 2014. 113: p. 990-1007.

136. Hunger, M., et al., The behavior of self-compacting concrete containing microencapsulated phase change materials. Cement and Concrete Composites, 2009. 31(10): p. 731-743.

137. Geetha, N. and R. Velraj, Passive cooling methods for energy efficient buildings with and without thermal energy storage-A review. Energy Education Science and Technology Part A: Energy Science and Research, 2012. 29(2): p. 913-946.

138. Darkwa, K. and J. Kim, Heat transfer in neuron composite laminated phase-change drywall. Proceedings of the Institution of Mechanical Engineers, Part A: Journal of Power and Energy, 2004. 218(2): p. 83-87.

139. Lai, C.-m., R. Chen, and C.-Y. Lin, Heat transfer and thermal storage behaviour of gypsum boards incorporating micro-encapsulated PCM. Energy and Buildings, 2010. 42(8): p. 1259-1266. 
140. Hasse, C., et al., Realization, test and modelling of honeycomb wallboards containing a phase change material. Energy and Buildings, 2011. 43(1): p. 232238.

141. Banu, D., D. Feldman, and D. Hawes, Evaluation of thermal storage as latent heat in phase change material wallboard by differential scanning calorimetry and large scale thermal testing. Thermochimica Acta, 1998. 317(1): p. 39-45.

142. Memon, S.A., Phase change materials integrated in building walls: A state of the art review. Renewable and sustainable energy reviews, 2014. 31: p. 870-906.

143. Kong, X., et al., Numerical study on the thermal performance of building wall and roof incorporating phase change material panel for passive cooling application. Energy and Buildings, 2014. 81: p. 404-415.

144. Feldman, D., D. Banu, and D.W. Hawes, Development and application of organic phase change mixtures in thermal storage gypsum wallboard. Solar Energy Materials and Solar Cells, 1995. 36(2): p. 147-157.

145. Panayiotou, G.P., S.A. Kalogirou, and S.A. Tassou, Evaluation of the application of Phase Change Materials (PCM) on the envelope of a typical dwelling in the Mediterranean region. Renewable Energy, 2016. 97: p. 24-32.

146. Kuznik, F. and J. Virgone, Experimental assessment of a phase change material for wall building use. Applied Energy, 2009. 86(10): p. 2038-2046.

147. Xu, X., et al., Modeling and simulation on the thermal performance of shapestabilized phase change material floor used in passive solar buildings. Energy and Buildings, 2005. 37(10): p. 1084-1091.

148. Zhang, Y., et al., Experimental study on the thermal performance of the shapestabilized phase change material floor used in passive solar buildings. Journal of solar energy engineering, 2006. 128(2): p. 255-257.

149. Koschenz, M. and B. Lehmann, Development of a thermally activated ceiling panel with PCM for application in lightweight and retrofitted buildings. Energy and Buildings, 2004. 36(6): p. 567-578.

150. Pasupathy, A. and R. Velraj, Effect of double layer phase change material in building roof for year round thermal management. Energy and Buildings, 2008. 40(3): p. 193-203.

151. Abuelnuor, A., et al. Buildings cooling: An experimental study of Phase Change Materials storage for low energy buildings. in Communication, Control, Computing and Electronics Engineering (ICCCCEE), 2017 International Conference on. 2017. IEEE.

152. Ismail, K. and J. Henrıquez, Parametric study on composite and PCM glass systems. Energy conversion and management, 2002. 43(7): p. 973-993.

153. Merker, O., et al. A new solar shading system with phase change material (PCM). in Proceedings of the World Renewable Energy Congress WII, Cologne (Germany). 2002.

154. Mehling, H. Strategic project "Innovative PCM-Technology"results and future perspectives. in 8th expert meeting and work shop, Kizkalesi, Turkey. 2004. 
155. Weinläder, H., A. Beck, and J. Fricke, PCM-facade-panel for daylighting and room heating. Solar Energy, 2005. 78(2): p. 177-186.

156. Fokaides, P.A., A. Kylili, and S.A. Kalogirou, Phase change materials (PCMS) integrated into transparent building elements: a review. Materials for Renewable and Sustainable Energy, 2015. 4(2): p. 6.

157. Silva, T., R. Vicente, and F. Rodrigues, Literature review on the use of phase change materials in glazing and shading solutions. Renewable and Sustainable Energy Reviews, 2016. 53: p. 515-535.

158. de Gracia, A., et al., Energy performance of a ventilated double skin facade with PCM under different climates. Energy and Buildings, 2015. 91: p. 37-42.

159. Luo, Y., et al., A comparative study on thermal performance evaluation of a new double skin façade system integrated with photovoltaic blinds. Applied Energy, 2017. 199: p. 281-293.

160. Hossain, R., et al., Energy storage system based on nanoparticle-enhanced phase change material inside porous medium. International Journal of Thermal Sciences, 2015. 91: p. 49-58.

161. Castellón, C., et al., Experimental study of PCM inclusion in different building envelopes. Journal of Solar Energy Engineering, 2009. 131(4): p. 041006.

162. Telkes, M. Trombe wall with phase change storage material. in Proceedings of the 2nd National Passive Solar Conference, Philadelphia, PA, USA. 1978.

163. Rabani, M., et al., Numerical simulation of a Trombe wall to predict the energy storage rate and time duration of room heating during the non-sunny periods. Heat and Mass Transfer, 2013. 49(10): p. 1395-1404.

164. Huang, M., P. Eames, and B. Norton, Thermal regulation of building-integrated photovoltaics using phase change materials. International Journal of heat and mass transfer, 2004. 47(12): p. 2715-2733.

165. Huang, M., P. Eames, and B. Norton, Phase change materials for limiting temperature rise in building integrated photovoltaics. Solar Energy, 2006. 80(9): p. $1121-1130$.

166. Ma, T., et al., Using phase change materials in photovoltaic systems for thermal regulation and electrical efficiency improvement: a review and outlook. Renewable and Sustainable Energy Reviews, 2015. 43: p. 1273-1284.

167. Hasan, A., H. Alnoman, and Y. Rashid, Impact of integrated photovoltaic-phase change material system on building energy efficiency in hot climate. Energy and Buildings, 2016. 130: p. 495-505.

168. Liu, S. and Y. Li, Heating performance of a solar chimney combined PCM: $A$ numerical case study. Energy and Buildings, 2015. 99: p. 117-130.

169. Amori, K.E. and S.W. Mohammed, Experimental and numerical studies of solar chimney for natural ventilation in Iraq. Energy and Buildings, 2012. 47: p. 450457. 
170. Zalewski, L., et al., Experimental study of small-scale solar wall integrating phase change material. Solar Energy, 2012. 86(1): p. 208-219.

171. Chaiyat, N., Energy and economic analysis of a building air-conditioner with a phase change material (PCM). Energy Conversion and Management, 2015. 94: p. 150158.

172. Tyagi, V.V., et al., Thermal performance assessment of encapsulated PCM based thermal management system to reduce peak energy demand in buildings. Energy and Buildings, 2016. 117: p. 44-52.

173. Mosaffa, A. and L.G. Farshi, Exergoeconomic and environmental analyses of an air conditioning system using thermal energy storage. Applied Energy, 2016. 162: p. 515-526.

174. Promoppatum, P., et al., Experimental and numerical investigation of the crossflow PCM heat exchanger for the energy saving of building HVAC. Energy and Buildings, 2017. 138: p. 468-478.

175. Tyagi, V.V., et al., Phase change material (PCM) based thermal management system for cool energy storage application in building: An experimental study. Energy and Buildings, 2012. 51: p. 248-254.

176. Hed, G. and R. Bellander, Mathematical modelling of PCM air heat exchanger. Energy and Buildings, 2006. 38(2): p. 82-89.

177. Turnpenny, J., D. Etheridge, and D. Reay, Novel ventilation cooling system for reducing air conditioning in buildings.: Part I: testing and theoretical modelling. Applied Thermal Engineering, 2000. 20(11): p. 1019-1037.

178. Turnpenny, J., D. Etheridge, and D. Reay, Novel ventilation system for reducing air conditioning in buildings. Part II: testing of prototype. Applied thermal engineering, 2001. 21(12): p. 1203-1217.

179. Yanbing, K., J. Yi, and Z. Yinping, Modeling and experimental study on an innovative passive cooling system-NVP system. Energy and buildings, 2003. 35(4): p. 417-425.

180. Zalba, B., et al., Free-cooling of buildings with phase change materials. International Journal of Refrigeration, 2004. 27(8): p. 839-849.

181. Marín, J.M., et al., Improvement of a thermal energy storage using plates with paraffin-graphite composite. International Journal of Heat and Mass Transfer, 2005. 48(12): p. 2561-2570.

182. Nagano, K., et al., Thermal characteristics of a direct heat exchange system between granules with phase change material and air. Applied Thermal Engineering, 2004. 24(14): p. 2131-2144.

183. Nagano, K., et al., Study of a floor supply air conditioning system using granular phase change material to augment building mass thermal storage-heat response in small scale experiments. Energy and Buildings, 2006. 38(5): p. 436-446.

184. Nagano, K., Development of the PCM floor supply air-conditioning system, in Thermal Energy Storage for Sustainable Energy Consumption. 2007, Springer. p. 367-373. 
185. Stritih, U. and V. Butala, Energy saving in building with PCM cold storage. International Journal of Energy Research, 2007. 31(15): p. 1532-1544.

186. Stritih, U. and V. Butala, Energy savings in building with a PCM free cooling system. Strojniški vestnik-Journal of Mechanical Engineering, 2011. 57(2): p. 125-134.

187. Arkar, C. and S. Medved, Influence of accuracy of thermal property data of a phase change material on the result of a numerical model of a packed bed latent heat storage with spheres. Thermochimica Acta, 2005. 438(1): p. 192-201.

188. Arkar, C. and S. Medved, Free cooling of a building using PCM heat storage integrated into the ventilation system. Solar Energy, 2007. 81(9): p. 1078-1087.

189. Arkar, C., B. Vidrih, and S. Medved, Efficiency of free cooling using latent heat storage integrated into the ventilation system of a low energy building. International Journal of Refrigeration, 2007. 30(1): p. 134-143.

190. Medved, S. and C. Arkar, Correlation between the local climate and the free-cooling potential of latent heat storage. Energy and Buildings, 2008. 40(4): p. 429-437.

191. Lazaro, A., et al., PCM-air heat exchangers for free-cooling applications in buildings: experimental results of two real-scale prototypes. Energy Conversion and Management, 2009. 50(3): p. 439-443.

192. Lazaro, A., et al., PCM-air heat exchangers for free-cooling applications in buildings: Empirical model and application to design. Energy Conversion and Management, 2009. 50(3): p. 444-449.

193. Dolado, P., et al., Characterization of melting and solidification in a real-scale PCMair heat exchanger: Experimental results and empirical model. Renewable Energy, 2011. 36(11): p. 2906-2917.

194. Dolado, P., et al., Characterization of melting and solidification in a real scale PCMair heat exchanger: numerical model and experimental validation. Energy Conversion and Management, 2011. 52(4): p. 1890-1907.

195. Waqas, A. and S. Kumar, Thermal performance of latent heat storage for free cooling of buildings in a dry and hot climate: An experimental study. Energy and Buildings, 2011. 43(10): p. 2621-2630.

196. Waqas, A. and S. Kumar, Utilization of latent heat storage unit for comfort ventilation of buildings in hot and dry climates. International Journal of Green Energy, 2011. 8(1): p. 1-24.

197. Halawa, E., F. Bruno, and W. Saman, Numerical analysis of a PCM thermal storage system with varying wall temperature. Energy Conversion and Management, 2005. 46(15): p. 2592-2604.

198. Raj, V.A.A. and R. Velraj, Heat transfer and pressure drop studies on a PCM-heat exchanger module for free cooling applications. International Journal of Thermal Sciences, 2011. 50(8): p. 1573-1582.

199. Bulut, H. and M.A. Aktacir, Determination of free cooling potential: A case study for Istanbul, Turkey. Applied Energy, 2011. 88(3): p. 680-689. 
200. Jaber, S. and S. Ajib, Novel cooling unit using PCM for residential application. International Journal of Refrigeration, 2012. 35(5): p. 1292-1303.

201. Mosaffa, A.H., et al., Thermal performance optimization of free cooling systems using enhanced latent heat thermal storage unit. Applied Thermal Engineering, 2013. 59(1-2): p. 473-479.

202. Mosaffa, A., et al., Thermal performance of a multiple PCM thermal storage unit for free cooling. Energy Conversion and Management, 2013. 67: p. 1-7.

203. Mosaffa, A., et al., Thermal performance optimization of free cooling systems using enhanced latent heat thermal storage unit. Applied Thermal Engineering, 2013. 59(1): p. 473-479.

204. Rouault, F., et al., Numerical modelling of tube bundle thermal energy storage for free-cooling of buildings. Applied Energy, 2013. 111: p. 1099-1106.

205. Darzi, A.R., et al., Numerical investigation of free-cooling system using plate type $P C M$ storage. International Communications in Heat and Mass Transfer, 2013. 48: p. $155-163$.

206. Rajagopal, M., et al., Free Cooling Potential and Technology Options for Thermal Energy Management of a Commercial Building in Bangalore City, India. Energy Engineering, 2014. 111(2): p. 11-24.

207. Waqas, A., M. Ali, and Z. Ud Din, Performance analysis of phase-change material storage unit for both heating and cooling of buildings. International Journal of Sustainable Energy, 2015(ahead-of-print): p. 1-19.

208. Borderon, J., J. Virgone, and R. Cantin, Modeling and simulation of a phase change material system for improving summer comfort in domestic residence. Applied Energy, 2015. 140: p. 288-296.

209. Iten, M. and S. Liu, Experimental Study on the Performance of RT 25 to be Used as Ambient Energy Storage. Energy Procedia, 2015. 70: p. 229-240.

210. Osterman, E., et al., Parametrical analysis of latent heat and cold storage for heating and cooling of rooms. Applied Thermal Engineering, 2015. 84: p. 138-149.

211. Osterman, E., V. Butala, and U. Stritih, PCM thermal storage system for 'free'heating and cooling of buildings. Energy and Buildings, 2015. 106: p. 125133.

212. Mirahmad, A., S. Sadrameli, and A. Jamekhorshid, A Comprehensive Study on a Latent Heat Thermal Energy Storage System and its Feasible Applications in Greenhouses. Iranian Journal of Chemical Engineering, 2016. 13(2).

213. Muthuvelan, T., et al., Experimental investigation of free cooling using phase change material-filled air heat exchanger for energy efficiency in buildings. Advances in Building Energy Research, 2016: p. 1-11.

214. Rajagopal, M., et al., Investigation on phase change material-based flat plate heat exchanger modules for free cooling applications in energy-efficient buildings. Advances in Building Energy Research, 2016: p. 1-23. 
215. Rajagopal, M., Studies on free cooling potential and PCM based heat exchanger for thermal management of buildings. 2014.

216. Alam, M., A comparative study on the effectiveness of passive and free cooling application methods of phase change materials for energy efficient retrofitting in residential buildings. 2017.

217. Butala, V. and U. Stritih, Experimental investigation of PCM cold storage. Energy and Buildings, 2009. 41(3): p. 354-359.

218. Rodriguez-Ubinas, E., et al., Applications of phase change material in highly energy-efficient houses. Energy and Buildings, 2012. 50: p. 49-62.

219. Chandel, S. and T. Agarwal, Review of current state of research on energy storage, toxicity, health hazards and commercialization of phase changing materials. Renewable and Sustainable Energy Reviews, 2017. 67: p. 581-596.

220. Salunkhe, P.B. and P.S. Shembekar, A review on effect of phase change material encapsulation on the thermal performance of a system. Renewable and Sustainable Energy Reviews, 2012. 16(8): p. 5603-5616.

221. Jamekhorshid, A., S.M. Sadrameli, and M. Farid, A review of microencapsulation methods of phase change materials (PCMs) as a thermal energy storage (TES) medium. Renewable and Sustainable Energy Reviews, 2014. 31: p. 531-542.

222. Schossig, P., et al., Micro-encapsulated phase-change materials integrated into construction materials. Solar Energy Materials and Solar Cells, 2005. 89(2): p. 297-306.

223. Giro-Paloma, J., et al., Types, methods, techniques, and applications for microencapsulated phase change materials (MPCM): A review. Renewable and Sustainable Energy Reviews, 2016. 53: p. 1059-1075.

224. Tyagi, V.V., et al., Development of phase change materials based microencapsulated technology for buildings: A review. Renewable and Sustainable Energy Reviews, 2011. 15(2): p. 1373-1391.

225. Liu, L., et al., Preparation, heat transfer and flow properties of microencapsulated phase change materials for thermal energy storage. Renewable and Sustainable Energy Reviews, 2016. 66: p. 399-414.

226. Farid, M.M., et al., A review on phase change energy storage: materials and applications. Energy conversion and management, 2004. 45(9): p. 1597-1615.

227. Solomon, G.R. and R. Velraj, Analysis of the heat transfer mechanisms during energy storage in a Phase Change Material filled vertical finned cylindrical unit for free cooling application. Energy Conversion and Management, 2013. 75: p. 466473.

228. Velraj, R., et al., Heat transfer enhancement in a latent heat storage system. Solar energy, 1999. 65(3): p. 171-180.

229. Mesalhy, O., et al., Numerical study for enhancing the thermal conductivity of phase change material (PCM) storage using high thermal conductivity porous matrix. Energy Conversion and Management, 2005. 46(6): p. 847-867. 
230. Ibrahim, N.I., et al., Heat transfer enhancement of phase change materials for thermal energy storage applications: A critical review. Renewable and Sustainable Energy Reviews, 2017. 74: p. 26-50.

231. Liu, L., et al., Thermal conductivity enhancement of phase change materials for thermal energy storage: A review. Renewable and Sustainable Energy Reviews, 2016. 62: p. 305-317.

232. Fan, L. and J. Khodadadi, Thermal conductivity enhancement of phase change materials for thermal energy storage: a review. Renewable and Sustainable Energy Reviews, 2011. 15(1): p. 24-46.

233. Costa, M., D. Buddhi, and A. Oliva, Numerical simulation of a latent heat thermal energy storage system with enhanced heat conduction. Energy Conversion and Management, 1998. 39(3): p. 319-330.

234. Stritih, U. and V. Butala, Experimental investigation of energy saving in buildings with PCM cold storage. International journal of refrigeration, 2010. 33(8): p. 16761683.

235. Satzger, P., B. Exka, and F. Ziegler, Matrix-heat-exchanger for a latent-heat coldstorage. Proceedings of Megastock_98, Sapporo (Japan), 1998.

236. Py, X., R. Olives, and S. Mauran, Paraffin/porous-graphite-matrix composite as a high and constant power thermal storage material. International Journal of heat and mass transfer, 2001. 44(14): p. 2727-2737.

237. Jegadheeswaran, S. and S.D. Pohekar, Performance enhancement in latent heat thermal storage system: a review. Renewable and Sustainable Energy Reviews, 2009. 13(9): p. 2225-2244.

238. Farid, M.M. and A. Kanzawa, Thermal performance of a heat storage module using PCM's with different melting temperatures: mathematical modeling. Journal of solar energy engineering, 1989. 111(2): p. 152-157.

239. Gong, Z.-X. and A.S. Mujumdar, Enhancement of energy charge-discharge rates in composite slabs of different phase change materials. International Journal of Heat and Mass Transfer, 1996. 39(4): p. 725-733.

240. Oró, E., et al., Review on phase change materials (PCMS) for cold thermal energy storage applications. Applied Energy, 2012. 99: p. 513-533.

241. Rathod, M.K. and J. Banerjee, Thermal stability of phase change materials used in latent heat energy storage systems: a review. Renewable and Sustainable Energy Reviews, 2013. 18: p. 246-258.

242. Sharma, S., D. Buddhi, and R. Sawhney, Accelerated thermal cycle test of latent heat-storage materials. Solar Energy, 1999. 66(6): p. 483-490.

243. Silakhori, M., et al., Accelerated thermal cycling test of microencapsulated paraffin wax/polyaniline made by simple preparation method for solar thermal energy storage. Materials, 2013. 6(5): p. 1608-1620.

244. Solé, A., et al., Thermal stability test of sugar alcohols as phase change materials for medium temperature energy storage application. Energy Procedia, 2014. 48: p. 436-439. 
245. Shukla, A., D. Buddhi, and R. Sawhney, Thermal cycling test of few selected inorganic and organic phase change materials. Renewable Energy, 2008. 33(12): p. 2606-2614. 